GUILHERME DE MEDEIROS ANTAR

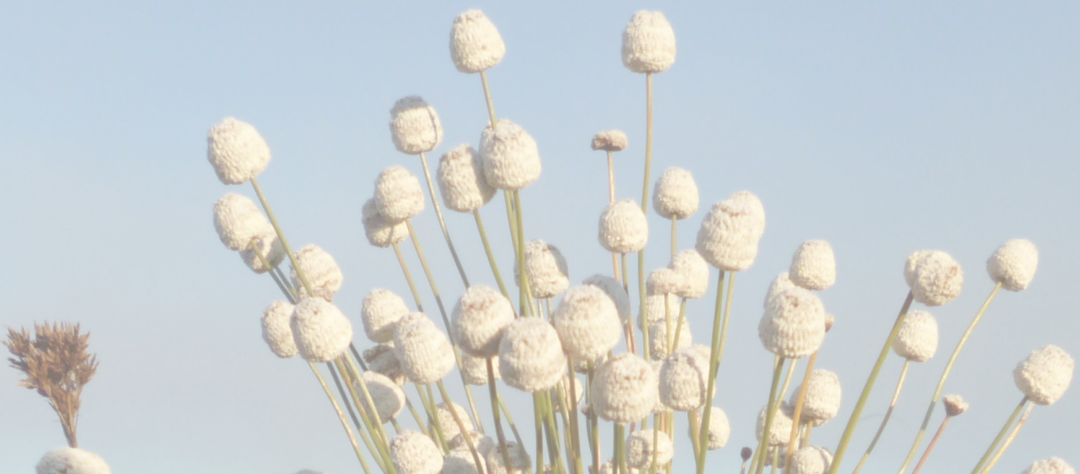

FLORÍSTIGA E EFEITOS DO REGIME DE FOGO NO ESTRATO HERBÁCEO-SUBARBUSTIVO NO JALAPÃO, TOCANTINS, BRASIL

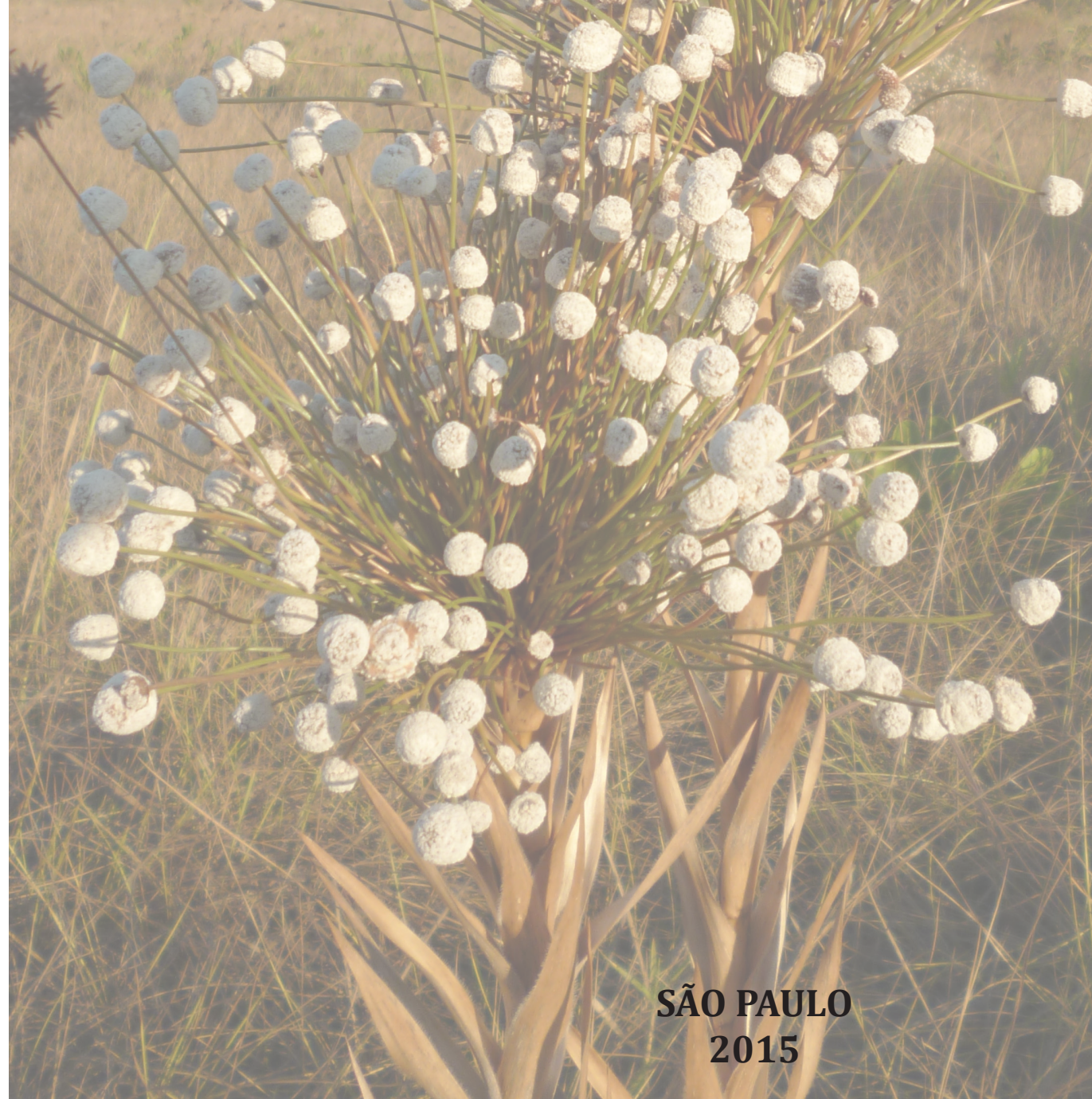




\section{Florística e efeitos do regime de fogo no estrato herbáceo-subarbustivo no Jalapão, Tocantins, Brasil.}

Floristics and effects of fire regime on the herbaceous and subshrub layer at Jalapão, Tocantins, Brazil

Dissertação apresentada ao Instituto de

Biociências da Universidade de São Paulo para obtenção do título de Mestre em Ciências, Área de concentração em Botânica.

Orientador: Prof. Dr. Paulo Takeo Sano 


\section{Antar, Guilherme de Medeiros}

Florística e efeitos do regime de fogo no estrato herbáceo-subarbustivo no Jalapão, Tocantins, Brasil.

$89 \mathrm{pp}$.

Dissertação (Mestrado) - Instituto de Biociências da Universidade de São Paulo. Departamento de Botânica.

1.Cerrado; 2. Queimadas; 3. Diversidade.

\section{Comissão Julgadora:}


Dedico às minhas avós More e Josephina e à minha tia Ângela (in memoriam). 
"Floras não recebem e, pode-se dizer, nunca receberam a consideração e o prestígio de outros temas e ciências irmãs, a quem ficam destinados os louros, seja como prioridades para captação de recursos financeiros para projetos, ou mesmo recebendo os créditos exclusivos oriundos do desenvolvimento científico. Sempre é bom lembrar, que o nome correto de uma planta é que permite acessar toda informação a respeito da mesma, o que inclui a recuperação de informações passadas, a proposição de novas investigações, as expectativas de usos potenciais e a possibilidade de formular projetos em outras áreas da ciência. Identificar corretamente é básico."

Bruno M. T. Walter

“... a biodiversidade de uma das regiões mais ricas, como é o Cerrado, vai sumindo sob o reino da soja. Enquanto isso, ainda não temos uma flora do Cerrado, como ainda não temos de muitas outras regiões da América do Sul. Na medida que o tempo passar e a flora do cerrado continuar não sendo cabalmente conhecida, não teremos como implementar políticas certas de conservação. Não bastam boas intenções. Políticas desenhadas para conservar e proteger o desconhecido dificilmente vão dar certo. E uma Flora-do-que-já-era também não presta..." 
À Universidade de São Paulo, particularmente ao Instituto de Biociências.

À FAPESP (processo 2014/01851-7) pela bolsa concedida.

À CAPES pelos primeiro meses de bolsa e pela verba PROEX.

À IdeaWild pelo financiamento de material de campo.

À Naturatins, principalmente ao Parque Estadual do Jalapão

Ao ICMBio pela concessão da licença de coleta e a Estação Ecológica Serra Geral do Tocantins. Ao meu orientador, Paulo Takeo Sano, por toda ajuda na minha formação, não apenas como cientista mas como pessoa, pela paciência e oportunidade de conhecer o Jalapão. Por ter me mostrado outro Brasil.

À equipe do Parque Estadual do Jalapão por todo o apoio e interesse pela pesquisa, destacandose: Rejane, Aline, Lauana, Claudemir, Jucinei, Alessandro, Reinaldo, Vanessa e Edson.

À equipe da Estação Ecológica da Serra Gerral do Tocantins por todo suporte, com destaque para Ubiratan, Marco, Máximo, Fábio e Ana Carolina.

Ao Manoel Bonfim Farias de Oliveira pela indicação de escolha das áreas e pelas conversas sobre o Jalapão e suas vivências.

À Isabel Schmidt, ao Alexandre Sampaio e à Taciana Cavalcanti pela ajuda com a bibliografia Aos curadores e pessoas que ajudaram nos herbário visitados, principalmente: HCF, Marcelo Caxambu e Clayson Cândido de Araújo; MBM, Juarez Cordeiro, Osmar dos Santos Ribas, Tadeu Motta, Marcelo Brotto e Eraldo Barboza; HRCB, Julio Lombardi; ESA, Thiago Flores e Vinicius Castro Souza; UEC, Washington Oliveira; BHCB, Gustavo e Alexandre Salino; UB, Cassia Munhoz, Carol Proença e Jose; HUEFS, Teonildes; CEN, Bruno Walter, José Valls e Taciana Cavalcanti; HEPH, Roberta Chacon e Dina.

À Cassiana, pelas conversas sobre o Jalapão e pelo bom humor constante.

Ao seu Zé Roberto e à dona Josinete pela hospedagem e pelas dicas de como se virar no Jalapão. A todos os moradores do Jalapão, principalmente aos moradores das comunidades da Mumbuca e da Boa Esperança.

À Marcela Escaramai, ao Lucas Nascimento, à Heloisa Antar e ao Ubiratan Chagas pela inestimável ajuda no trabalho de campo e por ter transformado esse momento em algo muito mais prazeroso do que já é. 
Aos companheiros de viagens para o Jalapão: Marcio Martins, Rebeca Viana, Eliana Dessen, Leila Macias e Vera Scatena.

Aos especialistas botânicos que ajudaram nas determinações. Parabéns pelo conhecimento que possuem.

Ao Norberto, Carlos, Danilo e Cesário da secretaria da Botânica.

Aos funcionários da secretaria de pós-graduação do IB-USP.

Aos professores do Laboratório de Sistemática Vegetal: José Rubens Pirani, Lúcia Lohmann e Renato Mello-Silva pelos ensinamentos e por serem exemplos profissionais.

Aos técnicos do laboratório de Sistemática Vegetal, Viviane Jono, Roberta Figueiredo e Abel Cangussu e ao Técnico do Departamento de Ecologia, Mauricio Perine.

A todos os colegas e amigos do laboratório de sistemática vegetal: Alexandre Zuntini, Adriana, Alisson Nazareno, Annelise Frazão, Anselmo Nogueira, Augusto Giaretta, Beatriz Gomes, Benoit Loeullie, Bruno Santos, Caetano Oliveira, Carolina Siniscalchi, Caroline Andrino, Carolina Agostini, Cintia Luz, Daniela Gomes, Eduardo Silva, Euder Glendes, Gisele Alves, Gustavo Heiden, Ian Souza, Isabela Akemi, Juan Pablo, Juliana El Ottra, Juliana Lovo, Juliana Rando, Jenifer Lopes, Jéssica Franscisco, Kyoshi Beraldo, Leonardo Borges, Luiz Henrique, Maila Beyer, Maria Fernanda, Marcelo Devecchi, Marcelo Kubo, Matheus Fortes, Mauricio Watanabe, Miriam Kaehler, Paulo Baleeiro, Paulo Gonella, Receba Viana, Renato Ramos, Rodolph Sartin e Verônica Aydos.

Aos amigos extra-dissertação, entre eles: os amigos 2008 Integral, vulgarmente conhecidos como Meio-Burros, os amigos do Colégio e aos amigos do time de natação Faca-na-manteiga. Ao meu avô, José Hortêncio (in memoriam), por todos os ensinamentos e por primeiro ter me chamado de biólogo.

À minha família por todo suporte, especialmente minha mãe Heloisa, meu pai Jorge, meu irmão Alexi e minha segunda mãe Vita.

À Carol, que me acompanhou e fez os dias serem melhores durante esses 2 anos. 
Famílias com especialistas que contribuíram com identificações e/ou confirmações de espécies, seguidos da instituição a que estão vinculados:

Acanthaceae - Rodolph Sartin USP-SP/ Cintia Kameyama IBt-SP.

Alstromeriaceae - Marta Camargo de Assis Embrapa Meio Ambiente -SP

Amaranthaceae - Luisa Senna UEFS

Amaryllidaceae - Renata Oliveira USP-SP

Anacardiaceae - Cíntia Luíza da Silva Luz USP-SP

Annonaceae - Jenifer de Carvalho Lopes USP-SP/ Renato de Mello-Silva USP-SP/ Heimo Rainer Museu de História Natural de Viena

Apocynaceae - Alessandro Rapini UEFS/ Juan Francisco Morales Instituto Nacional de Biodiversidad-Costa Rica

Araliaceae - Pedro Fiaschi UFSC

Arecaceae - Renata Martins UnB/ Larry Noblick Montgomery Botanical Center - Estados Unidos

Asteraceae - Benoit Louile USP-SP/ Caetano T. Oliveira USP-SP/ Mara Magenta Universidade Santa Cecília/ Jimi Nakajima UFU/ Nádia Roque UFBA/ João Semir UNICAMP/ Gustavo Silva UFG

Bignoniaceae - Fabiana Firetti USP-SP/ Alexandre Zuntini USP-SP/ Luiz Henrique Fonseca USP-SP/ Miriam Kaehler USP-SP/ Beatriz Gomes USP-SP.

Boraginaceae - Maria Stapf Smithsonian Tropical Research Institute - Panama

Bromeliaceae - Rafaela Forzza JBRJ

Burseraceae - Daly Douglas The New York Botanical Garden - Estados Unidos

Cactaceae - Daniela Zappi Kew-Inglaterra

Calophyllaceae - Rafaela Jorge Trad UNICAMP/ Wanderson Alkimin UnB

Capparaceae - Raimundo Luciano Soares Neto - UFRN

Clusiaceae - Lucas Marinho UEFS

Convolvulaceae - Rosangela Simão-Bianchini IBt-SP/ Fernanda Petrongari IBt-SP/ Mayara Pastore IBt-SP/ André Moreira UnB

Cyperaceae - Marccus Alves UFPE/ Pedro Joel Silva Filho- UFRGS/ Ana Paula Prata UFS 
Dilleniaceae - Claudio Fraga JBRJ

Dioscoreaceae - Diogo Araújo UNESP - Rio Claro

Ebenaceae - Matheus Fortes Santos USP-SP

Eriocaulaceae - Marcelo Trovó UFRJ/ Maurício Watanabe USP-SP

Erythroxylaceae - Thiago Araújo UEFS

Euphorbiacae - Inês Cordeiro IBt-SP/ Marcio L. Lopes Martins UFRB/ Otávio Marques IBt-SP/ Fernanda Hurbath IBt-SP/ Alan Pscheidt IBt-SP

Fabaceae - Ana Paula Fortuna-Perez UNESP-Botucatu/ Guilherme Ceolin UFSM/ Luciano P. Queiroz UEFS/ Jorge Costa UFSB/ Rodrigo Augusto Camargo UNICAMP/ Leonargo Maurici Borges USP-SP/ Carolina Siniscalchi USP-SP/ Marcelo Devecchi USP-SP/ Ângela F. Vaz JBRJ/ Kamilla Lopes Barreto UEFS/ Matheus M. T. Cota USP-SP/ Josimar Pereira Santos UnB/ Juliana G. Rando UFOB

Iridaceae - Juliana Lovo USP-SP/ Lilian Eggers UFRGS

Lamiaceae - Cíntia Luz USP-SP/ Flávio França UEFS/ Juliana Silva UFRPE

Loganiaceae - Daniela Zappi Kew-Inglaterra

Loranthaceae - Claudenir Caires UESB

Lythraceae - Taciana Cavalcanti Embrapa-Brasília/ Shirley Graham Missouri Botanical GardenEstados Unidos

Malpighiaceae - Augusto Francener IBt-SP

Marantaceae - Mariana Saka UNESP-Rio Claro

Melastomataceae - Rosana Romero UFU/ Renato Goldenberg UFPR/ Ricardo Kriebel University of Wisconsin-Madison- Estados Unidos

Moraceae - Euder Glendes Martins USP-SP

Myrtaceae - Matheus Fortes Santos USP-SP/ Jair Eutáquio Quintino de Faria Júnior UnB/ Nyctaginaceae - Cyl Farney UnB

Ochnaceae - Roberta Chacon JBB

Orchidaceae - Thiago Meneguzzo JBRJ/ Silvana Helena Monteiro UFRGS

Oxalidaceae - Pedro Fiaschi UFSC 
Poaceae - Rodrigo Rodrigues IBt-SP/ José F.M. Valls Embrapa-Brasília/ Tarciso Filgueiras IBtSP

Polygalaceae - José Floriano Barêa Pastore UFSC -Curitibanos

Rubiaceae - Elnaltan Souza UEVA/ Maria Fernanda Calió UNICAMP/ Roberto Salas University of Corrientes-Argentina/ Pietro Delprete UFG

Rutaceae - José Rubens Pirani USP-SP

Santalaceae - Claudenir Caires UESB

Sapindaceae - Genise Freire UERJ/ Pedro Acevedo Smithsonian Institution -Estados Unidos

Sapotaceae - Cláudia Elena Carneiro UEFS/ Anderson Alves Araújo UEFS

Simaroubaceae - Marcelo Devecchi USP-SP

Smilacaceae - Regina Andreata Universidade Santa Úrsula - Rio de Janeiro

Solanaceae - Leandro Giacomin UFOP

Turneraceae - Lamarck Rocha UEFS

Velloziaceae - Renato de Mello Silva USP-SP

Verbanaceae - Fátima Regina G. Salimena UFJF

Vitaceae - Julio Lombardi UNESP-Rio Claro

Vochysiaceae - Gustavo Shimizu UNICAMP

Xyridaceae - Maria das Graças Lapa Wanderley IBt-SP 


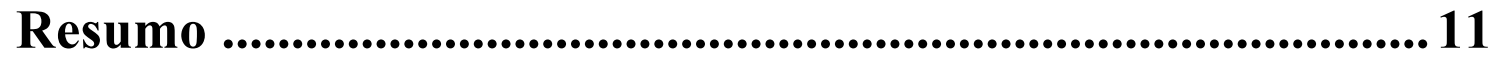

Introdução geral ............................................................................... 14

Capítulo I: Angiosperms of Jalapão region, the most conserved area of Brazilian savannah 34

Capítulo II: Diversidade do estrato herbáceo-subarbustivo em áreas sujeitas a diferentes frequências de fogo na região do Jalapão, Tocantins 65

Considerações finais 89 
O Cerrado é um domínio fitogeográfico tipicamente savânico, com altos valores de diversidade e endemismos e com uma grande pressão antrópica associada. A maior área contínua ainda conservada de Cerrado é a região do Jalapão (TO). Apesar de protegida por Unidades de Conservação de proteção integral, esta é uma região pouco estudada, existindo, assim, uma grande lacuna de conhecimento sobre sua flora e sobre os efeitos das queimadas, que lá ocorrem frequentemente, na diversidade de plantas. O fogo exerce forte influência na constituição biológica e na ecologia do Cerrado. A ausência de queimadas ou a sua presença frequente transformam a fitofisionomia do local, adensando a vegetação ou levando a formações mais campestres, respectivamente. Com a crescente ocupação antrópica, a frequência de fogo tem aumentado no Cerrado. Simultaneamente, as Unidades de Conservação restringem queimas, por vezes naturais, em suas áreas. Diante desse panorama, tornam-se necessários mais estudos sobre a flora e os efeitos do fogo no Jalapão. Esse projeto tem o objetivo de colaborar no conhecimento desses temas. Para o trabalho florístico, áreas de cerrado aberto com solo seco não pedregoso foram percorridas em diferentes períodos do ano e todas as angiospermas em estágio reprodutivo foram coletadas e identificadas. Foram revisados os herbários com as coleções mais significativas, resultando na compilação de uma lista de angiospermas para a região. Para a análise da ação do fogo, áreas de campo sujo na região do Jalapão com diferentes históricos de fogo foram selecionadas, sendo três áreas com frequência bienal de queimas e uma área livre do fogo há dez anos. 15 parcelas de $4 \mathrm{~m}$ foram instaladas em cada área. Todos os indivíduos de hábito herbáceo-subarbustivo foram identificados e contabilizados. Densidade, riqueza e composição de espécies foram avaliadas e comparadas entre as áreas com diferentes históricos de queima. A lista resultou em 528 espécies, distribuídas em 85 famílias. As famílias mais representativas foram Fabaceae, Poaceae, Asteraceae, Rubiaceae, Lamiaceae e Myrtaceae. O número de espécies encontradas quase dobra o número de registros nessas fisionomias para a região. A análise da ação do fogo resultou em maiores valores de densidade de indivíduos e riqueza nas áreas com regime de fogo bienal; entretanto, entre os diferentes tratamentos, não houve diferença na composição de espécies. Esses resultados são corroborados pelas evidências levantadas na literatura da necessidade de fogo para reprodução e ocorrência de certas espécies vegetais e dos ganhos obtidos com maior acesso à luz e maior disponibilidade de nutrientes pelo estrato rasteiro, após queimadas. O fogo no Cerrado não deve ser entendido como prejudicial, sendo necessário incluir programas específicos de queimadas controladas para o manejo da biodiversidade em áreas protegidas. 
The Cerrado is a savanic phytogeographic domain with high biodiversity and endemism values, under high anthropic pressure. One of the largest, continuous and still conserved areas of Cerrado is the Jalapão region, in the Tocantins State. Despite the existence of protected areas, there is a huge information gap about its flora and about the effects of fires, which are frequent in the region, on its plant diversity. Fire has a strong influence in the biological constitution of Cerrado and on its ecology. The absence or presence of fires may transform the local phytophysiognomy, by controlling the abundance of woody species. Hence, its presence is associated to occurrence of dense formations, while its absence leads to a prevalence of grasslands. With the increasing human occupation of Cerrado areas, the frequency of fires has been growing. At the same time, management of protected areas tends to restrain fires on their territory, even when those occur spontaneously. In this context, studies characterizing the flora and the effects of fires over it in the Jalapão region are of utmost importance. The present work aims to collaborate to the increasing of the knowledge about those subjects. For the floristic survey of the area, fieldwork was conduced during different periods of the year, and all angiosperms occurring in savannah physionogmies with dry, non rocky soils, were collected. Additionally, herbaria with representative collections from Jalapão were visited and its specimen's identifications reviewed, resulting in a checklist for angiosperms occurring in the region. To evaluate the effects of fire in plant diversity, "campo sujo" physionogmies in Jalapão region with different fire history were selected. Three areas had bienal fire history and one area is protected from fire for 10 years. 15 quadrants of $4 \mathrm{~m}$ were set in each area, and all plants with herbaceous and subshrub habit were collected and identified. Individual density, species richness and composition were analysised and compared in areas with different fire historys. For the checklist 528 species belonging to 85 families were recorded. The most representative families are Fabaceae, Poaceae, Asteraceae, Rubiaceae, Lamiaceae and Myrtaceae. Nine species are listed as rare and nine as threatened. This study presents almost twice as many species recorded by previous inventories of those physiognomies in Jalapão. The analyses of fire effects resulted in higher individual density and species richness values in the areas with bienal fire regime. There were no differences in species composition between the evaluated areas. Our results are reinforced by the already current knowledge that some plant species rely on fire occurrence in order to reproduce and even to establish themselves in the environment. Moreover, it is also known that the herbaceous stratum benefits from the increasing in light and nutrient availability promoted after fires. Fire must not be seen as a villain and specific programs that include 
supervised burns should be adopted in protected areas management plans in order to achieve a holistic conservation of the Cerrado Domain. 
Introdução geral 


\section{Cerrado}

O Cerrado, enquadrado como formação de savana tropical (Sarmiento 1984), é o segundo maior domínio fitogeográfico no território brasileiro, abrangendo aproximadamente $22 \%$ do território do país, com mais de 2.000.000 $\mathrm{km}^{2}$. Encontra-se presente nos estados de Tocantins, Goiás, Mato Grosso, Mato Grosso do Sul, Minas Gerais, Bahia, Maranhão, Piauí, Rondônia, Amapá, São Paulo, Paraná e no Distrito Federal (Fantinati 2004; Silva et al. 2008; Ribeiro \& Walter 2008), congregando também áreas da Bolívia e do Paraguai (Ratter et al. 1997).

Ambientalmente, é caracterizado pelo clima estacional, com uma estação chuvosa, de setembro a abril, e uma seca, de maio a agosto, bem definidas, majoritariamente enquadrado na classificação Aw de Koppen (Silva et al.2008; Ribeiro \& Walter 2008). A média anual de precipitação é de $1500 \mathrm{~mm}$ (Moreira 2000), variando de $700 \mathrm{~mm}$ a $2000 \mathrm{~mm}$, e as médias anuais de temperatura variam entre $22^{\circ}$ e $27^{\circ} \mathrm{C}$ (Klink \& Machado 2005). Seus solos são geralmente pobres em nutrientes e ácidos, profundos, de coloração avermelhada e constantemente com presença de grandes quantidades de alumínio (Gottsberger \& Silberbauer-Gottsberger 2006).

Quanto à cobertura vegetal, o Cerrado apresenta várias fitofisionomias (Eiten 1972; Coutinho 1978; Ribeiro et al. 1983; Pivello \& Coutinho 1996; Ratter et al. 1997; Eiten 2001; Ribeiro \& Walter 2008), desde formações exclusivamente campestres até florestais. Entretanto, é caracterizado como fitofisionomia savânica (Ratter et al. 1997; Castro-Neves 2007; Walter et al. 2008), com um contínuo estrato herbáceo, composto por gramíneas e ciperáceas, em sua maioria, entremeado por árvores, arbustos e subarbustos, esparsamente distribuídos. Vários fatores condicionam a fitofisionomia que prevalece em determinada área, como a quantidade de nutrientes, o tipo e a profundidade do solo, a quantidade de água disponível, as interações entre as espécies e a ocorrência e a frequência de distúrbios, antrópicos ou naturais, como pastagem de gado e fogo (Coutinho 1978; Coutinho 1990; Pivello \& Coutinho 1996; Henriques 2005; Silva e Batalha 2011). 
Diversas classificações foram propostas quanto às fitofisionomias do domínio Cerrado (Eiten 1972; Coutinho 1990; Ratter et al 1997; Ribeiro et al. 1983; Ribeiro \& Walter 2008). São detalhadas a seguir as onze principais fitofisionomias, segundo Ribeiro \& Walter (2008).

\section{Campo limpo}

Fisionomia campestre formada majoritariamente por plantas herbáceas, com raros arbustos, que não transpassam, em altura, o estrato herbáceo (Eiten 1972; Gottsberger \& Silberbauer-Gottsberger 2006; Ribeiro \& Walter 2008). O campo limpo pode ocorrer em solos secos, associado a encostas e chapadas, onde o lençol freático é baixo; ou em solos úmidos, associado a fundos de vales ou locais contíguos a corpos d'água, áreas onde o lençol freático é alto (Ribeiro \& Walter 2008). O campo limpo seco e o campo limpo úmido apresentam composições florísticas distintas, com táxons específicos em cada um deles (Ribeiro \& Walter 2008). As famílias mais representativas nas fisionomias de campo limpo são: Poaceae, Cyperaceae, Asteraceae, Polygalaceae, Iridaceae, Orchydaceae, Lythraceae; e, destacando-se em solos úmidos, Xyridaceae, Eriocaulaceae, Droseraceae e Lentibulariaceae (Ribeiro \& Walter 2008).

Campo sujo

O campo sujo é caracterizado pelo estrato herbáceo contínuo, entremeado por alguns subarbustos, arbustos, raramente por árvores (Coutinho 1982; Henriques 2005). A cobertura de espécies lenhosas, segundo Moreira (2000), chega a até 3\% do ambiente, sendo que essas se apresentam como indivíduos menos desenvolvidos que os de Cerrado sensu stricto (Munhoz 2003; Ribeiro \& Walter 2008).

Pode-se dividir os campos sujos em três categorias: (i) campo sujo úmido, com o lençol freático alto; (ii) campo sujo seco, com o lençol freático baixo; e (iii) campo sujo com murundus, 
quando esses estão em relevos elevados (Ribeiro \& Walter 2008). As famílias de plantas vasculares mais expressivas nesse tipo de fitofisionomia - campo sujo - são: Poaceae, Asteraceae, Cyperaceae, Fabaceae, Lamiaceae, Myrtaceae e Rubiaceae (Munhoz 2003; Ribeiro \& Walter 2008).

\section{Campo rupestre}

Fisionomia campestre caracterizada pela presença de afloramentos rochosos, restrita a localidades de maior altitude, a partir de 900 metros até 2.000 metros (Alves \& Kolbeck 2000; Ribero \& Walter 2008). É predominantemente herbáceo-arbustiva, podendo ocorrer árvores esparsas de até $2 \mathrm{~m}$ de altura (Ribeiro \& Walter 2008). É tida como umas das fitofisionomias de maior diversidade vegetal do Brasil, com expressivo número de endemismos (Joly 1970; Ribeiro \& Walter 2008), ocorrendo principalmente na Cadeia do Espinhaço, em Minas Gerais e Bahia, como também dentro do domínio da Caatinga (Ribeiro \& Walter 2008; Alves \& Kolbeck 2010).

Algumas espécies de campo rupestre apresentam o hábito rupícola, enquanto outras crescem em fendas de rochas. Essas cavidades possuem particularidades únicas devido ao tipo e à quantidade de substrato, ao grau de sombreamento e à disponibilidade hídrica, entre outros fatores, perfazendo um mosaico de microclimas e diferentes habitats (Rapini et al. 2008). As famílias com grande representatividade nessa fisionomia são: Poaceae, Asteraceae, Bromeliaceae, Velloziaceae, Fabaceae, Cactaceae, Orchidaceae, Melastomataceae, Myrtaceae, Vochysiaceae, Cyperaceae, Rubiaceae, Eriocaulaceae, Xyridaceae, Iridaceae e Lamiaceae (Rapini et al. 2008; Ribeiro \& Walter 2008).

\section{Cerrado sensu stricto}

Vegetação característica de savana, com continuo estrato herbáceo entremeado por arbustos ou árvores esparsamente encontrados, cobrindo de 10 a 50\% da área, com alturas de até 
6 metros (Felfini et al. 2002; Moreira 2000; Ribeiro \& Walter 2008). É tido como a fitofisionimia mais amplamente distribuída no domínio do Cerrado, cobrindo até $70 \%$ de sua área (Assunção \& Felfini 2004; Marimon-Júnior \& Haridasan 2005).

O estrato herbáceo/subarbusivo é representado principalmente por Poaceae, Cyperaceae, Asteraceae, Fabaceae e Iridaceae e o componente lenhoso por Fabaceae, Vochysiaceae, Apocynaceae, Bignoniaceae, Annonaceae e Rubiaceae (Ribeiro \& Walter 2008).

Essa fitofisionomia pode ser dividida em cerrado denso, cerrado típico, cerrado aberto e cerrado rupestre, esse último com espécies diagnósticas (Ribeiro \& Walter 2008).

\section{Parque do Cerrado}

Fitofisionomia savânica caracterizada pela cobertura arbórea de 5 a $20 \%$ da área, estando agrupada em elevações do terreno, chamados de "murundus" (Oliveira-Filho 1992; Ribeiro \& Walter 2008). Nessas elevações ocorrem muitos cupinzeiros, diversos e comuns no Cerrado (Oliveira-Filho 1992; Ribeiro \& Walter 2008). Por vezes, a parte não elevada desses campos está sujeita a inundações durante a estação chuvosa, impedindo a fixação de certas espécies de plantas lenhosas nessa área, caracterizando, assim, tais elevações como ilhas de vegetação lenhosa. As famílias mais representativas no componente herbáceo são Poaceae e Cyperaceae e, no componente lenhoso, Rubiaceae, Fabaceae, Asteraceae, Euphorbiaceae, Vochysiaceae e Malvaceae (Ribeiro \& Walter 2008).

\section{Palmeiral}

Fitofisionomia caracterizada pelo domínio de pelo menos uma espécie de hábito arborescente de Arecaceae, associado a uma matriz contínua de estrato herbáceo subarbustivo, podendo ocorrer outras espécies lenhosas em densidade muito baixa (Ribeiro \& Walter 2008). 
O dossel pode ser contínuo ou, mais comumente, não contínuo. São 4 espécies de palmeiras mais comuns: Mauritia flexuosa L.f., o buriti; Acrocomia aculeata (Jacq.) Lodd. ex Mart., a macaúba; Syagrus oleracea (Mart.) Becc., a guariroba; e Attalea speciosa Mart. ex Spreng., o babaçu. (Ribeiro \& Walter 2008).

Vereda

Fisionomia savanoide, caracterizada por agrupamentos, muitas vezes de maneira linear, com dossel não contínuo, da palmeira Mauritia flexuosa, popularmente conhecida como buriti, associada a outras espécies arbustivas e arbóreas, margeadas por matriz herbáceo-arbustiva. Essa fisionomia ocorre ligada a solos úmidos, saturados de água, onde ocorrem os buritis (Ribeiro \& Walter 2008).

As famílias mais comuns nessa borda campestre são: Poaceae, Asteraceae, Cyperaceae, Melastomataceae, Fabaceae, Eriocaulaceae e Xyridaceae. Já na porção mais central da Vereda, ocorrem principalmente Fabaceae, Melastomataceae, Urticaceae e Annonaceae, além de outras famílias comuns em matas de galeria (Ribeiro \& Walter 2008).

\section{Mata Seca}

Fisionomia florestal caracterizada por árvores de 15 a 25 metros, que apresentam certo nível de caducifolia durante a estação seca (Ribeiro \& Walter 2008). O solo normalmente é mais rico em nutrientes que as outras fitofisionomias do Cerrado, o que explica, em parte, sua extensa perda de área para a agropecuária. Pode ocorrer também em solos calcários, apresentando, então, composição florística específica, caracterizada por espécies típicas, como Cavanillesia umbellata Ruiz \& Pav. (Malvaceae), conhecida popularmente como Barriguda (Ribeiro \& Walter 2008). 
Durante a estação chuvosa, o dossel possui cobertura de 70 a $95 \%$, chegando a $50 \%$ durante a estação seca, sendo essas folhas caducas muito importantes para compor a serrapilheira e possibilitar a reciclagem de nutrientes da mata (Ribeiro \& Walter 2008).

As famílias mais representativas são: Fabaceae, Bignoniaceae, Malvaceae, Meliaceae e Rutaceae (Ribeiro \& Walter 2008).

\section{Cerradão}

Formação florestal semidecídua crescendo em solos profundos, ácidos e normalmente pouco férteis, podendo ocorrer solos moderadamente férteis. As árvores atingem até 8 a 15 metros de altura e possuem características esclerofilas, normalmente perenifólias, podendo haver algumas caducifólias durante a estação seca (Gottsberger \& Silberbauer 2006; Ribeiro \& Walter 2008).

A cobertura do dossel é de $50 \%$ a $90 \%$, variando entre a estação seca e chuvosa (Ribeiro \& Walter 2008). Possui elementos florísticos de matas secas, matas de galeria e principalmente de cerrados mais abertos.

O subosque possui uma cobertura vegetal menor, sendo formado por espécies arbustivas e herbáceas, com pouca abundância de espécies graminoides (Gottsberger \& Silberbauer 2006; Ribeiro \& Walter 2008).

As famílias mais representativas no Cerradão são: Fabaceae, Vochysiaceae, Caryocaraceae, Annonaceae, Malvaceae e Myrtaceae (Ribeiro \& Walter 2008). 


\section{Mata Ciliar}

Formação florestal associada a rios de médio e grande porte, geralmente ocorrendo em terrenos acidentados, chegando a, no máximo, 100 metros de largura em cada margem (Ribeiro \& Walter 2008).

Floristicamente é mais próxima da mata seca, com exceção das espécies encontradas próximas à água. É uma floresta semidecidual chegando a 50\% de cobertura do dossel na estação seca e 90\% na estação chuvosa (Ribeiro \& Walter 2008).

Famílias representativas nesse tipo de formação são: Fabaceae, Bignoniaceae, Moraceae, Apocynaceae, Malvaceae e Urticaceae (Ribeiro \& Walter 2008).

Mata de Galeria

Fitofisionomia florestal associada a corpos d'água de pequeno porte. O dossel atinge até $30 \mathrm{~m}$ de altura e as folhas são perenes, não havendo deciduidade. A cobertura arbórea do dossel varia de $70 \%$ a $95 \%$ (Ribeiro \& Walter 2008).

Normalmente estão relacionadas a fundos de vales e linhas de drenagem. A transição pode ser abrupta entre esse tipo de físionomia e formações campestres ou savânicas. Apesar dessa proximidade, possui composição florística muito distinta das formações campestres e savânicas próximas (Gottsberg \& Silberbauer-Gottsberger 2006). As famílias mais representativas são: Fabaceae, Rubiaceae, Lauraceae, Myrtaceae, Apocynaceae, Orchidaceae, Vochysiaceae, Annonaceae, Melastomataceae e Meliaceae (Ribeiro \& Walter 2008).

\section{Biodiversidade e ameaças ao Cerrado}

Tamanha heterogeneidade de fisionomias constitui um dos fatores pelos quais o Cerrado é caracterizado como o domínio savânico de maior biodiversidade vegetal (Klink \& Machado 
2005; Mendonça et al. 2008; Forzza et al. 2012), com alto número de endemismos. Mendonça e colaboradores (2008), em uma compilação de dados, listaram 12.356 espécies de plantas vasculares nativas para o Cerrado; Forzza e colaboradores (2012), analisando dados publicados no catálogo de plantas e fungos do Brasil (Forzza et al. 2010), chegaram ao número de 11.637 plantas vasculares para o Cerrado, das quais $36 \%$ são endêmicas.

Apesar dessa grande biodiversidade, o Cerrado historicamente não recebe o mesmo valor que a Mata Atlântica ou a Floresta Amazônica, nem politicamente, nem pela sociedade, nem pela comunidade internacional (Ratter et al. 1997; Silva \& Bates 2002; Klink \& Machado 2005). Isso pode ser demonstrado pela legislação, exemplificada no Código Florestal Nacional, (Lei $\mathrm{N}^{\mathrm{o}}$ 12.651, de 25 de maio de 2012) o qual dispõe, para a Amazônia Legal, a necessidade de 35\% da área da propriedade como reserva legal para fisionomias de cerrado em oposição a $80 \%$ para fisionomias de florestas tropicais. Também denuncia esse menor valor atribuído ao Cerrado, a pequena área protegida por Unidades de Conservação, de apenas $11 \%$ da área total do domínio (Martinelli et al. 2013), e pelo fato de aproximadamente $50 \%$ de toda a sua área já ter sido substituída (Klink \& Machado 2005; Martinelli et al. 2013).

O desmatamento do Cerrado está muito associado a fatores políticos de ocupação do Brasil Central, impulsionados principalmente pela transferência da capital nacional com a construção de Brasília na década de 1960 (Ratter et al. 1997). As principais causas da perda de áreas do Cerrado foram, e ainda são, a criação de gado, a indústria do carvão vegetal, e a agricultura, destacando-se o cultivo de arroz, milho, mandioca e a soja, esse último que tem se intensificado muito nas últimas décadas, visando à exportação (Ratter et al. 1997; Silva \& Bates 2002; Martinelli et al. 2013)

Muitas das áreas ainda existentes encontram-se fragmentadas e, por vezes, com certo grau de degradação (Gottsberg \& Silberbrauer-Gottsberg 2006); sendo, dessa maneira, muito mais suscetíveis à erosão do solo (Klink \& Machado 2005; Ribeiro \& Walter 2008) e à invasão de plantas exóticas, principalmente de gramíneas africanas, mais nutritivas que as gramíneas 
nativas, utilizadas na agropecuária para a diminuição do tempo de engorda do gado (Klink \& Machado 2005). Tais gramíneas, principalmente Melinis minutiflora P.Beauv., conhecida popularmente como capim-gordura, Hyparrhenia rufa (Nees) Stapf, Panicum maximum Jacq. e algumas espécies do gênero Urochloa, conhecidas popularmente como braquiária (Pivello et al. 1999; Klink \& Machado 2005; Gorgone-Barbosa 2015), possuem altas taxas de crescimento. Assim, além de substituir e competir com espécies nativas, elas acabam aumentando rapidamente a biomassa da fisionomia invadida, modificando também o regime de queimas (Gorgone-Barbosa et al. 2015).

Diante desse panorama: uma enorme biodiversidade com expressivo número de endemismos associada a uma grande pressão antrópica, o Cerrado é enquadrado como o único domínio de Savana entre os hotspots da biodiversidade (Myers et al. 2000; Scariot et al. 2002).

Nesse cenário, uma das áreas de Cerrado melhor conservadas é a região do Jalapão, o que se deve principalmente ao seu solo pouco fértil e seu isolamento geográfico (Schmidt et al. 2007; Figueiredo 2007), sendo, também, a maior área protegida contínua de Cerrado do Brasil (Silva \& Bates 2002).

Jalapão

O Jalapão está localizado majoritariamente no extremo leste do estado do Tocantins, na região da divisa com os estados do Maranhão, da Bahia e do Piauí, entre o paralelo $10^{\circ} 12^{\prime} \mathrm{S}$ e o meridiano $45^{\circ} 47^{\prime} \mathrm{W}$, a aproximadamente 260 quilômetros ao sul de Palmas (Rezende 2007).

O Jalapão, como área delimitada, ainda não possui uma definição geográfica bem estabelecida (Viana, 2013). Alguns autores citam a região como possuindo aproximadamente $34.000 \mathrm{~km}$, incluindo os municípios de Lagoa do Tocantins, Novo Acordo, Lizarda, Mateiros, Ponte Alta do Tocantins, Santa Tereza do Tocantins, São Felix do Tocantins, Rio Sono (Chagas, 2007). Outros referem uma área de aproximadamente $53.330 \mathrm{~km}$, incluindo os municípios de 
Barra do Ouro, Campos Lindos, Centenário, Goiatins, Itacajá, Itapirins, Lagoa do Tocantins, Lizarda, Mateiros, Novo Acordo, Ponte Alta do Tocantins, Recursolândia, Rio Sono, Santa Tereza do Tocantins e São Felix do Tocantins (Scariot et al. 2002; Santos et al. 2011). Outros autores, ainda, preferem delimitar o Jalapão principalmente entre os municípios de Mateiros, Ponte Alta do Tocantins e São Felix do Tocantins (Figueiredo, 2007).

A área é caracterizada fisicamente por solos arenosos, pobres em nutrientes e que retêm pouca água (Bellia \& Dias 2003). A temperatura média varia de $24{ }^{\circ} \mathrm{C}$ em julho, o mês mais frio, a $27^{\circ} \mathrm{C}$ em setembro, o mês mais quente. A precipitação, como no resto do domínio do Cerrado, está concentrada nos meses de outubro a março, e sua média é de $1600 \mathrm{~mm} / \mathrm{ano}$ (Bellia \& Dias 2003).

Devido à abundância de cursos d'água, são frequentes, na região do Jalapão, matas de galeria e veredas (Figueiredo 2007; Sampaio et al. 2008). Entretanto, sua vegetação é caracterizada por um cerrado ralo, basicamente de campo limpo e campo sujo (Figueiredo 2007).

É uma das regiões do Brasil com menor densidade demográfica. Comunidades tradicionais habitam a região, desenvolvendo produtos a partir de recursos vegetais locais, como o artesanato de capim dourado, confeccionado com Syngonanthus nitens Ruhland e o buriti, Mauritia flexuosa L.f.. (Schmidt et al. 2007; Figueiredo 2007; Viana et al. 2014). Em razão do manejo que essas comunidades fazem da vegetação e de sua proximidade com regiões agropecuárias, queimadas antrópicas são frequentes na região, principalmente durante a estação seca (Chagas 2007; Figueiredo 2007).

As três principais Unidades de Conservação ali existentes são o Parque Estadual do Jalapão, a Estação Ecológica de Serra Geral do Tocantins e o Parque Nacional Nascentes do Paraíba. Completam esse mosaico de Unidades de Conservação, conhecido como Corredor Ecológico do Jalapão, a Área de Proteção Ambiental Serra da Tabatinga e a Área de Proteção Ambiental Jalapão (Figueiredo 2007; Viana 2013). Juntamente com a Estação Ecológica do Rio 
Preto e a Área de Proteção Ambiental do Rio Preto constituem o projeto de corredor ecológico da região do Jalapão (Santos et al. 2011).

Apesar de protegida e relativamente bem conservada, existe uma grande lacuna de conhecimentos sobre a flora do Jalapão (Proença et al. 2007). Um levantamento preliminar detectou 434 espécies de plantas vasculares na região, estimando a diversidade em 600 espécies (Arruda \& Behr 2002). Um segundo levantamento para todas as fitofisionimias, avaliando apenas o entorno do Parque Estadual do Jalapão, encontrou 235 espécies (Scariot et al. 2002). Posteriormente, no levantamento florístico realizado para o Plano de Manejo do Parque Estadual do Jalapão (SEPLAN 2003a) e para o Plano de Manejo da Área de Proteção Ambiental do Jalapão (SEPLAN 2003b) compilou-se todas as coletas realizadas na área do Parque, somadas a novas coletas e listou-se 463 espécies de plantas vasculares, sendo essa a lista mais completa realizada até agora para o Jalapão (Alexandre B. Sampaio com. pess.). Rezende (2007) levantou a flora de campos limpos úmidos do Parque Estadual do Jalapão e chegou a 136 espécies de plantas vasculares. Posteriormente, Barbosa-Silva (2012), levantando as plantas vasculares da Estação Ecológica Serra Geral de Tocantins, encontrou 417 espécies.

As maiores ameaças à conservação dos cerrados do Jalapão são o crescimento desordenado do turismo, a expansão da fronteira agrícola, principalmente com o cultivo da soja, e a mudança no regime de fogo, com o grande aumento da frequência de queimas (Figueiredo 2007). 


\section{Cerrado e o fogo}

O estrato herbáceo do Cerrado é caracterizado por ervas graminoides, majoritariamente com metabolismo C4 (Ramos 1990), com alta produtividade e capacidade de acumular grande biomassa rapidamente. Tal estrato encontra-se seco durante o inverno, estando, assim, sujeito a queimadas no começo da estação chuvosa, com a presença de raios, e também durante a estação seca, principalmente por causas antropogênicas (Simon 2009; Bond et al. 2005; Ramos-Neto 2000). Desse modo, é enquadrado como um dos ambientes naturais mais inflamáveis do mundo (Bond et al. 2005).

Considera-se que esse é um ecossistema adaptado ao fogo (Eiten 1972; Klink \& Machado 2005), ao qual está sujeito há aproximadamente 32.000 anos (Ferraz-Vicentini 1993). Isso é evidenciado pela recuperação relativamente rápida de sua vegetação após queimadas, principalmente do estrato herbáceo-arbustivo, por meio de rebrotas (Andrade \& Miranda 1996), e pelas características morfológicas e fisiológicas conspícuas das espécies que lá ocorrem, dentre as quais destacam-se: folhas escleromorfas e concentradas no ápice dos ramos, madeira relativamente densa, presença de caules subterrâneos (xilopódios), casca espessa nos galhos, grande quantidade de tricomas no indumento e reprodução pós-fogo (Gottsberger \& SilberbauerGottsberger 2006; Kolbek 2008).

Quando a presença de fogo é menos frequente, há o favorecimento da instalação de uma vegetação mais adensada (Coutinho 1982; Coutinho 1990, Ratter et al 1997; Moreira 2000). Em situação contrária, formações mais fechadas tendem a se tornar campestres (Pivello \& Coutinho 1996), devido à morte de indivíduos jovens das espécies arbóreas (Sato et al. 1998; Sato 2003; Medeiros 2005; Henriques 2005; Silva \& Batalha 2010), a menores taxas de recrutamento de suas plântulas (Ramos 1990; Hoffmann 1998), e ao comprometimento da floração e frutificação (Ramos 1990; Hoffmann 1998). Para a vegetação herbácea, verificou-se que, em gramíneas, a ação do fogo leva a um aumento na produção de sementes e pode mudar a taxa de reprodução assexuada em certas espécies (Miranda 2002). 
O fogo ali ocorre não apenas naturalmente, mas é usado para abertura de novas áreas para a agropecuária, para manejo do componente herbáceo para o gado (Klink 2005; Gottsberger \& Silberbauer-Gottsberger 2006), ou para aumentar a produção de produtos utilizados pelas comunidades humanas, como, por exemplo, o capim-dourado (Syngonanthus nitens) (Figueiredo 2007). Logo, o fogo é um fator ecológico muito relevante para o Cerrado e para sua biodiversidade (Henriques 2005; Pennington et al. 2006; Ribeiro \& Walter 2008; Simon 2009), o que o faz objeto de estudos tanto na sua forma de ação quanto nos seus efeitos na composição de espécies.

\section{Estudos entre áreas com presença/ausência de fogo}

O fogo é considerado um distúrbio para o ecossistema no qual ele ocorre, tendo, no entanto, o papel de manter a biodiversidade em certos ambientes (Harrison et al. 2003; Medeiros et al. 2005; Uys et al. 2004). Além do Cerrado, diversas formações savânicas e campestres propensas a incêndios já foram utilizadas para a realização de trabalhos que avaliam a influência do fogo na biodiversidade local (Collins 1987; Collins \& Glenn 1995; Overbeck et al. 2005; Overbeck et al. 2006; Uys et al. 2004; Schwilk et al. 1997; Hobbs et al. 1984; Lunt \& Morgan 2002). Os resultados encontrados são muito diversos. Estudos como os de Harrison (2003), trabalhando em campos na California; Overbeck e colaboradores (2005; 2006) trabalhando em campos no sul do Brasil; Hobbs e colaboradores (1984), com charnecas na Escócia; e Gibson \& Hulbert (1987), em pradarias nos Estados Unidos, encontraram um aumento da diversidade de plantas em lugares que sofreram ação do fogo, em comparação com lugares livres do mesmo. De outro modo, Collins e colaboradores (1995), trabalhando com pradarias nos Estados Unidos da América, e Schwilk e colaboradores (1997), trabalhando com a vegetação de Fynbos na Africa do Sul, encontraram menores valores de diversidade para áreas pós-queimadas do que áreas protegidas. Já Uys e colaboradores (2004), trabalhando com arbustos em campos na África do Sul; e Lunt e Morgan (2002), em um estudo com campos na Austrália, não 
encontraram diferenças significativas entre lugares com diferentes frequências de fogo e lugares livres desse elemento.

Para o bioma Cerrado especificamente, Pivello e Coutinho (1996) argumentam que o fogo com grande frequência (1-2 anos) acaba levando à dominância de poucas espécies resistentes, mas que queimas menos frequentes mantêm a alta diversidade do estrato herbáceo e promovem a ciclagem dos nutrientes e seu reaproveitamento pela vegetação. Moreira (2000); Libano \& Felfili (2006) e Sato (2003) encontraram maior diversidade de plantas lenhosas em locais protegidos por longos períodos da ação do fogo. Silva e colaboradores (2011) mostraram que existem composições florísticas próprias para ambientes protegidos e ambientes com diferentes frequências de queimadas. Miranda (2002), trabalhando com Poaceae, encontrou que queimadas bienais reduzem a biodiversidade de espécies dessa família em campo sujo, principalmente se forem realizadas na estação chuvosa. Loiola e colaboradores (2010), encontraram mudanças na composição florística entre áreas com alta frequência de queima e áreas com média frequência ou protegidas, além de abundâncias de espécies únicas para cada área.

Diante dessa grande variação de resultados, constata-se que são fatores relevantes para os efeitos do fogo em uma comunidade: a frequência com que acontece (Thonicke et al. 2001; Miranda 2002); a intensidade (calor liberado durante a queima, que depende da quantidade de biomassa seca disponível); a estação na qual ocorre (Thonicke et al. 2001; Pivello et al. 1996; Miranda \& Sato 2005); as condições climáticas; a composição de espécies; a topografia, entre outros (Collins 1987).

Há uma lacuna de conhecimento em estudos comparativos sobre a diversidade de espécies herbáceas e subarbustivas no Cerrado, quando se cotejam ambientes que sofreram queimadas e outros protegidos do fogo (Munhoz 2003; Silva \& Batalha 2010), já que a maioria dos estudos anteriores se deteve no estrato lenhoso. 


\section{Objetivos}

Diante desse cenário, esta dissertação tem como objetivos: (i) Elaborar um checklist da flora de angiospermas de cerrado da região do Jalapão, TO, contribuindo assim com o conhecimento da flora do Jalapão e do Cerrado. (ii) Descrever padrões de diversidade de espécies do componente herbáceo-subarbustivo de áreas de campo sujo nas quais ocorreu a presença de fogo e áreas que não estiveram sujeitas a queimadas frequentes. (iii) Verificar o efeito do fogo na biodiversidade da comunidade herbáceo-subarbustiva de campos sujos. (iv) Fornecer subsídios para Unidades de Conservação e outras áreas de Cerrado, para o manejo do fogo.

Para tanto, a dissertaçãoo vem organizada em dois capítulos: o primeiro traz a listagem das espécies encontradas em nosso levantamento e o segundo, um estudo da diversidade do estrato herbáceo subarbustivo sujeito a diferentes regimes de fogo.

\section{Referências}

ALVES, R.J.V. \& KOLBECK, J. 2000 Primary succession on quartzite cliffs in Minas Gerais, Brazil. Biologia 1(55):69-83

ALVES, R.J.V. \& KOLBECK, J. 2010. Can campo rupestre vegetation be floristically delimited based on vascular plant genera? Plant Ecology, 207, 67-79.

ANDRADE, S.M.A.; MIRANDA, H.S. 1996. Dinâmica de combustível em uma área de campo sujo de Cerrado submetido à queimada prescrita no final da estação seca. In Contribuição ao conhecimento ecológico do Cerrado. UnB Ecil 1997. Pag 262-269.

ARRUDA, M.B.; BEHR, M.V. organizadores. 2002. Jalapão: Expedição científica e conservacionista. Edições Ibama. Ministério do Meio Ambiente

ASSUNÇÃO, S.L. \& FELFILI, J.M. 2004. Fitossociologia de um fragmento de cerrado sensu stricto na APA do Paranoá, DF, Brasil. Acta Botanica Brasilica 18:903-909.

BARBOSA-SILVA, D. 2012. Plano de Manejo para Estação Ecológica Serra Geral do Tocantins. Relatório Temático de Vegetação e Flora. Instituto Chico Mendes de Conservação da Biodiversidade (ICMBio) Brasília. 80 p.

BELliA, V. \& DIAS, R.R. (org.). 2003. Plano de Zoneamento Ecológico Econômico - Norte do Estado de Tocantins. Secretaria do Planejamento e Meio Ambiente. Palmas, TO.

BOND, W.J.; KEELEY, J.E. 2005. Fire as a global "herbivore": The ecology and evolution of flammable ecosystems. Trends Ecol Evol 20: 387-394.

CASTRO-NEVES, B.M. 2007. Efeito de queimadas em áreas de Cerrado Stricto sensu e na biomassa de raízes finas. Tese de doutorado. Departamento de Ecologia. Universidade de Brasília. 
CHAGAS, R.P. 2007. Políticas territoriais no estados do Tocantins: um estudo de caso sobre o Jalapão. Dissertação de Mestrado. Departamento de Geografia da Faculdade de Filosofia, Letras e Ciências Humanas, da Universidade de São Paulo.

COLLINS, S.L. 1987. Interaction of disturbances in tallgrass prairie: A field experiment. Ecology 68: $1243-1250$.

COLLINS, S.L.; GLENN, S.M.; GIBSON, D.J. 1995. Experimental analysis of intermediate disturbance and initial floristic composition: decoupling cause and effect. Ecology 76: 486-492.

COUTINHO, L. M. 1978. O conceito do cerrado. Revta. Brasil. Bot., 1: 17-23.

COUTINHO, L. M. 1982. Aspectos ecológicos da saúva no cerrado - os murundus de terra, as características psamofíticas das espécies de sua vegetação e a sua invasão pelo capim-gordura. Revista Brasileira de Botânica 42: 147-153.

COUTINHO, L.M. 1990. Fire in the ecology of Brazilian Cerrado. Ecological Studies: analysis and synthesis. v. 84: 82-105 EITEN, G.1972. The cerrado vegetation of Brazil. Botanical Review.38 (2): 201-341.

EITEN, G. 2001. Vegetação Natural do Distrito Federal. Serviço de apoio às micro e pequenas empresas do Distrito Federal (SEBRAE) Brasil

FANTINATI, M.R. 2004. Levantamento florístico de áreas alagadas no cerrado da Estação Ecológica de Itirapina - SP. Dissertação de Mestrado. Universidade de São Paulo. São Paulo.

FELFINI, J.M.; NOGUEIRA, P.E.; SILVA-JÚNIOR, M.C.; MARIMON, B.S. \& DELITTI, W.B.C. 2002. Composição florística e fitossociologia do cerrado sentido restrito no município de Água Boa, MT. Acta Botanica Brasilica 16(1): 103-112.

FERRAZ-VICENTINI, K.R.C. 1993. Análise palinológica de uma vereda em Cromínia, GO. Dissertação de Mestrado.Universidade de Brasília, Brasília.

FIGUEIREDO, I.B. 2007. Efeito do fogo em populações de capim-dourado (Syngonanthus nitens ERIOCAULACEAE) no Jalapão-TO. Dissertação de mestrado. Instituto de Ciências Biológicas. Universidade de Brasília.

FORZZA, R.C.; FILARDI, F.L.R.; COSTA, A.; CARVALHO JUNIOR, A.A.; PEIXOTO, A.L.; WALTER, B.M.T.; BICUDO, C.; MOURA, C.W.N.; ZAPPI, D.; COSTA, D.P.; LLERAS, E.; MARTINELLI, G.; LIMA, H.C.; PRADO, J.; STEHMANN, J.R.; BAUMGRATZ, J.F.A.; PIRANI, J.R.; SYLVESTRE, L.S.; MAIA, L.C.; LOHMANN, L.G.; PAGANUCCI, L.; ALVES, M.V.S.; SILVEIRA, M.; MAMEDE, M.M.H.; BASTOS, M.N.C.; MORIM, M.P.; BARBOSA, M.R.; MENEZES, M.; HOPKINS, M.; SECCO, R.; CAVALCANTI, T. \& SOUZA, V.C., (coordenadores). 2010. Catálogo de Plantas e Fungos do Brasil. Andréa Jakobson Estúdio, Instituto de Pesquisas do Jardim Botânico do Rio de Janeiro, Rio de Janeiro, 2v.

FORZZA, R. C.; BAUMGRATZ, J. F. A.; BICUDO, C. E. M.; CANHOS, D. A. L.; CARVALHO, A.; COELHO, M. A. N.; COSTA, A. F.; COSTA, D. P.; HOPKINS, M. G.; LEITMAN, P. M.; LOHMANN, L. G.; LUGHADHA, E. N.; MAIA, L. C.; MARTINELli, G.; MENEZES, M.; MORIM, M. P.; PEIXOTO, A. L.; PIRANI, J. R.; PRADO, J.; QUEIROZ, L. P.; SOUZA, S.; SOUZA, V. C.; STEHMANN, J. R.; SYLVESTRE, L. S.; WALTER, B. M. T.; ZAPPI, D. C. 2012. New Brazilian floristic list highlights conservation challenges. Bioscience, Washington 62: 3945.

GIBSON, D.J.; HULBERT, L.C. 1987. Effects off fire, topography and year-to-year climatic variation on species composition in tallgrass prairie. Vegetatio 72:175-185.

GORGONE-BARBOSA, E.; PIVELLO, V.R.; BAUTISTA, S.; RISSI, M.N. \& FIDELIS, A. 2015. How can na invasive grass affect fire behavior in a tropical savana? A community and individual plant level approach. Biological Invasions, V. 17, p.1-9.

GOTTSBERGER, G.; SILBERBAUER-GOTTSBERGER I., 2006. Life in the Cerrado, a South American Tropical Seasonal Ecosystem. Vol 1. Origin, Structure, Dynamics and Plant Use. Reta Verlag, Ulm, Alemanha.

HARRISON, S.; INOUYE, B.D.; SAFFORD, H.D. 2003. Ecological Heterogeneity in Effects of Grazing and Fire on Grassland Diversity. Conservation Biology. 17(3): 837-845.

HENRIQUES, R.P.B. 2005. Influência da história, solo e fogo na distribuição e dinâmica das fitofisionomias no bioma do Cerrado. In Cerrado: Ecologia, Biodiversidade e Conservação (J.C. Souza Silva \& J.M. Felfili, eds.). Ministério do Meio Ambiente, Brasília, p.73-92. 
HOBBS, R.J.; MALLIK, A.U.; GIMINGHAM, C.H. 1984. Studies on fire in Scottish heathland communities: III. Vital attributes of the species. Journal of Ecology 72: 963-976.

HOFFMANN, W.A. 1998. Post-burn reproduction of woody plants in a neotropical savanna: the relative importance of sexual and vegetative reproduction. Journal of Applied Ecology 35: 422-433.

JOLY, A. B. 1970. Conheça a vegetação brasileira. EDUSP e Polígono. São Paulo.

KLINK, C.A. \& MACHADO, R.B. 2005. Conservation of Brazilian Cerrado. Conservarion Biology 19 (3) $707-713$.

KOLBEK, J.; ALVES, R.J.V. 2008. Impacts of cattles, fire and Wind in rocky savannas, Southeastern Brazil. Acta Universitatis Carolinae Environmentalica 22: 111-130.

LIBANO, A.M. \& FELFILI, J.M. 2006. Mudanças temporais na composição florística e na diversidade de um cerrado sensu stricto do Brasil Central em um período de 18 anos (1985-2003). Acta Botanica Brasilica 20: 927-936.

LOIOLA, P.P.; CIANCIARUSO, M.V.; SILVA, I.A. \& BATALHA, M.A. 2010. Functional diversity of herbaceous species under different fire frequencies in Brazilian savannas. Flora 205: 674-681.

LUNT, I.D.; MORGAN, J.W. 2002. The role of fire regimes in temperate lowland grasslands of southeastern Australia. In: BRADSTOCK, R.A.; WILLIAMS, J.E. \& GILL, A.M. (Eds.) 2002. Flammable Australia: The Fire Regimes and Biodiversity of a Continent. Cambridge University Press, Cambridge: 177-196.

MARIMON-JÚNIOR, B.H. \& HARIDASAN, M. 2005. Comparação da vegetação arbórea e características edáficas de um cerradão e um cerrado sensu stricto em áreas adjacentes sobre solo distrófico no leste de Mato Grosso, Brasil. Acta Botanica Brasilica 1: 913-926.

MARTINELli, G.; VALENTE, A.S.M.; MAURENZA, D.; KUTSCHENKO, D.C.; JUDICE, D.M.; SILVA, D.S.; FERNANDEZ, E.P.; MARTINS, E.M.; BARROS, F.S.M.; SFAIR, J.C.; FILHO, L.A.F.S.; ABREU, M.B.; MORAES, M.A.; MONTEIRO, N.P.; PIETRO, P.V.; FERNANDES, R.A.; HERING, R.L.O.; MESSINA, T. \& PENEDO, T.S.A. 2013. Avaliação de risco de extinção de espécies da flora brasileira. In: Martinelli, G. \& Moraes, M.A. (orgs.). 2013. Livro Vermelho da Flora do Brasil. Centro Nacional de Conservação da Flora.

MIRANDA, M.I. 2002. Efeito de diferentes regimes de queima sobre a comunidade de gramíneas de Cerrado. Dissertação de Mestrado. Universidade Nacional de Brasília.

MIRANDA, H.S. \& SATO, M.N. 2005. Efeitos do fogo na vegetação lenhosa lenhosa de Cerrado. In: SCARIOT, A.; SOUSA-SILVA, J.C.; FELFILI, J.M. orgs. Cerrado: Ecologia, Biodiversidade e Conservação. Brasília: Ministério do Meio Ambiente.

MEDEIROS, M.B.; MIRANDA, H.S. 2005. Mortalidade Pós-fogo em espécies lenhosas de campo sujo submetido a três queimadas prescritas anuais. Acta Botânica Brasil 19: 493-500.

MENDONÇA, R. C.; FELFILI, J. M.; WALTER, B. M. T.; SILVA-JÚNIOR, M. C.; REZENDE, A. V.; FILGUEIRAS, T. S. \& NOGUEIRA, P. E. 2008. Flora Vascular do Cerrado: 289-556. In: S. M. Sano \& S. P. Almeida (eds). Cerrado: ambiente e flora. Planaltina, EMBRAPA-CPAC

MOREIRA, A.G. 2000. Effects off fire protection on savanna structure in Central Brazil. Journal of Biogeography 27: 10211029.

MUNHOZ, C.B.R. 2003. Padrões de destribuição sazonal e espacial das espécies do estrato herbáceo-subarbustivo em comunidades de campo limpo úmido e de campo sujo. Tese de Doutorado. Instituto de Ciências Biológicas. Departamento de Ecologia. Universidade de Brasília.

MYERS, N.; MITTERMEIER, R.A.; FONSECA, G.A.B.; KENT, J. 2000. Biodiversity hotspots for conservation priorities. Nature $403: 853-858$.

OLIVEIRA-FILHO, A.T. 1992. The vegetation of Brazilian "murundus": the island-effect on the plant community. Journal of Tropical Ecology, Cambridge 8(4): 465-486.

OVERBECK, G.E.; MULLER, S.C.; PILLAR, V.D.; PFADENHAUER, J. 2005. Fine-scale post fire dynamics in southern Brazilian subtropical Grassland. Journal of Vegetation Science 16: 655-664. 
OVERBECK, G.E.; MULLER, S.C.; PILLAR, V.D.; PFADENHAUER, J. 2006. Floristic composition, environmental variation and species distribution patterns in burned grassland in southern Brazil. Brazilian Journal of Biology 66(4): $1-10$.

PENNINGTON, R.T.; LEWIS, G.P.; RATTER, J.A. 2006. An overview of the plant diversity, biogeography and conservation of neotropical savannas and seasonally dry forests. Neotropical Savannas and Seasonally Dry Forests: Plant Diversity, Biogeography, and Conservation, eds Pennington, R.T.; Lewis G.P.; Ratter, J.A.: 1-29.

PIVELLO, V.R.; COUTINHO, L.M. 1996. A qualitative successional model to assist in the management of Brazilian cerrados. Forest Ecology Management 87: 127-138.

PIVEllO V.; CARVAlHO V. \& Lopes, P. 1999. Abundance and distribution of native and alien grasses in a "Cerrado"'(Brazilian savanna) biological reserve. Biotropica 31:71-82

PROENÇA, C.E.B.; FARIAS-SINGER, R. \& GOMES, B.M. 2007. Pleonotoma orientalis (Bignoniaceae-Bignonieae): Expanded description, distribution and a new variety of a poorly known species. Edinburgh Journal of Botany 64(1): 17-23

RAMOS, A.E. 1990. Efeitos da queima sobre a vegetacão lenhosa do cerrado. Dissertação de Mestrado. Universidade de Brasília.

RAMOS-NETO, M.B.; PIVELLO, V.R. 2000. Lightning fires in a Brazilian savanna national park: rethinking management strategies. Environmental Management 26: 675-684.

RAPINI, A.; RIBEIRO, P.L.; LAMBERT, S. \& PIRANI, J.R. 2008. A flora dos campos rupestres da Cadeia do Espinhaço. Megadiversidade 4: 16-24.

RATTER, J.A.; RIBEIRO, J.F.; BRIDGEWATER, S. 1997. The brazilian cerrado vegetation and threats to its biodiversity. Annals of biology 80: $223-230$

REZENDE, J.M., 2007, Florística, Fitossociologia e a influencia do gradiente de umidade do solo em campo limpos úmidos no parque estadual do jalapão, Tocantins. Dissertação de Mestrado em Ciencias Florestais. Universidade de Brasília.

RIBEIRO, J. F. 1983. Comparação da concentração de nutrientes na vegetação arbórea e nos solos de um cerrado e um cerradão no Distrito Federal, Brasil. Dissertação de Mestrado. Universidade de Brasília.

RIBEIRO, J.F.; WALTER, B.M.T. 2008. As pricipais fitofisionomias do bioma Cerrado. : SANO, S.M.; ALMEIDA, S.P. \& RIBEIRO, J.F. 2008. Cerrado: Ecologia e flora. EMBRAPA. Vol 1. Capítulo 6. Pág: 153-212.

SAMPAIO, M.B.; SCHMIDT, I.B.; FIGUEIREDO, I.B. 2008. Harvesting effects and population ecology of the Buriti palm (Mauritia flexuosa L. f., Arecaceae) in the Jalapão region, Central Brazil. Economic Botany, 62(2): 171-181.

SANTOS. R.P.; CREMA, A.; SZMUCHROWSKI, M.A.; ASANO, K.; KAWAGUCHI, M. 2011. Atlas do corredor ecológico da região do Jalapão. Instituto Chico Mendes de Conservação da Biodiversidade

SARMIENTO, G. 1984. The ecology of neotropical savannas. Harvard University, Cambridge, 235 p.

SATO, M.N.; GARDA, A.A.; MIRANDA, H.S. 1998. Effects of fire on the mortality of woody vegetation in Central Brazil. In D. X. Viegas (Ed.). Proceedings of the 14th Conference on fire and forest meteorology, University of Coimbra, Coimbra,Portugal. Volume 2, p. 1777-1783.

SATO, M.N. 2003. Efeito ao longo prazo de queimadas prescritas na estrutura da comunidade de lenhosas da vegtação do cerrado sensu stricto. PhD Thesis. Universidade de Brasília.

SCARIOT, A.; CAVAlCANTI, T.B.; SEVILHA, A.C.; SAMPAIO, A.B.; SILVA, M.C. \& SILVA, G.P. 2002. Flora e vegetação do Entorno do Parque Estadual do Jalapão (TO). Relatório Final. EMBRAPA.

SCHMIDT. I.B.; FIGUEIREDO, I.B. \& SCARIOT, A.2007. Ethnobotany and Effects of Harvesting on the Population of Syngonanthus nitens (Bong.) Ruhland (Eriocaulaceae), a NTFP from Jalapão Region, Central Brazil. Economic Botany 61(1): 73-85 
SCHWIK, D.W.; KEELY, J.E.; BOND, W.J. 1997. The intermediate Disturbance Hypothesis does not explain fire and diversity patterns in fynbos. Plant Ecology 132: 77-84.

SEPLAN - Secretaria do Planejamento e Meio Ambiente do Estado de Tocantins. Plano de Manejo do Parque Estadual do Jalapão. Palmas; Seplan, 2003a. 132p.

SEPLAN - Secretaria do Planejamento e Meio Ambiente do Estado de Tocantins. Plano de Manejo da Área de Proteção Ambiental do Jalapão. Palmas; Seplan 2003b. 205p.

SILVA, J.M.C.\& BATES, J.M. 2002. Biogeographyc patterns and conservation in the South America Cerrado: A Tropical Savana Hotspot. BioScience 52(3) 225-233.

SILVA, F.A.M.; ASSAD, E.D.; EVANGELISTA, B.A. 2008. Caracterização Climática do bioma Cerrado. : SANO, S.M.; ALMEIDA, S.P. \& RIBEIRO, J.F. 2008. Cerrado: Ecologia e flora. EMBRAPA. Vol 1. Capítulo 2: 71-88.

SILVA, I.A.; BATALHA, M.A., 2010. Phylogenetic structure of Brazilian savannas under different fire regimes. Journal of Vegetation Science 21: 1003-1013.

SILVA, I.A.; BATALHA, M.A., 2011. Plant functional types in Brazilian savannas. The niche partitioning between herbaceous and woody species. Perspect. Plant Ecol. Evol. Syst. 2011. p. 1-6.

SIMON, M.F.; GRETHER, R.; QUEIROZ, L.P.; SKEMAE, C.; PENNINGTON, R.T.; HUGHES, C.S., 2009. Recent assembly of the Cerrado, a neotropical plant diversity hotspot, bt in situ evolution of adaptations to fire. Proc. Natl. Acad Sci. USA. 106: 20359-20364.

THONICKE, K.; VENEVSKY, S.; SITCH, S.; CRAMER, W. The role of fire disturbance for global vegetation dynamics: coupling fire into a Dynamic Vegetation Model. Global Ecology \& Biogeohraphy 10:661-677.

UYS, R.G.; Bond, W.J.; EVERSON, T.M. 2004. The effect of different fire regimes on plant fiversity in southern African grasslands. Biological Conservation 118: 489-499.

VIANA, R.V.R. 2013. Diálogos possiveis entre saberes científicos e locais associados ao capim-dourado e ao buriti na região do Jalapão, TO. Dissertação de Mestrado. Instituto de Biociências. Universidade de São Paulo.

VIANA, R.V.R.; SANO, P.T. \& SCATENA, V.L. 2014. Pesquisa de Campo como Possibilidade de Concretizar Oportunidades de Diálogo: Experiência em Duas Comunidades Artesãs do Jalapão-TO. Revista Desenvolvimento Social 13: 57-67.

WALTER, B.M.T.; CARVALHO, A.M.; RIBEIRO, J.F. 2008. O conceito de Savana e de seu componente Cerrado.: SANO, S.M.; ALMEIDA, S.P. \& RIBEIRO, J.F. 2008. Cerrado: Ecologia e flora. EMBRAPA. Vol 1. Capítulo 1: 21-45. 
Antar and Sano | Angiosperms of Jalapão region

Angiosperms of Jalapão region, the most conserved area of Brazilian savannah

Guilherme de Medeiros Antar* and Paulo Takeo Sano

Universidade de São Paulo, Instituto de Biociências, Departamento de Botânica, Rua do Matão 277 - Postal Code 05508-090-São Paulo, SP, Brazil.

Corresponding author: Email: guilherme.antar@gmail.com

Abstract

This study provides a checklist of angiosperm species from Jalapão region, Tocantins, Brazil. The area is part of the Cerrado domain, one of the global biodiversity hotspots. Jalapão is highly conserved, however its plant richness is still poorly known. Fieldwork was conducted, herbarium samples were revised and a species list was compiled. Plants occurring in savanna physiognomies with dry, non-rocky soils were considered. 528 species distributed in 85 families were recorded. The most representative families are Fabaceae, Poaceae, Asteraceae, Rubiaceae, Lamiaceae and Myrtaceae. Nine plant species are listed as rare and nine as threatened. This study increases almost 2-fold the number of species from previous inventories of angiosperms occurring in these physiognomies in Jalapão.

Key words: Cerrado, conservation, floristics, checklist, plant biodiversity 
Introduction

The Cerrado is the second largest phytogeographic domain of Brazil, covering approximately $22 \%$ of the country area, reaching parts of Bolivia and Paraguay as well (Ratter $e t$ al. 1997; Ribeiro and Walter 2008). Despite being characterized as a savannah domain, it is composed by different physiognomies, like swamp forests ("veredas"), seasonal dry forests (“cerradão"), dry forests, highland rocky fields ("campos rupestres") and open areas where a tree density gradient is found, ranging from "campo limpo", with only a herbaceous layer, to “cerrado sensu strictu” with 50\% wood cover (Coutinho 1978; Coutinho 1990; Ratter et al 1997; Ribeiro and Walter 2008; Sampaio et al. 2008). These different physiognomies are shaped by factors as water availability, fire regimen, nutrient availability, depth and composition of the soil, species interaction, grazing and slope gradient (Coutinho 1990; Pivello and Coutinho 1996; Ratter et al. 1997; Moreira 2000; Ribeiro and Walter 2008; Silva and Batalha 2011; Amaral et al. 2013).

This variety of physiognomies is one of the reasons for the high biodiversity of the Cerrado, with 11,637 vascular plant species registered, $36 \%$ of them endemic; making it the savannah region with the highest plant diversity in the world (Forzza et al. 2012). Despite its great biodiversity, the Cerrado has been historically undervalued by the Brazilian government, international NGOs, and even by its population, who sees the Atlantic and Amazon rainforests as more valuable (Ratter et al. 1997; Klink and Machado 2005). It is estimated that more than 50\% of the Cerrado area has been deforested, mainly due to agriculture (mostly soybean monocultures), cattle ranching and charcoal production (Ratter et al. 1997; Klink and Machado 2005); the remnants being highly fragmented (Gottsberger and Silberbauer-Gottsberger 2006) and threatened by African alien grasses invasion, mostly from the genera Urochloa P.Beauv. and Melinis P.Beauv. (Pivello et al. 1999). This elevated biodiversity, with high endemism and 
intense anthropogenic pressure, makes the Cerrado one of the biodiversity hotspots in the world (Myers et al. 2000).

The Jalapão region, located in the Northeastern Cerrado province (Ratter et al. 2003; Bridgewater et al. 2004), is the most conserved area of Cerrado, mostly due to its nutrient-poor sandy soils and being one of the less populated Brazilian regions (Schmidt et al. 2007; Yamamoto et al. 2008). The region is also the largest continuous protected Cerrado area (Silva and Bates 2002), comprising several protected areas: "Parque Estadual do Jalapão", "Estação Ecológica Serra Geral do Tocantins", "Parque Nacional Nascentes do Parnaíba" and "Área de Proteção Ambiental do Jalapão" (Schmidt et al. 2007). In spite of this conservation and protection effort, Jalapão flora is still poorly known (Proença et al. 2007). This is confirmed by the high number of new species being described recently (Proença et al. 2007, França and Proença 2007, Araujo and Souza 2007, Yamamoto et al. 2008, Rua et al. 2008, Vieira and Souza 2008) and the low number of plant collections available in herbaria, as few field expeditions were conducted to date (Proença et al. 2007).

The first list of plant species from Jalapão recorded 434 vascular plant species, projecting plant diversity to 600 species (Arruda and Behr 2002). Since then, little progress has been made and the most comprehensive floristic list available for the area (A.B. Sampaio pers. comm.) updated the previous inventory with new collection efforts, now indicating 463 vascular plant species for all physionogmies in Jalapão (Seplan 2003).

While Cerrado areas are being rapidly replaced, Jalapão region arises as an important conserved area, but it still lacks an extensive list of plants that occurs in the region (Seplan 2003). Thus, the question remains: how can the Cerrado be conserved, if we do not know what is there in the first place? 
The objective of this work is to provide a list of the Angiosperm flora in Jalapão region, thus contributing to the knowledge of this botanically underexplored region and to the flora of the highly threatened Cerrado domain.

Material and Methods

Study area

Jalapão is located in the eastern part of Tocantins state, in the border region between Piauí, Bahia, and Maranhão states. There is no consensus of the exact delimitation of the region. For this study, only the core Jalapão area was considered, consisting of the municipalities of Mateiros, Ponte Alta do Tocantins and the south portion of São Felix do Tocantins (Figure 1). The areas covered by these municipalities are largely similar in climate, soil composition and physiognomy structure.

The climate is Koeppen's Aw (Alvares et al. 2014), as in the Cerrado domain in general, with two well-marked seasons, a rainy one from October to March, and a dry one from April to September (Ratter et al. 1997). During the dry season, anthropogenic fires are frequent, mainly due to cattle ranching (Schmidt et al. 2007). Mean precipitation is approximately $1500 \mathrm{~mm} /$ year, and mean temperature is around $26^{\circ} \mathrm{C}$ (Seplan 2012). The soils are quartzitic neosoils, mostly composed of sand, being deep, well drained and very poor in nutrients. Elevation ranges mostly from 400 to $550 \mathrm{~m}$, reaching up to $800 \mathrm{~m}$ in some instances, known as "Chapadões" (Seplan 2012).

The principal physiognomies (sensu Ribeiro and Walter 2008) are swamp forests ("veredas") accompanying many waterways (Schmidt et al. 2007; Sampaio et al. 2008) and mainly open savanna vegetation (Seplan 2003), such as "campo sujo" and "cerrado sensu stricto". 


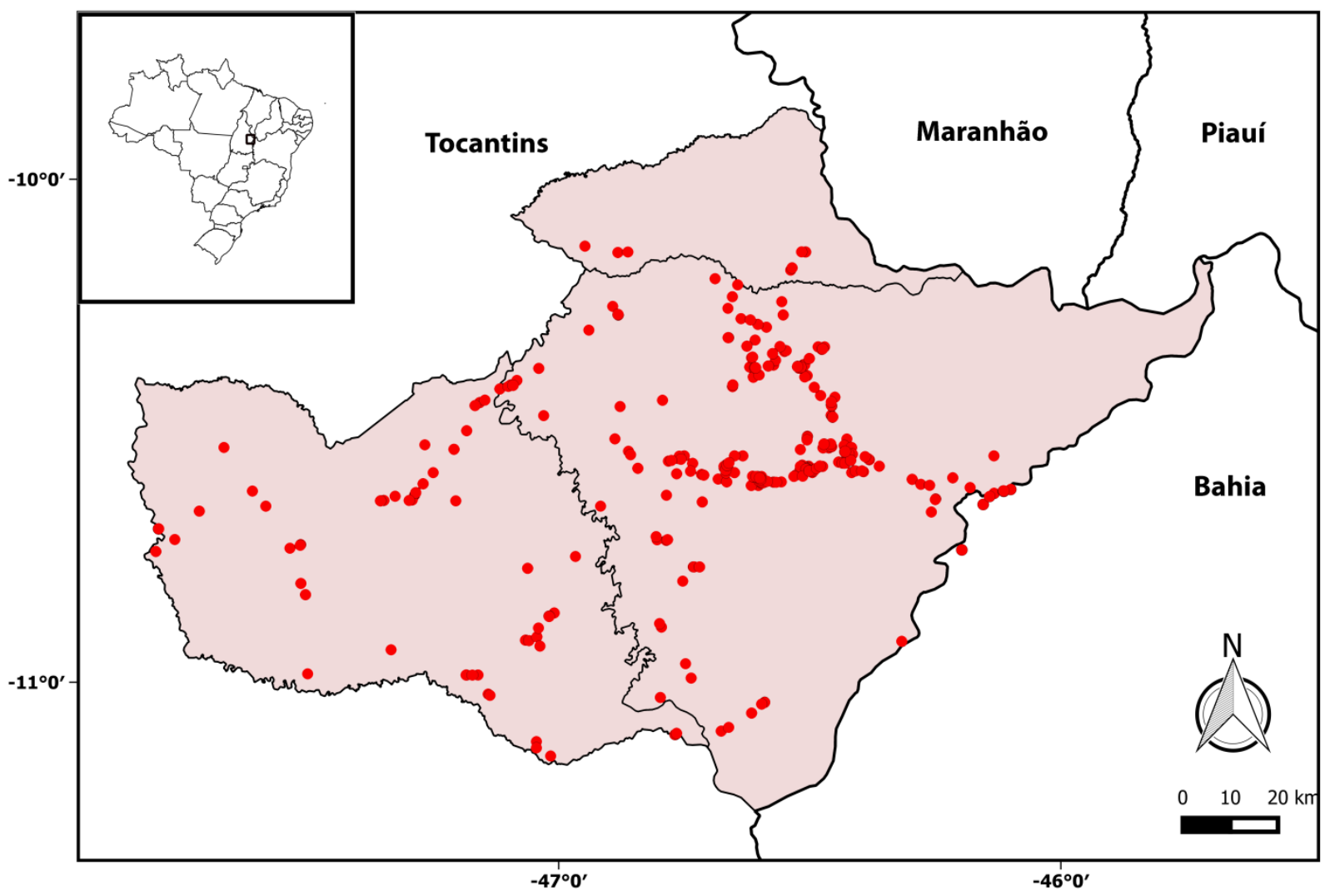

Figure 1. Study area and sampling points in municipalities located in eastern Tocantins, Brazil.

Data collection

Six expeditions were conducted in Jalapão from 2013 to 2014. These expeditions included different periods of the year, sampling specimens both from dry and wet seasons. All angiosperms in reproductive phase were collected by the "walk-through" method (Filgueras et al. 1994). Additionally, herbaria with representative collections from Jalapão plants were visited and identifications revised. The visited herbaria (according to Thiers 2015) were: BHCB, CEN, CEPEC, ESA, HEPH, HRCB, HTO, HUEFS, HUTO, SPF, UB and UEC. Also, images of specimens from the following herbaria were analyzed: RB, UFG and NY.

Only plant specimens occurring at non forestall savannah physiognomies, with dry, nonrocky soils, were considered in this study, encompassing "campo limpo", "campo sujo", "campo cerrado", "cerrado sensu stricto" and dune vegetation physiognomies, according to definitions in 
Coutinho (1990) (Figure 2). Comparisons with other herbarium specimens or information from literature were used to designate physiognomy when the physiognomy where some specimen occurred was not clear in herbaria labels.

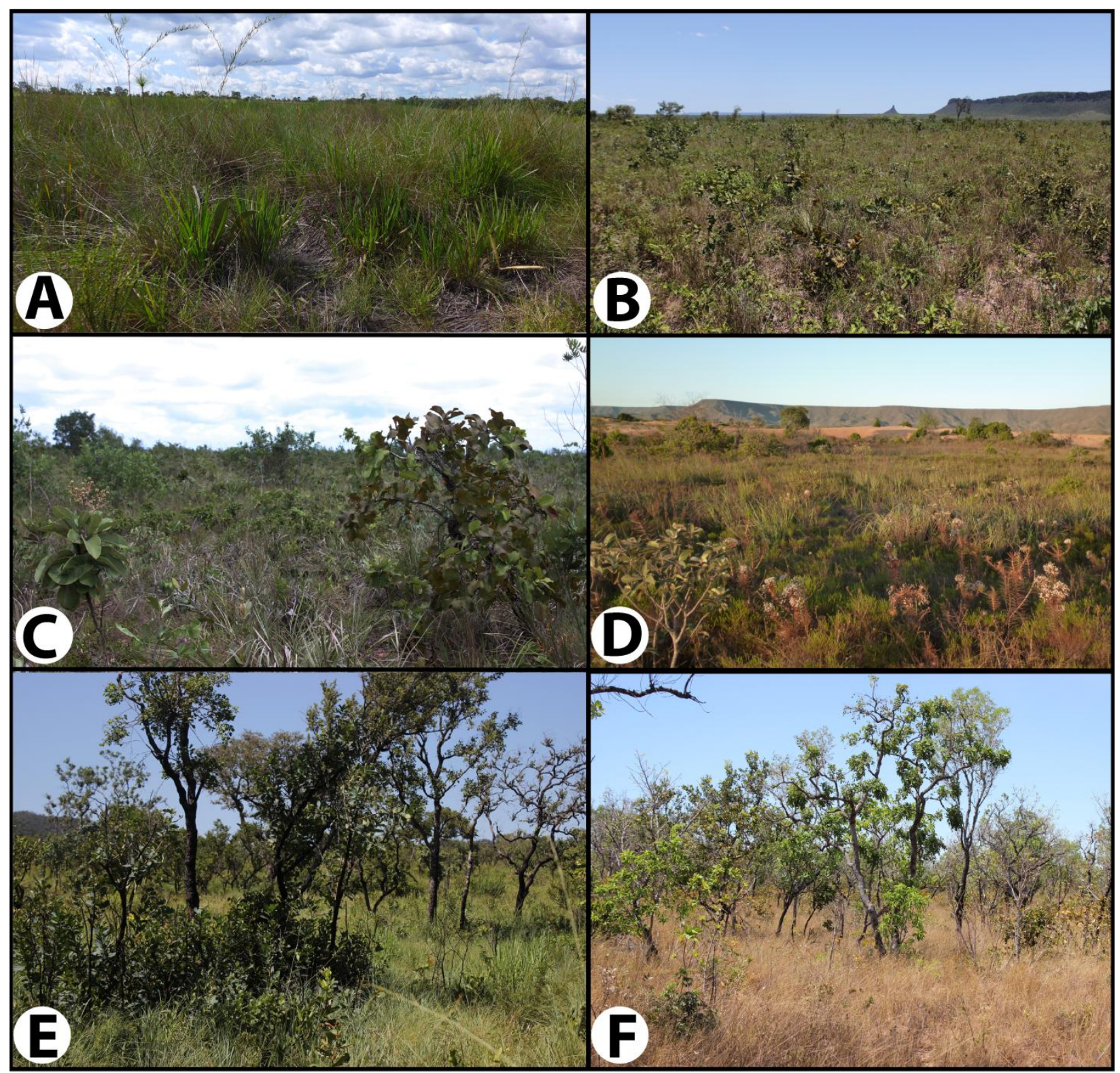

Figure 2. Physiognomies considered in the study A. "Campo limpo", field with herbaceous layer only. Photo R. Viana B. "campo sujo", field with an herbaceous and shrubby layer, with few scattered low trees. C. "Campo cerrado" savanna physiognomy with up to $10 \%$ of tree coverage D. Dune vegetation. E. "Cerrado sensu stricto", savanna physiognomy with up to $50 \%$ of tree coverage. Wet season. F. "Cerrado sensu stricto". Dry season. A-F. Mateiros municipality. 
The specimens collected were dried and incorporated at the SPF herbarium. The identification took place at Laboratório de Sistemática Vegetal, where specialized literature was considered and comparative studies were conducted using the SPF collection. Family experts were consulted in some instances for confirmation or identification of the material. The family names followed APG III and the species name followed the "Lista de Espécies da Flora do Brasil" (2015), with the exception of Chamaecrista, which followed Irwin and Barneby (1982). Authors name followed The International Plant Names Index - IPNI 2014 (http://www.ipni.org). The plant habit followed Beentje (2012), when the plant was not seen in field, the habitat written in the specimen label was considered.

Results

A total of 528 species from 85 families were recorded (Table 1). Considering infraspecific taxa, this number increases to 533. Thirteen recorded species are considered new to science. The most species-rich families were Fabaceae (85 spp.), Poaceae (38), Asteraceae (30), Rubiaceae (22), Lamiaceae (21) and Myrtaceae (20). Forty-two families had only one or two species registered on the region. The most representative genera were Chamaecrista (12), Byrsonima Rich ex Kunth (12), Mimosa L. (11), Paspalum L. (11), Polygala L. (11), Eugenia L. (10), Bauhinia L. (8), Hyptis Jacq. (8), Ouratea Aubl. (8) and Myrcia DC. (8).

Four species were considered threatened, based on Martinelli et al. (2014): Chamaecrista ochrosperma (H.S.Irwin \& Barneby) H.S.Irwin \& Barneby (vulnerable), Diplusodon tringitus T.B.Calvalc. (endangered), Ouratea acicularis R.G.Chacon \& K.Yamam. (endangered) and Stachytarpheta integrifolia (Pohl) Walp. (endangered). Based on Martinelli \& Moraes (2013), five species were considered threatened: Attalea barreirenses Glassman (vulnerable), Cereus mirabella N.P.Taylor (vulnerable), Diplusodon gracilis Koehne (critically endangered), 
Discocactus catingicola Buining \& Brederoo (vulnerable) and Strophopappus bicolor DC. (endangered).

Nine species occurring in Jalapão were considered rare, according to Giulietti et al. (2009): Borreria irwiniana E.L.Cabral, Chamaecrista ochrosperma, Diplusodon gracilis, Diplusodon trigintus, Duguetia rotundifolia R.E.Fr., Hyptis caduca Epling, Ouratea acicularis, Rhabdodendron gardnerianum (Benth.) Sandwith, and Stachytarpheta integrifolia (Pohl) Walp.

Regarding plant habitat, 147 taxa were classified as herbs, 8 as palms, 190 as shrubs, 103 as subshrubs, 72 as trees and 13 as vines. Percentages are shown in Figure 3.

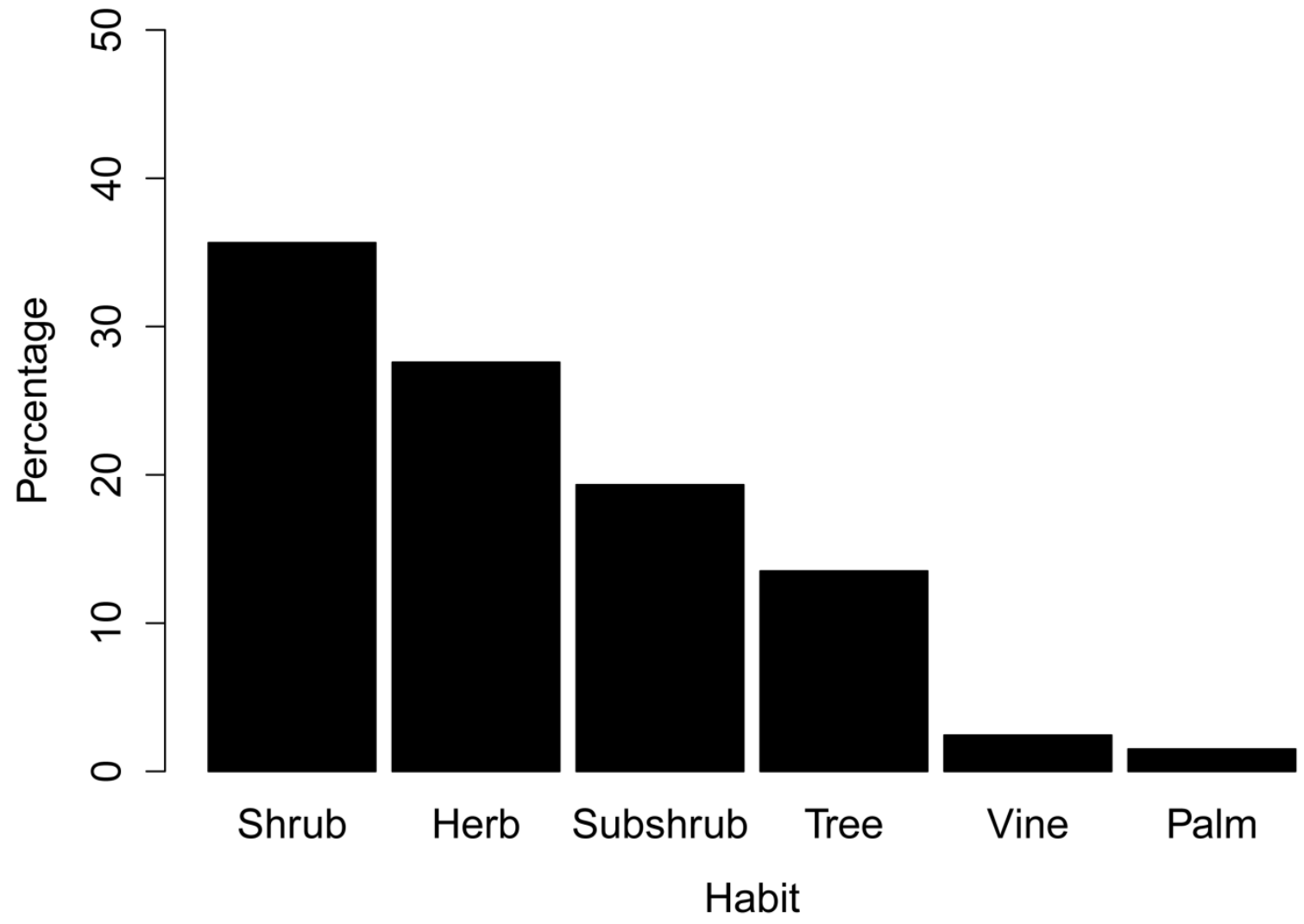

Figure 3. Percentage of habits found in non forestall savannah physiognomies, with dry, nonrocky soils of Jalapão region. 
TABLE 1. Taxons recorded in the Jalapão region for open cerrado physiognomies with dry non rocky soils, followed by habits and voucher. The prefix of the voucher is the acronym of the herbaria followed by the collector and its number of collection.

\begin{tabular}{|c|c|c|}
\hline Taxon & Plant habit & Voucher \\
\hline \multicolumn{3}{|l|}{ Acanthaceae } \\
\hline Lepidagathis montana (Nees) Kameyama & herb & HCF Caxambu 3227 \\
\hline Ruellia sp. & subshrub & ESA Souza 24186 \\
\hline \multicolumn{3}{|l|}{ Alstromeriaceae } \\
\hline A/stroemeria stenophylla M.C.Assis & herb & SPF Antar 410 \\
\hline \multicolumn{3}{|l|}{ Amaranthaceae } \\
\hline Alternanthera martii R.E.Fr. & herb & SPF Antar 417 \\
\hline Gomphrena agrestis Mart. & herb & SPF Antar 394 \\
\hline Gomphrena graminea Moq. & herb & UFG Rizzo 9210 \\
\hline Gomphrena virgataMart. & herb & SPF Antar 219 \\
\hline \multicolumn{3}{|l|}{ Amaryllidaceae } \\
\hline Habranthus sylvaticus Herb. & herb & HRCB Scatena 424 \\
\hline \multicolumn{3}{|l|}{ Anacardiaceae } \\
\hline Anacardium humile A.St.-Hil. & shrub & SPF Antar 218 \\
\hline Anacardium occidentale L. & tree & SPF Antar 460 \\
\hline \multicolumn{3}{|l|}{ Annonaceae } \\
\hline Annona aurantiaca Barb.Rodr. & shrub & SPF Antar 749 \\
\hline Annona coriacea Mart. & shrub & UB Sampaio 550 \\
\hline Annona dioica A.St.-Hil. & shrub & HUEFS Farias 167 \\
\hline Annona cf. malmeana R.E.Fr. & shrub & SPF Antar 279 \\
\hline Annona tomentosa R.E.Fr. & shrub & SPF Antar 543 \\
\hline Duguetia furfuracea (A.St-Hil.) Saff. & shrub & UB Soares-Silva 970 \\
\hline Duguetia rotundifolia R.E.Fr. & shrub & SPF Antar 536 \\
\hline Xylopia aromatica (Lam.) Mart. & tree & SPF Antar 457 \\
\hline \multicolumn{3}{|l|}{ Apocynaceae } \\
\hline Aspidosperma macrocarpon Mart. & tree & SPF Antar 444 \\
\hline Barjonia erecta (Vell.) K.Schum. & subshrub & HRCB Lombardi 10299 \\
\hline Blepharodon bicolor Decne. & vine & UB Farias 413 \\
\hline Blepharodon lineare (Decne.) Decne. & herb & HUEFS Melo 7228 \\
\hline Hancornia speciosa Gomes & tree & SPF Antar 298 \\
\hline Hemipogon acerosus Decne. & herb & SPF Antar 378 \\
\hline Hemipogon setaceus Decne. & herb & HUEFS Melo 7132 \\
\hline Himatanthus drasticus (Mart.) Plumel & tree & SPF Antar 307 \\
\hline Himatanthus obovatus (M.Arg.) R.E.Woodson & tree & UEC Farias 400 \\
\hline Mandevilla abortiva J.F.Morales & vine & HRCB Lombardi 10323 \\
\hline Mandevilla illustris (Vell.) Woodson & shrub & HUEFS Melo 7224 \\
\hline Minaria acerosa (Mart.) T.U.P.Konno \& Rapini & subshrub & CEN Simon 412 \\
\hline Minaria cordata (Turcz.) T.U.P.Konno \& Rapini & subshrub & SPF Antar 345 \\
\hline Nephradenia acerosa Decne. & herb & HEPH Barbosa-Silva 54 \\
\hline
\end{tabular}




\begin{tabular}{|c|c|c|}
\hline Odontadenia Iutea (Vell.) Markgr. & shrub & HUEFS Melo 7093 \\
\hline Oxypetalum capitatum Mart. & herb & RB Rizzo 3031 \\
\hline \multicolumn{3}{|l|}{ Araliaceae } \\
\hline Schefflera burchellii (Seem.) Frodin \& Fiaschi & tree & SPF Antar 715 \\
\hline \multicolumn{3}{|l|}{ Arecaceae } \\
\hline Allagoptera leucocalyx (Drude) Kuntze & palm & UB Martins 239 \\
\hline Astrocaryum campestre Mart. & palm & HCF Caxambu 3231 \\
\hline Attalea barreirenses Glassman & palm & CEN Sampaio 497 \\
\hline Attalea eichleri (Drude) A.J.Hind. & palm & SPF Antar 476 \\
\hline Syagrus allagopteroides Noblick \& Lorenzi & palm & UB Sampaio 495 \\
\hline Syagrus comosa (Mart.) Mart. & palm & SPF Antar 793 \\
\hline Syagrus glazioviana (Dammer) Becc. & palm & SPF Antar 275 \\
\hline Syagrus sp. & palm & SPF Antar 266 \\
\hline \multicolumn{3}{|l|}{ Asteraceae } \\
\hline Aldama oblongifolia (Gardner) E.E.Schill. \& Panero & subshrub & SPF Antar 403 \\
\hline Aldama robusta (Gardner) E.E.Schill \& Panero & herb & CEN Simpson 56 \\
\hline Aspilia leucoglossa Malme & subshrub & SPF Antar 685 \\
\hline Brickellia diffusa (Vahl) A.Gray & subshrub & MBM Silva 6900 \\
\hline Calea ferruginea Sch.Bip ex Baker & subshrub & SPF Antar 718 \\
\hline Calea gardneriana Baker & subshrub & MBM Cordeiro 2741 \\
\hline Calea multiplinervia Less. & herb & CEN Bringel 871 \\
\hline Calea purpurea G.M.Barroso & subshrub & SPF Antar 392 \\
\hline Calea rotundifolia (Less.) Baker & shrub & MBM Silva 6709 \\
\hline Calea villosa (Gardner) Baker & shrub & SPF Antar 808 \\
\hline Chromolaena chaseae (B.L.Robinson) R.M.King \& H.Rob. & shrub & CEN Sampaio 441 \\
\hline Chromolaena oxylepis (DC.) R.M.King \& H.Rob. & shrub & MBM Cordeiro 2752 \\
\hline Chrysolaena simplex (Less.) Dematt. & herb & HUEFS Melo 7125 \\
\hline Echinocoryne subulata (Baker) H.Rob. & herb & CEN Soares-Silva 2534 \\
\hline Eremanthus glomerulatus Less. & tree & SPF Antar 780 \\
\hline Lepidaploa aurea (Mart. ex DC.) H.Rob. & subshrub & UEC Cavalcanti 2793 \\
\hline Lepidaploa nitens (Gardner) H.Rob. & subshrub & SPF Antar 479 \\
\hline Lessingianthus laevigatus (Mart. ex DC.) H.Rob. & subshrub & UB Bringel 731 \\
\hline Lessingianthus lanuginosus Dematt. & subshrub & SPF Antar 705 \\
\hline Lessingianthus aff. monocephalus (Gardner) H.Rob. & shrub & SPF Antar 415 \\
\hline Lessingianthus psilophyllus (DC.) H.Rob. & subshrub & UB Sampaio 514 \\
\hline Pectis brevipedunculata (Gardner) Sch.Bip. & herb & CEN Bringel 746 \\
\hline Praxelis clematidea (Griseb.) R.M.King \& H.Rob. & subshrub & SPF Antar 397 \\
\hline Pseudobrickellia brasiliensis (Spreng.) R.M.King \& H.Rob. & shrub & SPF Antar 451 \\
\hline Riencourtia oblongifolia Gardner & subshrub & CEN Bringel 727 \\
\hline Riencourtia tenuifolia Gardner & subshrub & SPF Antar 360, SPF Antar 424 \\
\hline Spilanthes nervosa Chodat & herb & HUEFS Melo 7130 \\
\hline Strophopappus bicolor DC. & shrub & UB Simpson 9 \\
\hline Strophopappus glomeratus (Gardner) R.L.Esteves & subshrub & UEC Cavalcanti 2820 \\
\hline Vernonanthura ferruginea (Less.) H.Rob. & tree & UB Sampaio 458 \\
\hline
\end{tabular}


Adenocalyma pedunculatum (Vell.) L.G.Lohmann

Adenocalyma pubescens (Spreng.) L.G.Lohmann

Adenocalyma sp. nov.

Anemopaegma acutifolium DC.

Anemopaegma glaucum Mart. ex DC.

Anemopaegma goyazense K.Shum.

Anemopaegma scabriusculum Mart. ex DC.

Fridericia craterophora (DC.) L.G.Lohmann

Fridericia platyphylla (Cham.) L.G.Lohmann

Fridericia simplex (A.H.Gentry) L.G.Lohmann

Handroanthus ochraceus (Cham.) Mattos

Jacaranda brasiliana (Lam.) Pers.

Jacaranda praetermissa Sandwith

Jacaranda simplicifolia K.Schum. ex Bureau \& K.Schum.

Pleonotoma orientalis Sandwith

Zeyheria montana Mart.

Bixaceae

Cochlospermum regium (Mart. ex Schrank) Pilg.

Boraginaceae

Cordia rufescens A.DC.

Cordia superba Cham.

Varronia sp. nov.

Bromeliaceae

Dyckia aff. burchellii Baker

Burseraceae

Dacryodes paraensis Cuatrec.

Cactaceae

\section{Cereus mirabella N.P.Taylor}

Discocactus catingicola Buining \& Brederoo

Calophyllaceae

Kielmeyera abdita Saddi

Kielmeyera coriacea Mart. \& Zucc.

Kielmeyera petiolaris Mart. \& Zucc.

Kielmeyera rubriflora Cambess.

Capparaceae

Mesocapparis lineata (Dombey ex Pers.) Cornejo \& Iltis

Caryocaraceae

Caryocar coriaceum Wittm.

Caryophyllaceae

Polycarpae corymbosa (L.) Lam.

Chrysobalanaceae

Couepia grandiflora (Mart. \& Zucc.) Benth.

Couepia sp.

Exellodendron cordatum (Hooker f.) Prance

Hirtella ciliata Mart. \& Zucc.

$\begin{array}{ll}\text { shrub } & \text { SPF Antar 253 } \\ \text { shrub } & \text { SPF Antar 527 } \\ \text { shrub } & \text { SPF Sano s/n } \\ \text { subshrub } & \text { ESA Souza 24190 } \\ \text { shrub } & \text { SPF Antar 466 } \\ \text { shrub } & \text { SPF Antar 366 } \\ \text { shrub } & \text { SPF Antar 462 } \\ \text { shrub } & \text { MBM Cordeiro 2797 } \\ \text { shrub } & \text { SPF Antar 521 } \\ \text { shrub } & \text { MBM Soares-Silva } 935 \\ \text { tree } & \text { SPF Paula-Souza } 9072 \\ \text { tree } & \text { MBM Silva } 6821 \\ \text { shrub } & \text { SPF Antar 277 } \\ \text { shrub } & \text { SPF Antar 786 } \\ \text { vine } & \text { HRCB Lombardi } 10324 \\ \text { shrub } & \text { HCF Caxambu } 3248\end{array}$

shrub SPF Antar 518

shrub SPF Antar 498

shrub MBM Cordeiro 4208

shrub $\quad$ SPF Antar 289

herb UB Soares-Silva 953

shrub MBM Silva 6866

shrub SPF Antar 785

herb SPF Antar 691

shrub UEC Trad 451

tree $\quad$ SPF Antar 505

tree SPF Antar 480

shrub SPF Antar 511

subshrub SPF Antar 549

tree $\quad$ SPF Antar 477

herb $\quad$ MBM Silva 6849

tree $\quad$ SPF Antar 482

shrub SPF Antar 245

tree $\quad$ MBM Soares-Silva 931

tree $\quad$ SPF Antar 237 
Licania dealbata Hook.f.

shrub

SPF Antar 223

Clusiaceae

Vismia cayennensis (Jacq.) Pers.

tree

HUEFS Melo 7091

Combretaceae

Buchenavia tetraphylla (Aubl.) R.A.Howard

Combretum mellifluum Eichler

tree

CEN Cavalcanti 2817

Terminalia fagifolia Mart.

tree $\quad$ SPF Antar 716

Connaraceae

Connarus suberosus Planch.

shrub

SPF Paula-Souza 9212

Rourea induta Planch.

shrub

HUEFS Melo 7204

SPF Antar 450

Convolvulaceae

Evolvulus sericeus $\mathrm{Sw}$.

herb

SPF Antar 711

Ipomoea campestris Meisn.

herb SPF Antar 354

Ipomoea decora Meisn.

vine $\quad$ UB Farias 418

Jacquemontia evolvuloides (Moric.) Meisn.

herb SPF Antar 400

Jacquemontia sphaerocephala Meisn.

shrub

MBM Cordeiro 2849

Merremia aturensis (Kunth) Hallier f.

herb

SPF Antar 792

Merremia digitata (Spreng.) Hallier f. var. digitata

herb

SPF Antar 267

Merremia digitata var.ericoides(Meisn.) D.F.Austin \& Staples

herb

SPF Antar 776

Merremia tomentosa (Choisy) Hallier f.

shrub

HUEFS Melo 7127

Cyperaceae

Bulbostylis conifera (Kunth) C.B.Clarke

herb

SPF Antar 344

Bulbostylis jacobinae (Steud.) Lindm.

herb

CEN Sampaio 536

Bulbostylis junciformis (Kunth) C.B.Clarke

herb

CEN Sampaio 537

Bulbostylis paradoxa (Spreng.) Lindm.

herb

SPF Antar 703

Cryptangium verticillatum (Spreng.) Vitta

herb

SPF Antar 427

Cyperus aggregatus (Willd.) Endl.

herb

SPF Antar 343

Rhynchospora albiceps Kunth

herb

HUEFS Melo 7128

Rhynchospora cephalotes (L.) Vahl

herb

SPF Borges 858

Rhynchospora consaguinea (Kunth) Boeckeler

herb

MBM Cordeiro 2805

Rhynchospora exaltata Kunth

herb

HRCB Lombardi 10250

Rhynchospora aff. globosa (Kunth) Roem. \& Schult.

herb

UB Alves 622

Rhynchospora terminalis Nees ex Steud.

SPF Antar 425

Scleria sp.

herb

HUEFS Melo 7205

Dilleniaceae

Curatella americana L.

Davilla elliptica A.St.-Hil.

Davilla grandiflora A.St.-Hil.

Davilla nitida (Vahl) Kubitzki

Davilla villosa Eichler

Dioscoreaceae

Dioscorea sp. nov.

herb

tree

HUEFS Melo 7120

shrub

shrub

vine

shrub

HUEFS Melo 7119

Ebenaceae

Diospyros hispida A.DC.

tree

SPF Antar 516

Diospyros ovalis Hiern shrub
SPF Antar 374
SPF Paula-Souza 9095

SPF Antar 296 
Eriocaulaceae

Actinocephalus bongardii (A.St.-Hil.) Sano

Paepalanthus chiquitensis Herzog.

Paepalanthus elongatus (Bong.) Koern.

Paepalanthus microcaulon Ruhland

Syngonanthus davidsei Huft

Syngonanthus heteropep/us Ruhland

Syngonanthus humboldtii (Kunth) Ruhland

herb

herb

herb

herb

herb

herb

herb

Erythroxylaceae

Erythroxylum betulaceum Mart.

Erythroxylum campestre A.St.-Hil.

Erythroxylum suberosum A.St.-Hil.

Erythroxylum tortuosum Mart.

Euphorbiaceae

Cnidoscolus graminifolius Fern.Casas

Croton agoensis Baill.

Croton didrichsenii G.L.Webster

Croton glandulosus $\mathrm{L}$.

Croton grandivelus Baill.

Croton pedicelatus Kunth

Dalechampia linearis Baill.

Euphorbia goyazensis Boiss.

Euphorbia potentilloides Boiss.

Euphorbia sarcodes Boiss.

Euphorbia sp.

Manihot caerulescens Pohl

Manihot cf. salicifolia Pohl

Manihot cf. sparsifolia Pohl

Microstachys bidentata (Mart. \& Zucc.) Esser

Microstachys corniculata (Vahl) Griseb.

Gentianaceae

Curtia tenuifolia (Aubl.) Knobl.

Deianira chiquitana Herzog

Deianira cyathifolia Barb.Rodr.

Schultesia benthamiana Klotzsch ex Griseb.

Haemodoraceae

Schiekia orinocensis (Kunth) Meisner subsp. Orinocensis

Humiriaceae

Humiria ba/samifera var. floribunda (Mart.) Cuatrec.

Icacinaceae

Emmotum nitens (Benth.) Miers

Iridaceae

Alophia medusa (Baker) Goldblatt

Cipura formosa Ravenna

Cipura paradisiaca Ravenna

herb

SPF Conceição 555

SPF Antar 234

MBM Cordeiro 2778

SPF Borges 872

HRCB Lombardi 10317

SPF Echternacht 2111

MBM Cordeiro 4205

$\begin{array}{ll}\text { shrub } & \text { SPF Antar } 263 \\ \text { shrub } & \text { SPF Antar } 358 \\ \text { shrub } & \text { HUEFS Melo } 7134 \\ \text { tree } & \text { HUEFS Melo } 7096\end{array}$

UB Bringel 886

herb SPF Antar 271

subshrub IBGE Fagg 1976

subshrub SPF Antar 361

subshrub SPF Antar 287

subshrub MBM Silva 6822

subshrub SPF Antar 252

herb SPF Antar 734

herb HUEFS Melo 7154

herb SPF Antar 382

subshrub SPF Antar 686

shrub HUEFS Melo 7207

herb SPF Antar 264

shrub HUEFS Melo 7126

shrub SPF Antar 512

subshrub SPF Antar 379

$\begin{array}{ll}\text { herb } & \text { HRCB Lombardi } 10315 \\ \text { herb } & \text { UB Sampaio } 445 \\ \text { herb } & \text { SPF Antar } 707 \\ \text { herb } & \text { HRCB Lombardi } 10330\end{array}$

herb $\quad$ MBM Silva 6801

shrub HUEFS Melo 7201

shrub $\quad$ ESA Rizzo 9571

47 


\begin{tabular}{|c|c|c|}
\hline Cipura xanthomelas Klatt. & herb & UB Sampaio 513 \\
\hline Trimezia cathartica (Klatt) Niederl. & herb & SPF Antar 367 \\
\hline Trimezia juncifolia (Klatt) Benth. \& Hook. & herb & SPF Antar 709 \\
\hline \multicolumn{3}{|l|}{ Krameriaceae } \\
\hline Krameria argentea Mart. ex Spr. & shrub & SPF Antar 769 \\
\hline Krameria tomentosa A.St.-Hil. & shrub & SPF Antar 542 \\
\hline \multicolumn{3}{|l|}{ Lamiaceae } \\
\hline Amasonia campestris (Aubl.) Moldenke & shrub & SPF Antar 712 \\
\hline Amasonia hirta Benth. & subshrub & SPF Antar 356 \\
\hline Cyanocephalus selaginifolius (Mart. ex Benth.) Harley \& J.F.B.Pastore & shrub & SPF Paula-Souza 9041 \\
\hline Eriope arenaria Harley & subshrub & SPF Paula-Souza 9128 \\
\hline Eriope crassipes Benth. & subshrub & SPF Paula-Souza 9082 \\
\hline Eriope sp. nov. & shrub & HUEFS Melo 7227 \\
\hline Hypenia irregularis (Benth.) Harley & shrub & SPF Antar 222 \\
\hline Hyptidendron asperrimum (Spreng.) Harley & shrub & SPF Antar 459 \\
\hline Hyptis brevipes Poit. & herb & HCF Caxambu 3174 \\
\hline Hyptis caduca Epling & herb & MBM Silva 6817 \\
\hline Hyptis campestris Harley \& J.F.Pastore & subshrub & CEN Cavalcanti 2791 \\
\hline Hyptis crenata Pohl ex Benth. & subshrub & SPF Borges 885 \\
\hline Hyptis deminuta (Epling) Epling & subshrub & MBM Silva 6858 \\
\hline Hyptis obtecta Benth. & shrub & SPF Antar 529 \\
\hline Hyptis selaginifolia Mart. & shrub & SPF Trovó 300 \\
\hline Hyptis turnerifolia Mart. ex Benth. & subshrub & HRCB Lombardi 10268 \\
\hline Medusantha multiflora (Pohl ex Benth.) Harley \& J.F.B.Pastore & shrub & HRCB Lombardi 10234 \\
\hline Marsypianthes foliolosa Benth. & subshrub & SPF Antar 762 \\
\hline Vitex cymosa Bertero ex Spreng. & tree & UB Ratter $8101 \mathrm{~V}$ \\
\hline Vitex rufescens A.Juss. & shrub & SPF Antar 449 \\
\hline Vitex panshiniana Moldenke & tree & UB Bridgewater S1080 \\
\hline \multicolumn{3}{|l|}{ Lauraceae } \\
\hline Cassytha filiformis L. & herb & HUEFS Farias 174 \\
\hline Ocotea xanthocalyx (Nees) Mez & shrub & SPF Antar 474 \\
\hline \multicolumn{3}{|l|}{ Lecythidaceae } \\
\hline Eschweilera nana (O.Berg) Miers & tree & SPF Antar 535 \\
\hline \multicolumn{3}{|l|}{ Fabaceae } \\
\hline Aeschynomene histrix Poir. & subshrub & UB Sampaio 483 \\
\hline Aeschynomene paniculata Willd. Ex Vogel & subshrub & SPF Antar 351 \\
\hline Aeschynomene paucifolia Vogel & subshrub & SPF Antar 706 \\
\hline Ancistrotropis firmula (Mart. ex Benth.) A.Delgado & subshrub & UB Simpson 42 \\
\hline Andira cordata Arroyo ex R.T.Penn. \& H.C.Lima & tree & SPF Antar 391 \\
\hline Andira humilis Mart. ex Benth. & subshrub & MBM Barbosa 3213 \\
\hline Andira vermifuga (Mart.) Benth. & tree & SPF Paula-Souza 9135 \\
\hline Arachis marginata Gardner & herb & CEN Bringel 881 \\
\hline Bauhinia cupulata Benth. & shrub & SPF Antar 240 \\
\hline Bauhinia cf. dubia G.Don & shrub & ESA Souza 24176 \\
\hline Bauhinia gardneri Benth. & shrub & HUEFS Melo 7187 \\
\hline
\end{tabular}


Bauhinia platyphylla Benth.

Bauhinia tenella Benth.

Bauhinia ungulata L.

Bauhinia sp. nov.1

Bauhinia sp. nov.2

Bowdichia virgilioides Kunth.

Calliandra dysantha Benth.

Cenostigma macrophyllum Tul.

Centrosema bifidum Benth.

Centrosema venosum Mart. ex Benth.

Chamaecrista claussenii var. megacycla (H.S.Irwin \& Barneby)

H.S.Irwin \& Barneby

Chamaecrista crenulata (Benth.) H.S.Irwin \& Barneby

Chamaecrista desvauxii var. mollissima (Benth.) H.S.Irwin \& Barneby

Chamaecrista desvauxii var. brevipes(Benth.) H.S.Irwin \& Barneby

Chamaecrista desvauxii var.desvauxii(Collad.) Killip

Chamaecrista aff. filicifolia (Benth.) H.S.Irwin \& Barneby

Chamaecrista flexuosa (L.) Greene var. flexuosa

Chamaecrista huntii (H.S.Irwin \& Barneby) H.S.Irwin \& Barneby Chamaecrista ochrosperma (H.S.Irwin \& Barneby) H.S.Irwin \& Barneby

Chamaecrista ramosa var. mollissima (Vogel) H.S.Irwin \& Barneby

Chamaecrista setosa (Vogel) H.S.Irwin \& Barneby

Chamaecrista sincorana (Harms) H.S.Irwin \& Barneby

Chamaecrista viscosa (Kunth) H.S.Irwin \& Barneby

Chamaecrista zygophylloides (Taub.) H.S.Irwin \& Barneby

Clitoria aff. guianensis (Aubl.) Benth.

Copaifera luetzelburgii Harms

Copaifera marginata Benth.

Copaifera martii var. rigida (Benth.) Ducke

Crotalaria maypurensis Kunth

Dalbergia miscolobium Benth.

Desmodium barbatum (L.) Benth.

Dimorphandra gardneriana Tul.

Dioclea coriacea Benth.

Enterolobium gummiferum (Mart.) J.F.Macbr.

Eriosema congestum Benth.

Eriosema crinitum var. stipulare (Benth.) Fortunato

Eriosema cf. floribundum Benth.

Eriosema venulosum Benth.

Galactia jussiaeana Kunth

Galactia glaucescens Kunth

Galactia grewiifolia (Benth.) Taub.

Galactia neesii DC.

Hymenaea eriogyne Benth.

Hymenae stigonocarpa Mart. ex Hayne

\begin{tabular}{|c|c|}
\hline shrub & SPF Antar 393 \\
\hline shrub & HRCB Lombardi 10244 \\
\hline shrub & ESA Souza 24175 \\
\hline shrub & SPF Antar 540 \\
\hline shrub & HRCB Lombardi 10245 \\
\hline tree & SPF Antar 491 \\
\hline shrub & SPF Antar 499 \\
\hline shrub & SPF Antar 270 \\
\hline vine & MBM Silva 6828 \\
\hline herb & SPF Antar 359A \\
\hline shrub & MBM Barbosa 3194 \\
\hline subshrub & ESA Souza 24195 \\
\hline subshrub & SPF Antar 741 \\
\hline subshrub & SPF Antar 413 \\
\hline subshrub & SPF Antar 408 \\
\hline shrub & SPF Borges 851 \\
\hline shrub & MBM Cordeiro 4263 \\
\hline shrub & MBM Cordeiro 2923 \\
\hline shrub & $\begin{array}{l}\text { SPF Antar } 216 \\
\text { SPF Antar } 230\end{array}$ \\
\hline shrub & \\
\hline shrub & SPF Borges 850 \\
\hline shrub & MBM Cordeiro 2839 \\
\hline shrub & HRCB Lombardi 10335 \\
\hline shrub & MBM Cordeiro 2838 \\
\hline subshrub & SPF Antar 404 \\
\hline shrub & SPF Antar 819 \\
\hline shrub & SPF Antar 501 \\
\hline shrub & HUEFS Melo 7185 \\
\hline subshrub & SPF Antar 388 \\
\hline tree & HRCB Lombardi 10239 \\
\hline subshrub & CEN Cavalcanti 2794 \\
\hline tree & SPF Antar 384 \\
\hline shrub & SPF Antar 239 \\
\hline tree & SPF Antar 455 \\
\hline shrub & ESA Souza 24185 \\
\hline subshrub & UB Soares-Silva 891 \\
\hline subshrub & MBM Barbosa 3243 \\
\hline subshrub & SPF Antar 481 \\
\hline herb & HRCB Lombardi 10329 \\
\hline subshrub & MBM Cordeiro 2743 \\
\hline shrub & SPF Antar 349 \\
\hline subshrub & MBM Silva 6711 \\
\hline shrub & HUEFS Melo 7189 \\
\hline ee & SPF Antar 713 \\
\hline
\end{tabular}


Leptolobium dasycarpum Vogel

Machaerium opacum Vogel

Mimosa flabellifolia Barneby

Mimosa foliolosa var. pubescens Benth.

Mimosa aff. gardneri Benth.

Mimosa hypoglauca var. allostegia Barneby

Mimosa piptoptera Barneby

Mimosa polycephala var. polycephala Bentham

Mimosa sericantha Benth.

Mimosa somnians var. lasiocarpa (Benth.) Barneby

Mimosa somnians var. longipes (Barneby) Barneby

Mimosa somnians var. viscida(Willd.) Barneby

Mimosa spixiana Barneby

Mimosa ursina Mart.

Mimosa sp.

Parkia platycephala Benth.

Peltogyne confertiflora (Mart. ex Hayne) Benth.

Platymenia reticulata Benth.

Pterodon emarginatus Vogl.

Senna alata (L.) Roxb.

Senna biglandularis A.O.Araujo \& V.C.Souza

Senna obtusifolia (L.) H.S.Irwin \& Barneby

Senna occidentalis (L.) Link

Senna rugosa (G.Don) H.S.Irwin \& Barneby

Senna silvestris (Vell.) H.S.Irwin \& Barneby

Senna velutina (Vogel) H.S.Irwin \& Barneby

Stryphnodendron adstringens (Mart.) Cov.

Stryphnodendron coriaceum Benth.

Stylosanthes gracilis Kunth

Stylosanthes guianensis (Aubl.) Sw

Tachigali aurea Tul.

Tachigali paniculata Aubl.

Tachigali subvelutina (Benth.) Oliveira-Filho

Zornia latifolia Sm.

Loganiaceae

Antonia ovata Pohl

Strychnos parvifolia A.DC.

Loranthaceae

Passovia ovata (Pohl ex DC.) Tiegh.

Psittacanthus dichroos (Mart.) Mart.

Struthanthus polyanthus (Mart.) Mart.

Lythraceae

Cuphea antisyphilitica H.B.K.

Cuphea micrantha Kunth

Cuphea sessilifolia Mart. subshrub SPF Antar 701

shrub MBM Silva 6731

shrub

MBM Silva 6829

shrub

subshrub

MBM Silva 6840

SPF Antar 300

shrub

SPF Antar 238

shrub

SPF Antar 220

shrub

subshrub

SPF Antar 739

shrub

MBM Cordeiro 2729

SPF Antar 430

shrub

subshrub

SPF Borges 868

shrub

SPF Antar 798

tree

MBM Cordeiro 2726

SPF Antar 550

shrub

SPF Paula-Souza 9237

tree

SPF Antar 517

tree

SPF Antar 492

tree

shrub

CEN Milhomens 171

subshrub

SPF Antar 812

subshrub

SPF Antar 799

shrub

SPF Antar 800

shrub

SPF Antar 433

shrub

ESA Souza 24179

shrub

ESA Souza 24180

tree

MBM Sampaio 467

tree

MBM Sampaio 430

subshrub

SPF Antar 807

subshrub

SPF Antar 292

tree

MBM Sampaio 468

tree

HUEFS Melo 7136

tree

SPF Antar 452

subshrub

SPF Antar 772
RB Cordeiro 2753

shrub $\quad$ SPF Borges 861

shrub ESA Souza 24188

herb HUEFS Melo 7090

herb SPF Antar 370

herb HRCB Lombardi 10267 
Cuphea tenuissima Koehne

Diplusodon gracilis Koehne

Diplusodon speciosus (Kunth) DC.

Diplusodon strigosus Pohl

Diplusodon trigintus T.B.Cavalc.

Lafoensia pacari A.St.Hil.

Physocalymma scaberrimum Pohl

Malpighiaceae

Banisteriopsis stellaris (Griseb.) B.Gates

Byrsonima chrysophylla Kunth.

Byrsonima coccolobifolia Kunth

Byrsonima correifolia A.Juss.

Byrsonima crassifolia (L.) Kunth

Byrsonima cydoniifolia A.Juss.

Byrsonima oblongifolia A.Juss.

Byrsonima pachyphylla A.Juss.

Byrsonima subterranea Brade \& Markgr.

Byrsonima umbellata Adr. Juss.

Byrsonima verbascifolia (L.) DC.

Byrsonima cf. variabilis A.Juss.

Byrsonima sp.

Heteropterys coriacea A.Juss.

Peixotoa goiana C.E.Anderson

Stigmaphyllon paralias A.Juss.

Malvaceae

Ayenia angustifolia A.St.-Hil. \& Nardin

Ayenia latifolia Cristóbal

Byttneria melastomaefolia A.St.-Hil.

Eriotheca gracilipes (K.Schum.) A.Robyns

Helicteres krapovickasii Cristóbal

Pavonia rosa-campestris A.St.-Hil.

Peltaea speciosa (Kunth) Staudley

Sida angustissima A.St.-Hil.

Waltheria brachypetala Turcz

Waltheria indica L.

Marcgraviaceae

Schwartzia adamantium (Cambess.) Bedell ex Gir.-Canãs

Marantaceae

Maranta longiflora S.Vieira \& V.C.Souza

Melastomataceae

Acisanthera uniflora (Vahl) Gleason

Cambessedesia hilariana DC.

Macairea radula(Bonpl.) DC.

Miconia albicans (Sw.) Triana

Miconia stenostachya DC.
subshrub
SPF Antar 708
subshrub
HCF Caxambu 3216
subshrub
SPF Antar 700
subshrub
UFG Rizzo 9744
subshrub
MBM Cordeiro 2738
tree
ESA Souza 24178
tree
ESA Souza 24184

vine

UB Soares-Silva 960

tree

HCF Caxambu 3175

shrub

HUEFS Melo 7092

shrub

SPF Antar 402

shrub

SPF Paula-Souza 9077

shrub

subshrub

HUTO Santos 1117

tree

SPF Antar 269

shrub

HUEFS Melo 7095

HUEFS Melo 7235

shrub

MBM Silva 6861

shrub

shrub

HCF Caxambu 3198

SPF Antar 448

shrub

SPF Antar 231

shrub

UB Haidar 227

shrub

SPF Antar 470

shrub

HUEFS Farias 163

$\begin{array}{ll}\text { subshrub } & \text { UB Sampaio 450 } \\ \text { subshrub } & \text { SPF Antar 405 } \\ \text { shrub } & \text { MBM Silva 6832 } \\ \text { tree } & \text { HUEFS Melo 7157 } \\ \text { shrub } & \text { SPF Antar 381 } \\ \text { subshrub } & \text { HUEFS Cavalcanti 2840 } \\ \text { shrub } & \text { HUEFS Melo 7124 } \\ \text { subshrub } & \text { SPF Antar 396 } \\ \text { shrub } & \text { SPF Antar 399 } \\ \text { subshrub } & \text { SPF Antar 294 }\end{array}$

SPF Antar 525

shrub

HUEFS Melo 7177

herb

MBM Silva 6850

subshrub

HRCB Lombardi 10264

subshrub

SPF Antar 236

shrub

SPF Antar 494

shrub

UB Farias 357 
Microlicia acuminata Naudin

Microlicia depauperata Naudin

Microlicia insignis Schltdl.

Microlicia polystemma Naudin

Mouriri elliptica Mart.

Mouriri pusa Gardner

Pterolepis buraeavii Cogn.

Pterolepis polygonoides (DC.) Triana

Menispermaceae

Cissampelos ovalifolia DC.

Moraceae

Brosimum gaudichaudii Trécul

Myristicaceae

Virola sebifera Aubl.

Virola subsessilis (Benth.) Warb.

Myrtaceae

Eugenia angustissima O.Berg

Eugenia blanchetiana O.Berg

Eugenia dysenterica (Mart.) DC.

Eugenia gemmiflora O.Berg

Eugenia hilariana DC.

Eugenia luetzelburgii Burret

Eugenia punicifolia (Kunth) DC.

Eugenia stictopetala Mart. ex DC.

Eugenia aff. vetula DC.

Eugenia sp. nov.

Myrcia bella Cambess.

Myrcia guianensis (Aubl.) DC.

Myrcia laricina (O.Berg) Burret ex Luetzelb.

Myrcia mansoniana O.Berg

Myrcia ochroides O.Berg

Myrcia aff. rufipes DC.

Myrcia splendens (Sw.) DC.

Myrcia uberavensis O.Berg

Myrciaria cuspidata O.Berg

Myrciaria delicatula (DC.) O.Berg

Nyctaginaceae

Guapira campestris (Netto) Lundell

Guapira graciliflora (Mart. ex Schmidt) Lundell

Neea theifera Oerst.

Ochnaceae

Ouratea acicularis R.G.Chacon \& K.Yamam.

Ouratea aff. confertiflora (Pohl) Engl.

Ouratea crassifolia (Pohl) Engl.

Ouratea floribunda De Wild.

$\begin{array}{ll}\text { shrub } & \text { HCF Caxambu } 3197 \\ \text { herb } & \text { HCF Caxambu } 3194 \\ \text { shrub } & \text { SPF Borges } 871 \\ \text { shrub } & \text { UB Sampaio } 524 \\ \text { tree } & \text { SPF Antar 504 } \\ \text { tree } & \text { SPF Antar 506 } \\ \text { subshrub } & \text { MBM Cordeiro } 2777 \\ \text { herb } & \text { HCF Caxambu } 3170\end{array}$

Herb $\quad$ MBM Silva 6739

shrub $\quad$ SPF Antar 514

tree UFG Rizzo 9577

shrub SPF Antar 224

$\begin{array}{ll}\text { shrub } & \text { SPF Antar } 273 \\ \text { shrub } & \text { SPF Antar } 683 \\ \text { tree } & \text { SPF Antar } 519 \\ \text { subshrub } & \text { SPF Antar } 286 \\ \text { shrub } & \text { CEN Faria } 2137 \\ \text { shrub } & \text { SPF Antar 262 } \\ \text { herb } & \text { RB Silva } 6708 \\ \text { shrub } & \text { SPF Antar 421 } \\ \text { shrub } & \text { SPF Antar 431 } \\ \text { shrub } & \text { UB Haidar 225 } \\ \text { shrub } & \text { SPF Antar 456 } \\ \text { shrub } & \text { SPF Antar 544 } \\ \text { tree } & \text { HRCB Lombardi } 10240 \\ \text { tree } & \text { HUEFS Melo } 7098 \\ \text { shrub } & \text { HUEFS Melo 7182 } \\ \text { tree } & \text { SPF Antar 500 } \\ \text { tree } & \text { SPF Antar 502 } \\ \text { shrub } & \text { SPF Antar 242 } \\ \text { shrub } & \text { CEN Cavalcanti } 2751 \\ \text { shrub } & \text { UB Soares-Silva 968 }\end{array}$

$\begin{array}{ll}\text { shrub } & \text { SPF Antar } 547 \\ \text { shrub } & \text { SPF Antar } 545 \\ \text { tree } & \text { UB Haidar } 243 \\ \text { shrub } & \text { SPF Antar } 261 \\ \text { shrub } & \text { HEPH Faria } 2138 \\ \text { shrub } & \text { CEN Cavalcanti } 2834 \\ \text { shrub } & \text { HUEFS Farias } 166\end{array}$




\begin{tabular}{|c|c|c|}
\hline Ouratea hexasperma (A.St.-Hil.) Baill. & shrub & SPF Antar 446 \\
\hline Ouratea macrantha (Erhard) Tiegh. & shrub & SPF Antar 221 \\
\hline Ouratea nervosa (A.St.-Hil.) Engl. & subshrub & UB Simon 411 \\
\hline Ouratea parvifolia (A.St.-Hil.) Engl. & shrub & CEN Rezende 987 \\
\hline Sauvagesia linearifolia A.St.-Hil. & herb & MBM Barbosa 3248 \\
\hline \multicolumn{3}{|l|}{ Olacaceae } \\
\hline Heisteria ovata Benth. & shrub & SPF Antar 228 \\
\hline \multicolumn{3}{|l|}{ Orchidaceae } \\
\hline Cyrtopodium eugenii Rchb.f & herb & CEN Rezende 988 \\
\hline Galeandra montana Barb.Rodr. & herb & SPF Antar 746 \\
\hline \multicolumn{3}{|l|}{ Orobanchaceae } \\
\hline Buchnera palustris (Aubl.) Spreng. & subshrub & UB Sampaio 527 \\
\hline Buchnera rosea Kunth. & subshrub & SPF Antar 487 \\
\hline Esterhazya macrodonta (Cham.) Benth. & shrub & MBM Sampaio 523 \\
\hline Esterhazya splendida J.C.Mikan & shrub & HRCB Lombardi 10248 \\
\hline \multicolumn{3}{|l|}{ Oxalidaceae } \\
\hline Oxalis gardneriana Progel & herb & SPF Antar 489 \\
\hline \multicolumn{3}{|l|}{ Passifloraceae } \\
\hline Passiflora mansoi (Mart.) Mast. & shrub & SPF Antar 688 \\
\hline \multicolumn{3}{|l|}{ Phyllanthaceae } \\
\hline Phyllanthus amarus Schumach. & herb & SPF Antar 817 \\
\hline \multicolumn{3}{|l|}{ Plantaginaceae } \\
\hline Scoparia dulcis L. & herb & CEN Sampaio 525 \\
\hline \multicolumn{3}{|l|}{ Poaceae } \\
\hline Andropogon bicornis L. & herb & UB Sampaio 463 \\
\hline Anthaenantia lanata (Kunth) Benth. & herb & CEN Rua 685 \\
\hline Aristida adscensionis $\mathrm{L}$. & herb & SPF Antar 797 \\
\hline Aristida capillacea Lam. & herb & HRCB Lombardi 10262 \\
\hline Aristida pendula Longhi-Wagner & herb & MBM Silva 6730 \\
\hline Aristida riparia Trin. & herb & UB Simpson 53 \\
\hline Aristida setifolia Kunth & herb & HRCB Lombardi 10271 \\
\hline Arthropogon villosus Nees & herb & HUEFS Melo 7206 \\
\hline Axonopus aureus P.Beauv. & herb & UB Sampaio 538 \\
\hline Axonopus brasiliensis (Spreng.) Kuhlm. & herb & CEN Rezende 959 \\
\hline Axonopus marginatus (Trin.) Chase & herb & CEN Rua 687 \\
\hline Axonopus singularis (Swallen) Alicia López \& Morrone & herb & CEN Rua 781 \\
\hline Axonopus suffultus (Mikan ex Trin.) Parodi & herb & HRCB Lombardi 10339 \\
\hline Cenchrus polystachios (L.) Morrone & herb & MBM Silva 6706 \\
\hline Digitaria gardneri Henrard & herb & CEN Rua 806 \\
\hline Eragrostis rufescens Schrad. ex Schult. & herb & HRCB Lombardi 10263 \\
\hline Gymnopogon foliosus (Willd.) Nees & herb & UB Soares-Silva 911 \\
\hline Ichnanthus calvescens (Nees ex Trin.) Doll & herb & UB Simpson 61 \\
\hline Ichnanthus hoffmannseggii (Roem. \& Schult.) Doll & herb & CEN Rua 801 \\
\hline Lasiacis sorghoidea (Desvs.) Hitchc. \& Chase & herb & MBM Silva 6904 \\
\hline Loudetia flammida (Trin.) C.E. Hubb. & herb & HUEFS Sampaio 462 \\
\hline
\end{tabular}


Loudetiopsis chrysothrix (Nees) Conert

Mesosetum loliiforme (Hochst.) Chase

Ocellochloa gardneri (Mez) Filg. \& R.S.Rodr.

Panicum sp.

Paspalum ammodes Trin.

Paspalum carinatum Humb. \& Bonpl. ex Fluggé

Paspalum gardnerianum Nees

Paspalum cf. hyalinum Nees ex Trin.

Paspalum lanciflorum Nees ex Steud.

Paspalum loefgrenii Ekman

Paspalum marmoratum Kuhlm.

Paspalum multicaule Poir.

Paspalum spissum Swallen

Paspalum subsequiglume Doell

Paspalum thrasyoides (Trin.) S.Denham

Streptostachys asperifolia Desv.

Trachypogon spicatus (L.f.) Kuntze

Polygalaceae

Asemia violacea (Aubl.) J.F.B.Pastore \& J.R.Abbott

Polygala adenophora DC.

Polygala cf. celosioides Mart. ex A.W.Benn.

Polygala celosioides Mart. ex A.W.Benn.

Polygala equisetoides A.St.-Hil. \& Moq.

Polygala longicaulis Kunth

Polygala poaya Mart.

Polygala pseudosericea Chodat

Polygala rigida A.St.-Hil. \& Moq.

Polygala subtilis Kunth

Polygala trichosperma Jacq.

Polygala sp. nov.

Portulacaceae

Portulaca mucronata Link

Proteaceae

Roupala montana Aubl.

Rhabdodendraceae

Rhabdodendron gardnerianum (Benth.) Sandwith

Rhamnaceae

Gouania sp. nov.

Rubiaceae

Alibertia sp.

Borreria capitata (Ruiz \& Pav.) DC.

Borreria crispata (K.Schum.) E.L.Cabral \& Bacigalupo

Borreria irwiniana E.L.Cabral

Borreria latifolia (Aubl.) K.Schum.

Borreria tenera DC. herb

herb

SPF Antar 365

SPF Antar 418

herb

SPF Antar 789

herb

CEN Rua 784

herb

CEN Rua 673

herb

SPF Antar 730

herb

CEN Rua 783

herb

CEN Rua 703

herb

herb

CEN Cavalcanti 2939

herb

CEN Rua 770

herb

CEN Rua 809

CEN Rua 706

herb

CEN Rua 779

herb

CEN Rua 811

herb

CEN Rua 675

herb

CEN Rua 810

herb

SPF Antar 353

subshrub

SPF Antar 803

herb

MBM Cordeiro 4276

herb

MBM Cordeiro 2828

herb

MBM Silva 6906

herb

SPF Antar 373

herb

SPF Antar 385

herb

MBM Barbosa 3206

herb

SPF Paula-Souza 9036

herb

UB Bringel 729

herb

MBM Barbosa 3244

herb

CEN Cavalcanti 2890

subshrub

SPF Antar 346

erb

SPF Antar 761

herb

HTO Alves 1045

tree

HRCB Lombardi 10230

shrub

MBM Silva 6826

vine

SPF Antar 548

tree

MBM Cordeiro 2796

subshrub

SPF Antar 350

subshrub

SPF Antar 750

herb

UB Farias 383

shrub

UB Farias 405 
Borreria warmingii K.Schum.

Borreria wunschmanni K.Schum

Chomelia parviflora (Mull.Arg.) Mull.Arg.

Cordiera rigida (K.Schum.) Kuntze

Coutarea hexandra (Jacq.) K.Schum.

Declieuxia fruticosa (Wild. ex Roem. \& Schult.) Kuntze

Diodella apiculata (Wild. ex Roem. \& Schult.) Delprete

Ferdinandusa elliptica Pohl

Mitracarpus parvulus K.Schum.

Mitracarpus steyermarkii E.L.Cabral \& Bacigalupo

Palicourea rigida Kunth

Sabicea brasiliensis Wernham

Spermacoce reflexa (J.H.Kirkbr.) Govaerts

Staelia paganuccii R.M.Salas \& E.L.Cabral

Tocoyena arenicola Delprete

Tocoyena formosa (Cham. \& Schltdl.) K.Schum.

Rutaceae

Esenbeckia aff. oligantha Kaastra

Esenbeckia pumila Pohl

Spiranthera odoratissima A.St.-Hil.

Salicaceae

Casearia sylvestris Sw.

Santalaceae

Dendrophthora warmingii (Eichler) Kuijt

Phoradendron crassifolium (Pohl ex DC.) Eichler

Phoradendron strongyloclados Eichler

Sapindaceae

Toulicia crassifolia Radlk.

Serjania lethalis A.St.-Hil.

Serjania sp.

Sapotaceae

Pouteria cf. glomerata (Miq.) Radlk.

Pouteria torta (Mart.) Radlk.

Pouteria ramiflora (Mart.) Radlk.

Pouteria subcaerulea Pierre ex. Dubard

Pouteria sp.

Simaroubaceae

Simaba pohliana Boas

Simaba suffruticosa Engl.

Simaba sp.

Simaba sp. nov.

Simarouba amara Aubl.

Smilacaceae

Smilax cf. fluminensis Steud.

Smilax oblongifolia Pohl ex Griseb. herb

UB Rizzo 9659

subshrub

UB Sampaio 515

tree

RB Delprete 10328

shrub

SPF Antar 302

shrub

SPF Antar 787

shrub

SPF Antar 386

subshrub

SPF Antar 398

shrub

ESA 24194

herb

UFG Rizzo 9654

herb

UB Soares-Silva 920

shrub

HUEFS Melo 7175

shrub

UB Rizzo 9590

herb

UB Farias 21a

subshrub

SPF Antar 401

herb

HUEFS Melo 7183

tree

HTO Curcino 18

subshrub

SPF Antar 301

shrub

SPF Antar 278

shrub

HRCB Lombardi 10247

tree

SPF Antar 520

shrub

UB Caires 442

shrub

UB Caires 443

shrub

BHCB Caires 440

shrub

SPF Antar 526

vine $\quad$ SPF Antar 458

vine

HCF Caxambu

shrub

SPF Antar 306

tree

SPF Antar 509

tree

SPF Antar 414

shrub SPF Antar 284

shrub

HCF Caxambu 3221

(n)

$\begin{array}{ll}\text { shrub } & \text { SPF Devecchi } 282 \\ \text { subshrub } & \text { SPF Paula-Souza } 9080 \\ \text { subshrub } & \text { SPF Antar } 309 \\ \text { subshrub } & \text { SPF Antar 528 }\end{array}$

tree

SPF Devecchi 288

vine $\quad$ SPF Antar 714

subshrub SPF Antar 478 
Smilax polyantha Griseb.

vine

SPF Paula-Souza 9231

Solanaceae

Schwenckia americana Rooyen ex L.

herb UB Soares-Silva 913

Solanum lycocarpum A.St.-Hil.

shrub $\quad$ SPF Antar 369

Solanum subinerme Jacq.

shrub UB Farias 144

Solanum stipulaceum Willd. ex Roem. \& Schult.

shrub $\quad$ SPF Antar 779

Styracaceae

Styrax camporum Pohl

shrub

MBM Barbosa 3188

Turneraceae

Piriqueta breviseminata Arbo

Piriqueta densiflora var. goiasensis Arbo

Piriqueta sidifolia (Cambess.) Urb.

Piriqueta sp. nov.

Turnera aff. coerulea DC.

Turnera melochioides Cambess.

Turnera aff. pinifolia Cambess.

Turnera sp. nov.

(a)

HUEFS Silva 6878

$\begin{array}{ll}\text { subshrub } & \text { HUEFS Silva } 6878 \\ \text { herb } & \text { HUEFS Melo } 7148\end{array}$

subshrub SPF Antar 285

subshrub SPF Antar 724

subshrub SPF Antar 390

herb UB Bringel 732

subshrub HRCB Lombardi 10350

subshrub MBM Cordeiro 2762

Velloziaceae

Vellozia goiasensis L.B.Sm.

herb SPF Antar 288

Vellozia seubertiana Goethart \& Henrard

herb HRCB Lombardi 10229

Vellozia squamata Pohl

herb SPF Antar 268

Verbenaceae

Casselia confertiflora (Moldenke) Moldenke

Lippia acutidens Mart.

subshrub SPF Antar 290

Lippia origanoides Kunth

subshrub SPF Antar 305

Lippia sp. nov.

subshrub CEN Cavalcanti 2895

Stachytarpheta integrifolia (Pohl) Walp.

shrub MBM Silva 6897

Stachytarpheta longispicata subsp. ratteri S.Atkins

shrub HRCB Lombardi 10241

Vitaceae

Cissus erosa Rich.

shrub SPF Antar 721

Vochysiaceae

Qualea grandiflora Mart.

SPF Antar 760

Qualea parviflora Mart.

tree SPF Antar 484

Salvertia convallariodora A.St.-Hil.

tree $\quad$ SPF Antar 461

Vochysia gardneri Warm.

tree HUEFS Melo 7172

Vochysia palmirana F.França \& Proença

shrub SPF Antar 229

Vochysia pruinosa Pohl

tree HUEFS Melo 7137

Vochysia rufa Mart.

tree

CEN Farias 354

Xyridaceae

Xyris sp.

herb

HRCB Lombardi 10318 


\section{Discussion}

The most species-rich families and genera recorded are overall highly representative and diverse in the Cerrado Domain (Eiten 1972; Ratter et al. 1997; Gottsberger and SilberbauerGottsberger 2006). Although Fabaceae is one of the most diverse families in Cerrado, the number of sampled species was much higher than for other families, this being unexpected in relation to other surveys (Mantovani and Martins 1993; Batalha et al. 1997; Batalha and Mantovani 2001; Carvalho et al. 2010; Amaral et al. 2013). Medeiros et al. (2012), sampling all Cerrado physiognomies in southern Tocantins and northern Goiás, found a similar proportion, suggesting this is not a collecting artifact, because Fabaceae species are normally very conspicuous and reproductive during long periods, favoring herbaria sampling. Chamaecrista, Bauhinia, and Mimosa are big genera, more diverse in the Cerrado (Irwin and Barneby 1982; Barneby 1991), which also contributes to the species number registered for the family.

The area presents high species richness and is botanically underexplored, with 13 new species being described. However, the number of rare and endangered species was not too high. This could be related to the criteria used to include plants as rare or endangered and to insufficient data being present for the threat analysis, as many of the species are poorly sampled, a consequence of the Jalapão region and surrounding being insufficiently explored. For example, Diospyros ovalis Hiern presents very few collections, being poorly known, but still is not considered neither as threatened nor rare.

Currently, Varronia sp. nov. , Dioscorea sp. nov., Eriope sp. nov., Bauhinia sp. nov., Eugenia sp. nov., Piriqueta sp. nov., Simaba sp. nov., Lippia sp. nov., Ouratea acicularis and Senna biglandularis A.O.Araujo \& V.C.Souza are considered endemic to the Jalapão region. These species should be priority in the elaboration of management plans of protected areas and institutes of nature management. 
The 528 species recorded in this inventory almost increases 2-fold the number of species known for these physiognomies in Jalapão, being 274 species until now (Seplan 2003). Additional sampling in physiognomies still poorly known, such as swamp forest ("veredas"), gallery forests, seasonal dry forests, rocky-soil savannahs, highland rocky fields ("campo rupestre"), and wet-soil fields, may further increase species numbers, possibly reaching 1,000 species for the entire Jalapão region, as found in a survey that included all physiognomies from another Cerrado area in Tocantins state (Medeiros et al. 2012).

Ratter et al. (2003), followed by Bridgewater et al. (2004), divided the Cerrado domain into six floristic provinces, based on floristic similarities of trees and large shrubs. Jalapão region is contained in the Northeastern province (Ratter et al. 2003, Bridgwater et al. 2004), characterized by few mesotrophic species. Although most of the tree species representing this province being present in Jalapão, such as Qualea parviflora Mart., Pouteria ramiflora (Mart.) Radlk., Qualea grandiflora Mart., Hymenaea stigonocarpa Mart. and Bowdichia virgilioides Kunth, additional studies analyzing layers of herbaceous plants, subshrubs, vines and small shrubs, which include the majority of plant diversity in the Cerrado (Ratter et al. 1997), may indicate that Jalapão region and surrounding areas should be treated as a different province, separated from the southern part of the Northeastern province.

Regarding species habitat, considering the large shrub definition by Ratter et al. (2003), the number of ground layer species growing in savannah physiognomies in Jalapão was twice as higher as taller, woody species (trees and large shrubs). This agrees with the concept that, in the Cerrado, the ground layer is richer in species diversity than the taller layer (Ratter et al. 1997, 2003).

The main threat to the Jalapão region is the advance of the agricultural frontier, which has already deforested large parts of Cerrado nearby, mostly in Bahia state. Other threats are indiscriminate tourism, uncontrolled extraction of traditional products and anthropogenic fires 
during the dry season, which are common in Jalapão region (Schmidt et al. 2007). This study contributes to the knowledge of plant biodiversity in Jalapão region, the first step required for planning and executing conservation actions. Despite that, the region is still relatively poorly collected and other physiognomies, such as swamp, gallery forest, seasonal dry forest and wetsoil field, require more studies.

\section{Acknowledgements}

We thank all plant experts who helped confirming or identifying specimens; ICMBio and Naturatins for providing collection permits and field work support at "Parque Estadual do Jalapão" and "Estação Ecológica Serra Geral do Tocantins"; Ubiratan Chagas, Lucas Nascimento, Marcela Escaramai, Heloisa Antar, Vera Scatena, Rebeca Viana and Marcio Martins for helping during field work; Alexandre B. Sampaio and Isabel B. Schmidt for helping with references and information about Jalapão; Luiz Henrique M. Fonseca for comments in an earlier version of this paper; CAPES, CNPq (proc. 308300/2012-2), FAPESP (2014/01851-7) and Idea Wild for financial support.

\section{Literature Cited}

Alvares, C.A.; Stape, J.L.; Sentelhas, P.C.; Gonçalves, J.L.M. \& Sparovek, G. 2014. Köppen’s climate classification map for Brazil. Meterologische Zeitschrift 22 (6): 711-728.

Amaral, A.G., C.B.R. Munhoz, C.U.O. Eugênio and J.M.Felfili. 2013. Vascular flora in dryshrub and wet grassland Cerrado seven years after a fire, Federal District, Brazil. Check List 9(3): 387-503.

APG III. 2009. An update of the Angiosperm Phylogeny Group classification for the orders and families of flowering plants: APG III. Botanical Journal of Linnean Society 161: 105-121. 
Araujo, A.O. and V.C. Souza. 2007. Uma nova espécie de Senna Mill. (LeguminosaeCaesalpinoideae) do Brasil. Rodriguésia 58 (2): 359-362.

Arruda, M.B., M.V. Behr. 2002. Jalapão: Expedição científica e conservacionista. Ibama. Brasília: Ministério do Meio Ambiente. 93 pp.

Barneby, R.C. 1991. Sensitivae censitae: a description of the genus Mimosa Linnaeus (Mimosaceae) in the new world. Memories of the New York Botanical Garden 65: 1-835.

Batalha, M.A., S. Aragaki and W. Mantovani. 1997. Florística do Cerrado em Emas (Pirassununga, SP). Boletim de Botânica da Universidade de São Paulo 16: 49-64

Batalha, M.A. and W. Mantovani. 2001. Floristic composition of the Cerrado in the Pé-doGigante reserve (Santa Rita do Passo Quatro, Southeastern Brazil). Acta Botanica Brasilica 15(3): 289-304.

Beentje, H. 2012. The Kew Plant Glossary: An Illustrated Dictionary of Plant Terms. Royal Botanical Garden, Kew: 164 pp.

Bridgewater, S., J.A. Ratter and J.F.Ribeiro. 2004. Biogeographic patterns, B diversiy and dominace in the cerrado biome of Brazil. Biodiversity and Conservation 13: 2295-2318.

Carvalho, M.B., K.L. Ishara and R.C.S. Maimoni-Rodella. 2010. Vascular Flora of a Cerrado sensu stricto remmant in Pratânia, state of São Paulo, southeastern Brazil. Checklist 6(3): 350357.

Coutinho, L. M. 1978. O conceito do cerrado. Revista. Brasileira de Botânica 1: 17-23.

Coutinho, L.M. 1990. Fire in the ecology of Brazilian Cerrado. Ecological Studies: analysis and synthesis. 84: 82-105

Eiten, G. 1972. The cerrado vegetation of Brazil. Botanical Review.38 (2): 201-341. 
Filgueiras, T.S., P.E. Nogueira, A.L. Brochado and G.F. Guala II. 1994. Caminhamento: um método expedito para levantamentos florísticos qualitativos. Caderno de Geociências 12: 39-43.

Forzza, R. C., J.F.A. Baumgratz, C.E.M. Bicudo, D.A.L. Canhos, A. Carvalho, M.A.N. Coelho, A.F. Costa, D.P. Costa, M.G. Hopkins, P.M. Leitman, L.G. Lohmann, E.N. Lughadha, L.C. Maia, G. Martinelli, M. Menezes, M.P. Morim, A.L. Peixoto, J.R. Pirani, J. Prado, L.P. Queiroz, S. Souza, V.C. Souza, J.R. Stehmann, L.S. Sylvestre, B.M.T. Walter and D.C. Zappi 2012. New Brazilian floristic list highlights conservation challenges. Bioscience 62: 39-45.

França, F. and C.E.B. Proença. 2007. Vochysia palmirana (Vochysiaceae), a new species from Goiás and Tocantins, Brazil. Brittonia 59(4): 374-376.

Giulietti, A.M., A. Rapini, M.J.G. Andrade, L.P. Queiroz and J.M.C. Silva. 2009. Plantas raras do Brasil. Belo Horizonte: Conservação Internacional. 496 pp.

Gottsberger, G.; Silberbauer-Gottsberger I. 2006. Life in the Cerrado, a South American Tropical Seasonal Ecosystem. Volume 1. Origin, Structure, Dynamics and Plant Use. Germany: Reta Verlag, 277 pp.

The International Plant Names Index (2015). Eletronic database accessible at http://www.ipni.org. Accessed at 20 May 2015.

Irwin, H.S. and R.C. Barneby.1982. The American Cassiinae. Memoirs of the New York Botanical Garden 35: 455-918.

Klink, C.A. and R.B. Machado. 2005. Conservation of Brazilian Cerrado. Conservation Biology 19 (3): 707-713.

Lista de Espécies da Flora do Brasil. Jardim Botânico do Rio de Janeiro. Electronic database accessible at http://floradobrasil.jbrj.gov.br/. Accessed at 20 May 2015. 
Mantovani, W. and F.R. Martins, 1993. Florística do Cerrado na Reserva Biológica de Mogi Guaçu, SP. Acta Botanica Brasilica 7(1): 33-60.

Martinelli, G. and M.A. Moraes. 2013. Livro Vermelho da Flora do Brasil. Rio de Janeiro. Instituto de Pesquisas Jardim Botânico do Rio de Janeiro. Centro Nacional de Conservação da Flora. 1100 pp.

Martinelli, G., T. Messina and L.Santos-Filho. 2014. Livro Vermelho da Flora do Brasil: Plantas Raras do Cerrado. Rio de Janeiro. Instituto de Pesquisas Jardim Botânico do Rio de Janeiro. Centro Nacional de Conservação da Flora. 320 pp.

Medeiros, M.B., B.M.T. Walter, G.P. Silva, B.M. Gomes, I.L.P. Lima, S.R. Silva, P. Moser, W.L. Oliveira and T.B. Cavalcanti. 2012. Vascular Flora of the Tocantins River Middle Basin, Brazil. Checklist 8(5): 852-885.

Moreira, A.G. 2000. Effects off fire protection on savanna structure in Central Brazil. Journal of Biogeography 27: 1021-1029.

Myers, N., R.A. MITTERMEIER, G.A.B. FONSECA and J. KENT. 2000. Biodiversity hotspots for conservation priorities. Nature 403: 853-858.

Pivello, V.R. and L.M. Coutinho. 1996. A qualitative successional model to assist in the management of Brazilian cerrados. Forest Ecology Management 87: 127-138.

Pivello, V.R. Carvalho, V.M.C.; Lopes, P.F.; Peccinini, A.A. \& Rosso, S. 1999. Abundance and distribution of Native and Alien Grasses in a "Cerado" Brazilian Savanna ) Biological Reserve. Biotropica 31 (1): 71-82.

Proença, C.E.B., R. FARIAS-SINGER and B.M. GOMES. 2007. Pleonotoma orientalis (Bignoniaceae-Bignonieae): Expanded description, distribution and a new variety of a poorly known species. Edinburgh Journal of Botany 64(1): 17-23. 
Ratter, J.A., J.F. Ribeiro and S. Bridgewater. 1997. The brazilian cerrado vegetation and threats to its biodiversity. Annals of biology 80: 223-230.

Ratter, J.A., S. Bridgewater and J.F. Ribeiro. 2003. Analysis of the floristic composition of the Brazilian cerrado vegetation III: Comparison of the Woody vegetation of 376 areas. Edinburgh Journal of Botany 60(1): 57-109.

Ribeiro, J.F. and B.M.T. WALTER. 2008. As principais fitofisionomias do bioma Cerrado; pp 153-212. In Sano, S.M., S.P. Almeida and J.F. Ribeiro. 2008. Cerrado: ecologia e flora. Vol 1. Embrapa Cerrados/ Embrapa Informação Tecnológica. Brasília.

Rua, G.H., J.F.M. Valls, D. Gracino-Ribeiro, and R.C. Oliveira. 2008. Four new species of Paspalum (Poaceae, Panicee) from Central Brazil, and Resurrection of and Old One. Sytematic Botany 33(2): 267-276.

Sampaio, M.B., I.B.Schmidt and I.B. Figueiredo. 2008. Harvesting Effects and Population Ecology of the Buriti Palm (Mauritia flexuosa L.f., Arecaceae) in the Jalapão Region, Central Brazil. Economic Botany 62(2): 171-181.

Schmidt, I.B., I.B. Figueiredo and A. Scariot. 2007. Ethnobotany and Effects of Harvesting on the Population of Syngonanthus nitens (Bong.) Ruhland (Eriocaulaceae), a NTFP from Jalapão Region, Central Brazil. Economic Botany 61(1): 73-85

SEPLAN - Secretaria do Planejamento e Meio Ambiente do Estado de Tocantins. 2003. Plano de Manejo da Área de Proteção Ambiental do Jalapão. Palmas; Seplan 2003. 205p.

SEPLAN - Secretaria do Planejamento e Meio Ambiente do Estado de Tocantins. 2012. Atlas do Tocantins: Subsídios ao Planejamento da Gestão Territorial. Palmas: Seplan. 79 
Silva, I.A. and M.A. Batalha. 2011. Plant functional types in Brazilian savannas. The niche partitioning between herbaceous and woody species. Perspectives in Plant Ecology, Evolution and Systematics. 13(3): 201-206.

Silva, J.M.C. and J.M. Bates. 2002. Biogeographyc patterns and conservation in the South America Cerrado: A Tropical Savana Hotspot. BioScience 52(3): 225-233.

Thiers, B. 2015. Index Herbariorum: A global directory of public herbaria and associated staff. New York Botanical Garden's Virtual Herbarium. Electronic Database accessible at http:// sweetgum.nybg.org/ih/. Captured on 10 May 2015.

Vieira, S. and Souza, V.C. Four new species of Maranta L. (Marantaceae) from Brazil. Bottanical Journal of Linnean society 158: 131-139.

Yamamoto, K., R.G.Chacon, C.Proença, T.B. Cavalcanti, D. Graciliano-Ribeiro. 2008. A Disntictive New Species of Ouratea (Ochnaceae) from the Jalapão Region, Tocantins, Brazil. Novon 18 (3): 397-404. 
Versão em língua portuguesa de artigo a ser submetido para o periódico Brazilian Journal of Biology 
Diversidade do estrato herbáceo-subarbustivo em áreas sujeitas a diferentes frequências de fogo na região do Jalapão, Tocantins

GUILHERME MEDEIROS ANTAR * VÂNIA REGINA PIVELLO \& PAULO TAKEO SANO

1. Departamento de Botânica, Instituto de Biociências, Universidade de São Paulo, Herbário SPF, Rua do Matão 277, 05508-090, São Paulo, SP, Brasil.

2. Laboratório de Ecologia da Paisagem e Conservação, Departamento de Ecologia, Universidade de São Paulo, Rua do Matão, 321 - Trav. 14, São Paulo, SP 05508-090, Brasil.

* Autor para correspondência: guilherme.antar@gmail.com 


\section{Resumo}

O fogo é um dos mais importantes filtros ambientais em formações savânicas. O Cerrado, a maior savana da América do Sul e de maior diversidade vegetal em termos mundiais, possui regime atual de fogo majoritariamente bienal, relacionado à ação antrópica. Esse é o caso da região do Jalapão, onde hoje se encontra a maior extensão de cerrado conservado e protegido por unidades de conservação. Apesar da grande importância do fogo no Cerrado, estudos sobre seus efeitos na comunidade vegetal são escassos, principalmente aqueles que se referem a plantas herbáceo-subarbustivas. Áreas de campo sujo na região do Jalapão com diferentes históricos de fogo foram selecionadas, sendo três áreas com frequência bienal de queimas e uma área livre do fogo há dez anos. Foram instaladas 15 parcelas de $2 \mathrm{~m}$ por área. Todos os indivíduos de hábito herbáceo-subarbustivo foram contabilizados e identificados. Densidade, riqueza e composição de espécies foram avaliadas e comparadas entre as áreas com diferentes históricos de queima. A área com 10 anos sem queima mostrou menores índices de riqueza e densidade do que as áreas com queimas bienais. A composição específica não mostrou diferença entre tratamentos. Esses resultados são corroborados pela descrição na literatura da necessidade de fogo para reprodução e ocorrência de certas espécies vegetais do estrato rasteiro, propiciando-lhes o maior acesso à luz e disponibilidade de nutrientes após queimadas. O fogo no Cerrado não deve ser entendido como prejudicial, sendo necessário incluir programas específicos de queimadas controladas para o manejo da biodiversidade em áreas protegidas.

Palavras-chave: Cerrado, Parque Estadual do Jalapão, estrutura da vegetação, Ecologia do Fogo. 
Introdução

O fogo é um dos fatores mais importantes na evolução e manutenção das formações savânicas (Bond \& Keeley, 2005). Apesar de haver semelhanças entre os efeitos do fogo nessas diferentes formações savânicas, os regimes de queima que moldaram a evolução da biodiversidade de tais formações são únicos (Keeley et al., 2011) e, dessa maneira, cada uma delas necessita de estudos específicos (Uys et al., 2004; Miranda et al., 2010).

A diversidade vegetal local é um dos fatores que condicionam o regime de fogo; porém, por sua vez, também é impactada por queimadas. Com a mudança no regime de fogo, causada pelo ser humano (Coutinho, 1990; Brooks et al., 2004; Pivello, 2011), estudos locais relacionados aos efeitos desse elemento na diversidade vegetal das formações savânicas tornamse ainda mais necessários.

A maior savana tropical da América do Sul é o Cerrado (Amaral et al., 2013), sendo também o segundo maior domínio fitogeográfico do Brasil, ocupando, originalmente, cerca de 2.000.000 km² (Ratter et al., 1997). É caracterizado pelo clima marcadamente estacional, com uma estação seca, de abril a setembro, e uma chuvosa, de outubro a março (Ratter et al., 1997). O Cerrado é considerado a savana de maior diversidade vegetal, com 11.637 espécies de plantas vasculares listadas, das quais 36\% são endêmicas (Forzza et al., 2012). Apesar dessa riqueza, não é devidamente valorizado (Ratter et al., 1997), e já possui mais de 50\% da área substituída, majoritariamente para a agropecuária (Klink \& Machado, 2005; Beuchle et al., 2015). Por essa alta diversidade, quantidade de endemismos e pela grande pressão antrópica, é considerado um dos hotspots mundiais da biodiversidade (Mittermeier et al., 2004).

O Cerrado é um domínio dependente do fogo (Coutinho, 1982, 1990), ao qual está sujeito há milênios (Simon et al., 2009). As queimadas causadas por raios geralmente ocorrem durante a estação chuvosa ou nos meses de transição entre época seca e úmida, quando há fortes tempestades (Ramos-Neto e Pivello, 2000; Medeiros e Fiedler, 2004; Miranda et al., 2010). Esses incêndios naturais, em sua maioria, não atingem larga extensão e transformam a paisagem em um mosaico de áreas queimadas e não queimadas (Ramos-Neto e Pivello, 2000). Entretanto, a frequência natural de queimadas não é totalmente conhecida (Miranda et al., 2010; Sato et al., 2010), especulando-se que ocorra, em média, uma vez a cada 10 anos (Eiten, 1972), variando conforme a fisionomia. Com a ocupação humana do Cerrado, o fogo passou a ser utilizado preferencialmente na estação seca, para estimular a rebrota do estrato graminoide usado na alimentação do gado e para a "limpeza" de áreas para a agricultura (Coutinho, 1990; Miranda et al., 2010; Pivello, 2011). Em decorrência desse uso antrópico, atualmente a frequência de 
queimas no Cerrado é majoritariamente bienal ou trienal (Gottsberger e Silberbauer-Gottsberger, 2006).

Apesar da relação do Cerrado com o fogo, pesquisas sistemáticas envolvendo a comunidade vegetal e visando compreender as consequências de queimadas para a biodiversidade do Cerrado foram intensificadas apenas nos últimos 30 anos (Dias e Miranda, 2010). Esses estudos tiveram foco no componente arbóreo, no qual o fogo, em maior frequência, apresenta efeitos destrutivos, principalmente em árvores de menor porte (Hoffmann, 1999; Sato et al., 2010) e altera a estrutura da comunidade, levando a formações mais abertas. Em oposição, a supressão de queimadas leva ao favorecimento da manutenção de uma vegetação lenhosa mais adensada (Coutinho, 1990; Moreira, 2000; Miranda et al., 2010; Amaral et al., 2013).

O estrato rasteiro, apesar de ser muito mais diverso que o lenhoso (Coutinho, 1990; Ratter et al., 1997; Mendonça et al., 1998) e de ser favorecido por uma alta frequência de queimas, acabou negligenciado quanto aos estudos sobre os efeitos do fogo na sua diversidade (Silva e Batalha, 2010; Loiola et al., 2010; Amaral et al., 2013), principalmente pela dificuldade de identificação de material vegetativo e pelo menor conhecimento taxonômico das plantas desse estrato.

Dentre os estudos focados no estrato rasteiro, Miranda (2002), trabalhando com Poaceae, encontrou que queimadas bienais - principalmente se forem tardias - reduzem a diversidade e aumentam a dominância de espécies dessa família em campo sujo. Loiola et al. (2010) encontraram mudanças na composição florística entre áreas com alta frequência de queima e áreas com média frequência ou protegidas, além de abundâncias de espécies únicas em cada área. Amaral et. al (2013) constataram que campo sujo e campo limpo sem queima após sete anos tiveram grande mudança na composição, tanto na diversidade como na estrutura, resultando em um pequeno incremento na riqueza após a supressão do fogo. César (1980) encontrou maior riqueza em parcelas queimadas em campo sujo, propondo que a exclusão do fogo reduz a riqueza da vegetação rasteira, já que a densa cobertura das gramíneas dominantes diminui o acesso à luz para as outras plantas.

O Jalapão, localizado no leste do Tocantins, é um ótimo modelo para estudos relacionados à ecologia do fogo. A região possui a maior área contínua de Cerrado conservado e protegido por unidades de conservação (Silva e Bates, 2002). Destacam-se o Parque Estadual do Jalapão, a Estação Ecológica Serra Geral do Tocantins, a Área de Proteção Ambiental do Jalapão e o Parque Nacional Nascentes do Parnaíba (Schmidt et al., 2007) como as principais unidades de conservação da região. Apesar de bem protegida, a flora do Jalapão é pouco conhecida 
(Proença et al., 2007) e queimadas de origem humana são muito frequentes, sendo raro encontrar locais com mais de 3 anos sem queima (Schmidt et al., 2007). Diante desse cenário, os estudos sobre os efeitos do fogo na diversidade da vegetação local são extremamente necessários. Este é o objetivo deste trabalho. Buscamos avaliar os efeitos de queimadas modais bienais e da supressão de queimadas na diversidade do componente herbáceo-subarbustivo do Cerrado, usando como modelo os campos sujos da região do Jalapão.

\section{Materiais e Métodos}

\section{Área de estudo}

A pesquisa ocorreu na região do Jalapão, extremo leste do Tocantins, no Parque Estadual do Jalapão (PEJ), $\left(10^{\circ} 08^{\prime}-10^{\circ} 35^{\prime} \mathrm{S} ; 4^{\circ} 04^{\prime}-47^{\circ} 35^{\prime} \mathrm{W}\right)$, e na Área de Proteção Ambiental do Jalapão (APAJ), que envolve o PEJ, ambos localizados nos municípios de Mateiros, Ponte Alta do Tocantins e Novo Acordo. O PEJ possui uma área de 158.885 ha (Seplan, 2003a) e a APAJ, 461.730 ha (Seplan, 2003b).

De acordo com o sistema de Köppen (Alvares et al., 2014), o clima regional é do tipo Aw, tropical úmido estacional, com verões úmidos e invernos secos. A temperatura média varia de 23,5 a $26,5^{\circ} \mathrm{C}$ e a precipitação total anual é de aproximadamente $1.500 \mathrm{~mm}$, com mais de $90 \%$ concentrada nos meses de outubro a março (Seplan, 2003).

As fisionomias mais abundantes na região são as veredas, caracterizadas pela presença da palmeira buriti (Mauritia flexuosa L.f), e formações de cerrado aberto, destacando-se o campo sujo, caracterizado pelo estrato herbáceo contínuo entremeado por alguns subarbustos, arbustos e, raramente, por árvores de porte reduzido, que cobrem até 3\% da área (Coutinho, 1982; Moreira, 2000; Henriques, 2005).

\section{Seleção de áreas com diferentes históricos de fogo}

Quatro áreas de campo sujo com aproximadamente 50 hectares foram selecionadas (Figura 1), com a participação de um brigadista local, experiente nas questões envolvendo o fogo e sua frequência na região. Três áreas possuíam regime de queimas bienais modais (em julho/ agosto), sendo a última queima realizada dois anos antes do início da tomada de dados para este

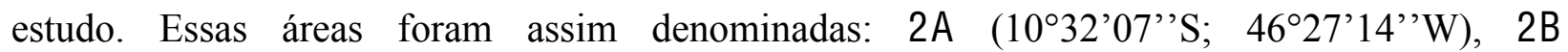

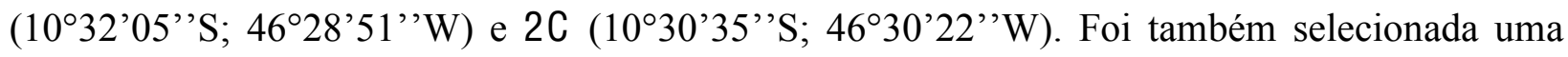


área protegida do fogo há pelo menos 10 anos, denominada $10 \mathrm{~A}\left(10^{\circ} 34^{\prime} 19^{\prime}\right.$ ' S; 46 4030'97', W), que serviu como controle ("ausência" de fogo). Essa última área permaneceu sem queima por esse tempo por estar próxima à sede do PEJ e ter seu entorno aceirado anualmente.

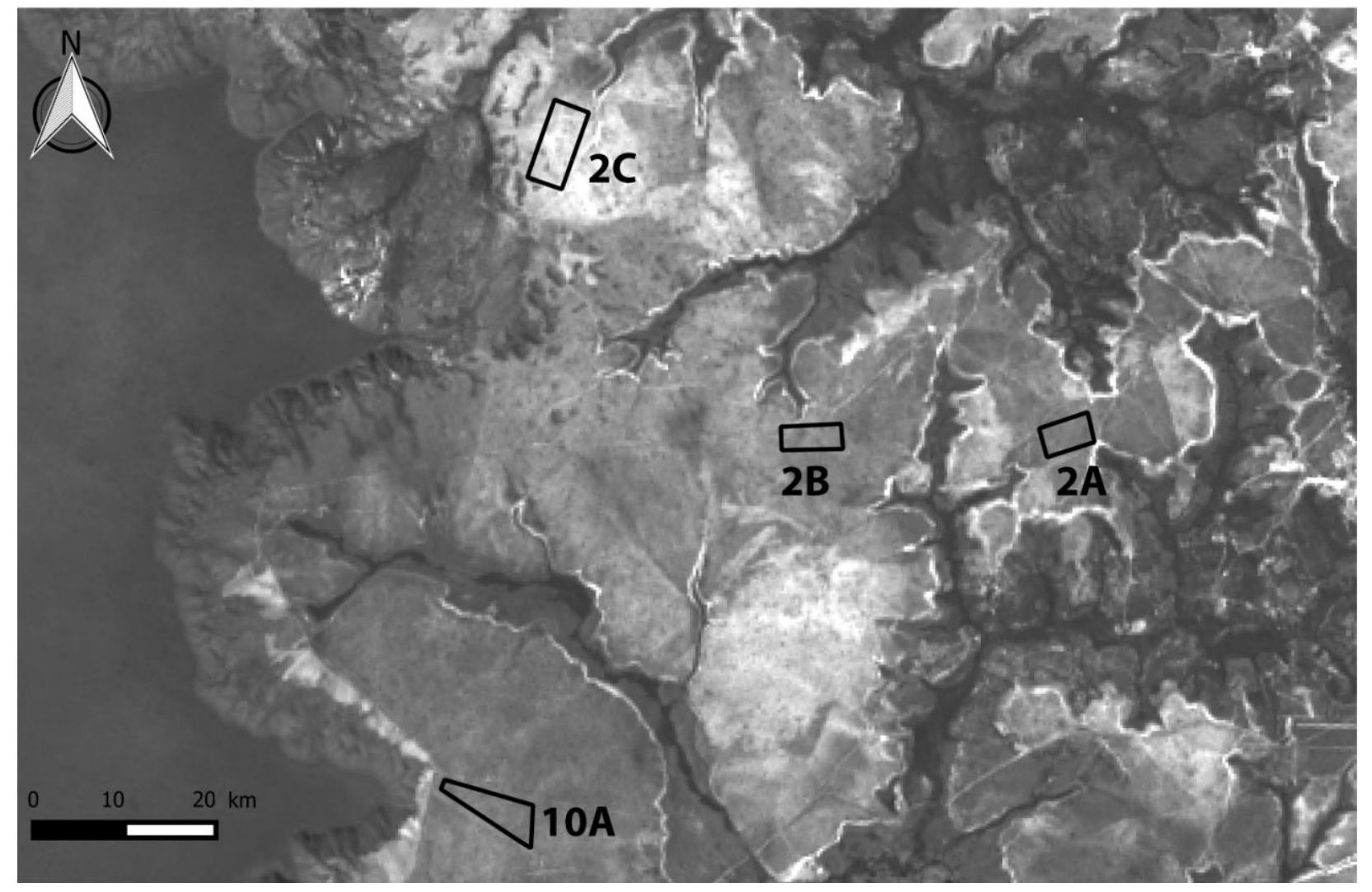

Figura 1 - Localização das áreas estudadas no Parque Estadual do Jalapão e na Área de Proteção Ambiental do Jalapão, estado de Tocantins. (Imagem obtida do satélite CBERS 2 obtidas junto ao INPE). $10 \mathrm{~A}$ é a área há 10 anos protegida do fogo, e 2A, 2B e 2C são as áreas com regime de queima bienal.

As áreas encontram-se localizadas próximas entre si, portanto, sob uma mesma influência climática. A variação de altitude é baixa, estando todas aproximadamente na cota de 520 metros. A estrutura da vegetação e os solos são visualmente semelhantes. Animais herbívoros não são muito abundantes, destacando-se o veado campeiro (Ozotocerus benzoarticus), ameaçado de extinção (Chiarello et al., 2008), que circula livremente entre as áreas. As áreas não apresentam impacto humano perceptível.

\section{Amostragem e caracterização dos solos}

Apesar da semelhança visual entre elas, as áreas foram analisadas quanto à granulometria e ao teor de matéria orgânica cinco amostras combinada de solo por área, sendo cada uma constituída de quatro amostras, aleatoriamente coletadas a $0-5 \mathrm{~cm}$ de profundidade. A análise 
granulométrica foi feita pelo método do densímetro de Boyoucus, conforme Camargo et al. (1986) e a matéria orgânica foi estimada por meio de oxidação por dicromato de sódio em $\mathrm{H}_{2} \mathrm{SO}_{4}$ e quantificação por colorimetria (Raij et al. 1987).

\section{Amostragem e caracterização das plantas herbáceo-subarbustivas}

Os dados de campo foram coletados durante a estação chuvosa, entre o final de outubro de 2013 e março de 2014. Foram estabelecidas 15 parcelas de $4 \mathrm{~m}$ em cada área e contabilizadas todas as espécies herbáceas subarbustivas com a base do indivíduo presentes dentro das parcelas. Seguiu-se Beentje (2012) para as definições de hábito. Devido ao hábito clonal muito presente no Cerrado, indivíduos foram definidos para plantas de hábito graminoide como touceiras e, para plantas com hábito subarbustivo, como cada ramo ("ramet").

O material coletado foi inicialmente morfotipado e posteriormente identificado até o nível de espécie, comparando com identificações de materiais reprodutivos obtidos próximos às parcelas e depositados no herbário SPF. Especialistas foram consultados para confirmação ou identificação de espécies duvidosas. Os materiais que foram identificados até o nível de espécie foram mantidos como morfotipos. O sistema de classificação adotado para famílias de angiospermas foi o APG III (2009) e os nomes de espécies e autores seguiram a "Lista de Espécies da Flora do Brasil” (2015).

\section{Análise dos dados}

Foram construídas curvas de suficiência amostral (curva do coletor) para cada área. Calculou-se a densidade média de indivíduos e a riqueza média de espécies por parcela para todas as áreas e para cada área separadamente.

Para as diferentes áreas também foi calculado o índice de diversidade de Shannon e a equabilidade de Pielou, com logaritmo de base natural (Zar, 2010). A comparação da composição entre áreas foi feita por meio dos índices de similaridade de Jaccard e de Bray-Curtis (Zar 2010), e também por um dendrograma de similaridade construído pelo método de UPGMA. Os dados foram transformados a partir do total marginal e posteriormente foram realizados testes de NMDS (Nonmetric Multidimensional Scaling) (Zar, 2010). As análises foram realizadas no programa R ( $\mathrm{R}$ developing core team, 2015), utilizando-se o pacote vegan (Oksanen et al., 2015). 


\section{Resultados}

As quatro áreas possuem solo arenoso, com aproximadamente $90 \%$ de areia fina + grossa, com composição textural muito similar. O teor de matéria orgânica em todas as áreas foi muito baixo, em torno de $0,5 \%$. As variações entre áreas foram de 2,48 para a porcentagem de areia grossa; 3,10 na porcentagem de areia fina; 1,28 para a porcentagem de partículas finas; e 0,581 para a porcentagem de matéria orgânica. Esses valores não são representativos para distinguir áreas.

Foram encontradas 68 espécies em todas as áreas, distribuídas em 15 famílias (tabela 1). As famílias mais representativas em número de indivíduos foram Poaceae, Cyperaceae, Euphorbiaceae, Arecaceae e Fabaceae. Em número de espécies, as famílias mais representativas foram Poaceae (17), Fabaceae (7), Cyperaceae (6), Amaranthaceae (3) e Polygalaceae (3). As espécies mais comuns foram Trachypogon spicatus (L.f) Kuntze, a única espécie presente em todas as parcelas; Croton agoensis Baill.; Syagrus glaziouviana (Dammer) Becc. e Bulbostylis junciformis (Kunth) C.B.Clarke.

Tabela 1- Lista de espécies agrupadas em famílias, com o número de indivíduos encontrado nas áreas com diferentes regimes de fogo. 10A é a área há 10 anos protegida do fogo, e 2A, 2B e 2C são as áreas com regime de queima bienal.

\begin{tabular}{|c|c|c|c|c|}
\hline Taxon & $10 \mathrm{~A}$ & $2 \mathrm{~A}$ & $2 \mathrm{~B}$ & $2 \mathrm{C}$ \\
\hline \multicolumn{5}{|l|}{ Amaranthaceae } \\
\hline Gomphrena agrestis Mart. & 3 & 12 & 20 & 6 \\
\hline Gomphrena graminea Moq. & 1 & 0 & 0 & 0 \\
\hline Gomphrena virgata Mart. & 1 & 0 & 0 & 2 \\
\hline \multicolumn{5}{|l|}{ Apocynaceae } \\
\hline Hemipogon acerosus Decne. & 0 & 0 & 0 & 13 \\
\hline \multicolumn{5}{|l|}{ Arecaceae } \\
\hline Astrocaryum campestre Mart. & 25 & 34 & 70 & 53 \\
\hline Syagrus glazioviana (Dammer) Becc. & 102 & 81 & 188 & 61 \\
\hline \multicolumn{5}{|l|}{ Asteraceae } \\
\hline Aspilia leucoglossa Malme & 1 & 13 & 23 & 1 \\
\hline \multicolumn{5}{|l|}{ Cactaceae } \\
\hline Discocactus catingicola Buining \& Brederoo & 0 & 0 & 2 & 0 \\
\hline \multicolumn{5}{|l|}{ Convolvulaceae } \\
\hline Ipomoea cf. pyrenea Meisn. & 0 & 11 & 0 & 37 \\
\hline Jacquemontia evolvuloides (Moric.) Meisn. & 0 & 6 & 0 & 1 \\
\hline
\end{tabular}


Bulbostylis conifera (Kunth) C.B.Clarke

Bulbostylis junciformis (Kunth) C.B.Clarke

Cryptangium verticillatum (Spreng.) Vitta

Cyperus aggregatus (Willd.) Endl.

Rhynchospora consanguinea (Kunth) Boeckeler

Rhynchospora terminalis Nees ex Steud.

$\begin{array}{cccc}32 & 50 & 10 & 181 \\ 10 & 127 & 99 & 119 \\ 54 & 40 & 0 & 21 \\ 1 & 7 & 0 & 0 \\ 12 & 7 & 0 & 1 \\ 0 & 11 & 22 & 177\end{array}$

Dioscoreaceae

Dioscorea sp. nov.

0

13

0

0

Euphorbiaceae

Croton agoensis Baill.

123

77

190

153

Croton grandivelus Baill.

$\begin{array}{llll}14 & 22 & 16 & 22\end{array}$

Euphorbia sarcodes Boiss.

0

Euphorbia potentilloides Boiss.

$20 \quad 25$

0

0

Manihot cf. salicifolia Pohl

0

25

33

74

2

3

25

\begin{tabular}{|c|c|c|c|c|}
\hline \multicolumn{5}{|l|}{ Fabaceae } \\
\hline Aeschynomene paniculata Willd. Ex Vogel & 0 & 1 & 0 & 0 \\
\hline Arachis marginata Gardner & 0 & 0 & 0 & 48 \\
\hline Centrosema venosum Mart. ex Benth. & 26 & 25 & 38 & 9 \\
\hline Chamaecrista desvauxii var.desvauxii (Collad.) Killip & 20 & 29 & 45 & 52 \\
\hline Clitoria aff. guianensis (Aubl.) Benth. & 15 & 7 & 18 & 2 \\
\hline Mimosa piptoptera Barneby & 6 & 1 & 11 & 2 \\
\hline Stylosanthes guianensis (Aubl.) Sw & 7 & 0 & 9 & 4 \\
\hline \multicolumn{5}{|l|}{ Iridaceae } \\
\hline Trimezia cathartica (Klatt) Niederl. & 0 & 3 & 3 & 0 \\
\hline \multicolumn{5}{|l|}{ Lamiaceae } \\
\hline Lamiaceae sp.1 & 1 & 0 & 0 & 0 \\
\hline \multicolumn{5}{|l|}{ Lythraceae } \\
\hline Cuphea micrantha Kunth & 0 & 0 & 17 & 5 \\
\hline \multicolumn{5}{|l|}{ Marantaceae } \\
\hline Maranta longiflora S.Vieira \& V.C.Souza & 0 & 0 & 1 & 1 \\
\hline \multicolumn{5}{|l|}{ Poaceae } \\
\hline Axonopus marginatus (Trin.) Chase & 1 & 52 & 92 & 51 \\
\hline Ichnanthus hoffmannseggii (Roem. \& Schult.) Doll & 0 & 0 & 0 & 14 \\
\hline Loudetiopsis chrysothrix (Nees) Conert & 31 & 27 & 9 & 86 \\
\hline Mesosetum loliiforme (Hochst.) Chase & 77 & 61 & 33 & 127 \\
\hline Paspalum marmoratum Kuhlm. & 0 & 0 & 1 & 28 \\
\hline Trachypogon spicatus (L.f.) Kuntze & 172 & 274 & 266 & 206 \\
\hline Poaceae sp.1 & 0 & 0 & 23 & 0 \\
\hline Poaceae sp.2 & 0 & 0 & 3 & 0 \\
\hline Poaceae sp.3 & 0 & 17 & 7 & 34 \\
\hline Poaceae sp.4 & 0 & 0 & 0 & 6 \\
\hline Poaceae sp.5 & 0 & 0 & 33 & 3 \\
\hline Poaceae sp.6 & 7 & 23 & 20 & 23 \\
\hline Poaceae sp.7 & 0 & 0 & 0 & 6 \\
\hline Poaceae sp. 8 & 0 & 0 & 0 & 4 \\
\hline
\end{tabular}




\begin{tabular}{|c|c|c|c|c|}
\hline Poaceae sp.9 & 0 & 18 & 0 & 2 \\
\hline Poaceae sp.10 & 0 & 1 & 0 & 1 \\
\hline Poaceae sp.11 & 1 & 19 & 43 & 0 \\
\hline \multicolumn{5}{|l|}{ Polygalaceae } \\
\hline Polygala equisetoides A.St.-Hil. \& Moq. & 0 & 0 & 2 & 2 \\
\hline Polygala longicaulis Kunth & 0 & 1 & 4 & 0 \\
\hline Polygala sp. nov. & 0 & 4 & 0 & 2 \\
\hline \multicolumn{5}{|l|}{ Rubiaceae } \\
\hline Borreria crispata (K.Schum.) E.L.Cabral \& Bacigalupo & 5 & 21 & 39 & 14 \\
\hline \multicolumn{5}{|l|}{ Smilacaceae } \\
\hline Smilax oblongifolia Pohl ex Griseb. & 0 & 2 & 12 & 16 \\
\hline \multicolumn{5}{|l|}{ Turneraceae } \\
\hline Piriqueta breviseminata Arbo & 0 & 71 & 23 & 0 \\
\hline Turnera aff. coerulea DC. & 8 & 4 & 2 & 7 \\
\hline \multicolumn{5}{|l|}{ Velloziaceae } \\
\hline Vellozia squamata Pohl & 8 & 7 & 8 & 9 \\
\hline \multicolumn{5}{|l|}{ Verbenaceae } \\
\hline Casselia confertiflora (Moldenke) Moldenke & 9 & 8 & 5 & 6 \\
\hline \multicolumn{5}{|l|}{ Indeterminadas } \\
\hline Indet sp.1 & 0 & 7 & 0 & 0 \\
\hline Indet sp.2 & 0 & 0 & 0 & 4 \\
\hline Indet sp.3 & 0 & 0 & 2 & 12 \\
\hline Indet sp.4 & 0 & 0 & 0 & 3 \\
\hline Indet sp.5 & 2 & 0 & 0 & 1 \\
\hline Indet sp.6 & 1 & 0 & 0 & 0 \\
\hline Indet sp.7 & 3 & 0 & 0 & 0 \\
\hline Indet sp. 8 & 2 & 0 & 0 & 0 \\
\hline Indet sp.9 & 0 & 9 & 20 & 0 \\
\hline
\end{tabular}

A densidade média de indivíduos por parcela foi de 86,7. A riqueza média por parcela foi de 17,3 espécies. As curvas do coletor (Figura 2) indicam ter havido suficiência amostral. Detectou-se uma diferença significativa na densidade de indivíduos por parcela entre as áreas com diferentes intensidades de fogo $\left(\mathrm{F}_{(3,56)}=24.19 ; \mathrm{p}<0,0001\right.$; Figura 3). Há diferença entre a área de 10 anos com as demais $(10 \mathrm{~A}-2 \mathrm{~A} \mathrm{p}<0.0001,10 \mathrm{~A}-2 \mathrm{~B} \mathrm{p}=0.0021786$ e $10 \mathrm{~A}-2 \mathrm{C}$ $\mathrm{p}<0.0001)$ e entre as áreas $2 \mathrm{C}$ e $2 \mathrm{~A}(\mathrm{p}=0.0002726)$. A densidade média por parcela foi sempre menor em 10A, representada por aproximadamente 1,5 vezes menor que a área 2A, 1,9 vezes menor que a área $2 \mathrm{~B}$ e 2,3 vezes menor que a área $2 \mathrm{C}$. 
$10 \mathrm{~A}$

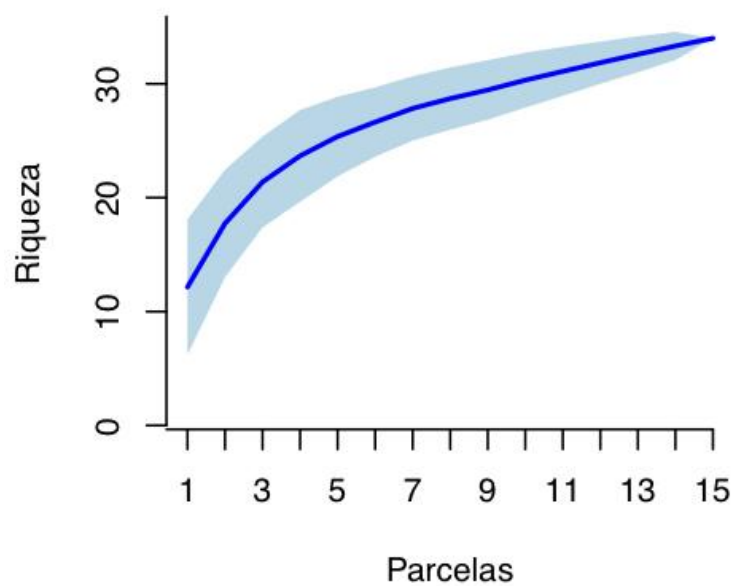

2B

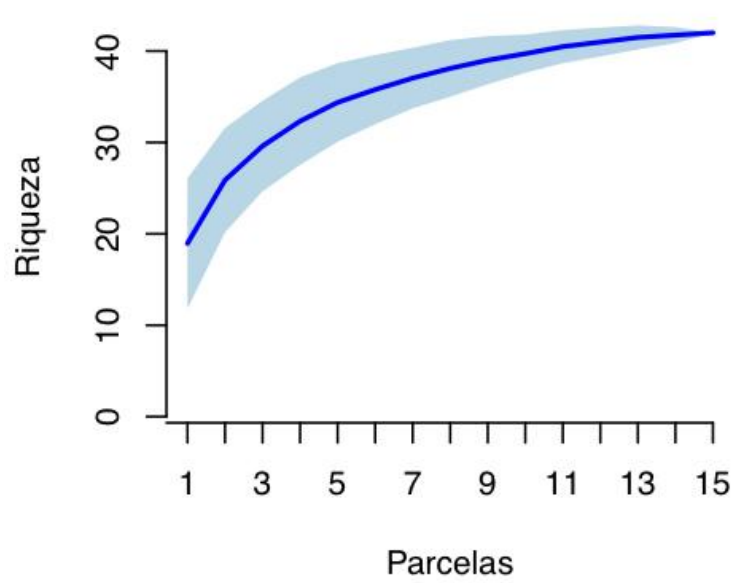

2A

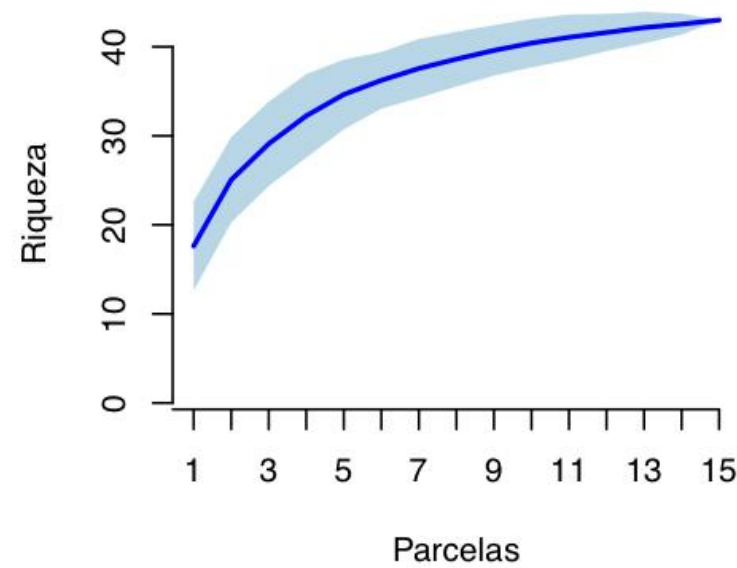

2C

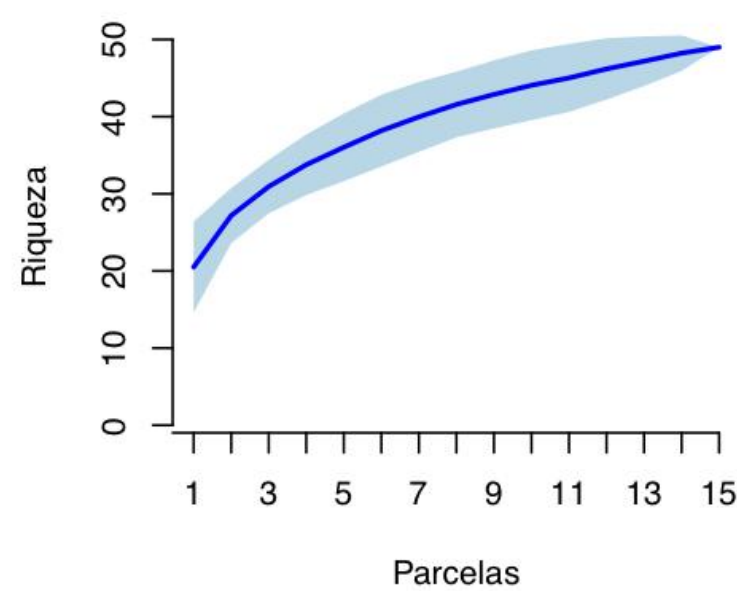

Figura 2 - Curvas de suficiência amostral (curva do coletor) apresentadas para as áreas estudadas (Jalapão, TO). 10A é a área há 10 anos protegida do fogo, e 2A, 2B e 2C são as áreas com regime de queima bienal. 


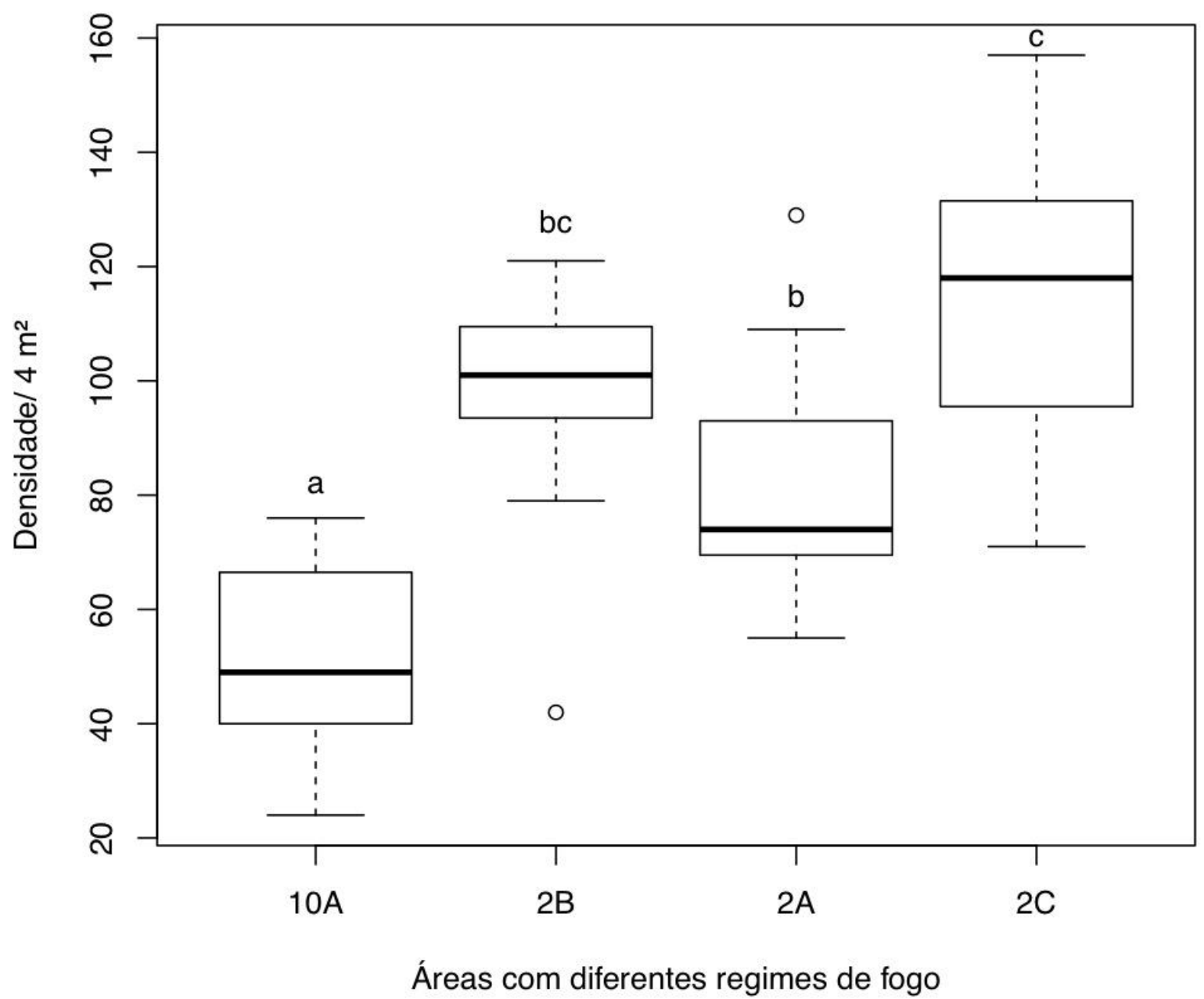

Figura 3 - Densidade de indivíduos de hábito herbáceo e subarbustivo por parcela (4 m ) nas áreas com diferentes regimes de fogo. $10 \mathrm{~A}$ é a área há 10 anos protegida do fogo, e $2 \mathrm{~A}, 2 \mathrm{~B}$ e $2 \mathrm{C}$ são as áreas com regime de queima bienal.

Detectou-se uma diferença significativa na riqueza entre as áreas com diferentes regimes de fogo $\left(F_{(3,56)}=19,2 ; p<0,0001\right.$; Figura 4). Foi encontrada diferença entre 10A e as áreas com regime de queima bienal $(10 \mathrm{~A}-2 \mathrm{~A} p<0,0001,10 \mathrm{~A}-2 \mathrm{~B} p<0,0001$ e $10 \mathrm{~A}-2 \mathrm{C} p<0,0001)$. A área $10 \mathrm{~A}$ mostrou menores valores, tendo 1,2 vezes menor riqueza média por parcela que a área $2^{\mathrm{A}} ; 1,6$ vezes menor riqueza que a área $2 \mathrm{~B}$ e 1,7 vezes menor riqueza que a área $2 \mathrm{C}$. Foram encontradas 34 espécies na área $10^{\mathrm{A}}$; 43 espécies nas áreas $2 \mathrm{~A}$ e 2B; e 51 espécies na área 2C. 


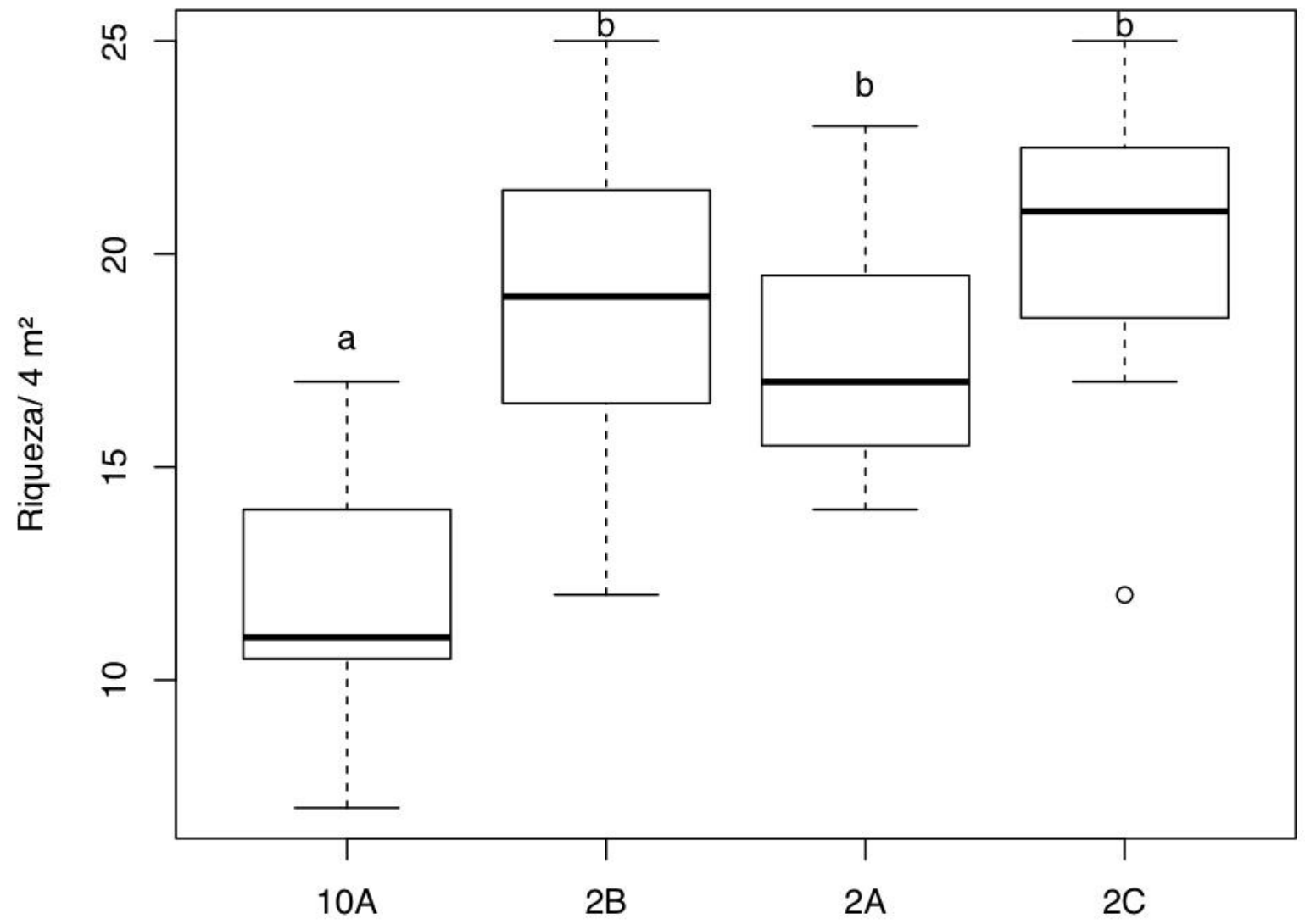

Áreas com diferentes regimes de fogo

Figura 4 - Riqueza por parcela (4 m ) nas áreas com diferentes regimes de fogo na região do Jalapão, TO. 10A é a área há 10 anos protegida do fogo, e 2A, 2B e 2C são as áreas com regime de queima bienal.

Houve diferença significativa entre as áreas quanto à composição, tanto considerando o índice de Jaccard $\left(\mathrm{F}_{(3,56)}=11,37 ; \mathrm{p}<0,0001\right.$; Figura 5), quanto o índice de Bray Curtis $\left(\left(\mathrm{F}_{(3,56)}\right.\right.$ $=11,24 ; \mathrm{p}<0,0001$; Figura 5): a área $2 \mathrm{C}$ se diferenciou das outras 3 áreas (para Jaccard: 10A $2 \mathrm{C} \mathrm{p}<0.0001,2 \mathrm{~A}-2 \mathrm{C} \mathrm{p}=0.00088$ e $2 \mathrm{~B}-2 \mathrm{C} \mathrm{p}<0.0001$; para Bray-Curtis: $10 \mathrm{~A}-2 \mathrm{C} \mathrm{p}<0.0001$, $2 \mathrm{~A}-2 \mathrm{C} \mathrm{p}=0.0016$ e 2B $-2 \mathrm{C} \mathrm{p}<0.0001)$. Não houve diferença entre $10 \mathrm{~A}$ e as áreas $2 \mathrm{~A}$ e $2 \mathrm{~B}$. Essa diferença entre 2C e as demais áreas também fica evidenciada pelo dendrograma (Figura 6), que a coloca mais distante das outras áreas, as quais formam um agrupamento mais próximo. Os mesmos resultados se deram tanto pelo índice de Jaccard como pelo índice de Bray-Curtis. A composição da comunidade por área está detalhada na Tabela 1. 


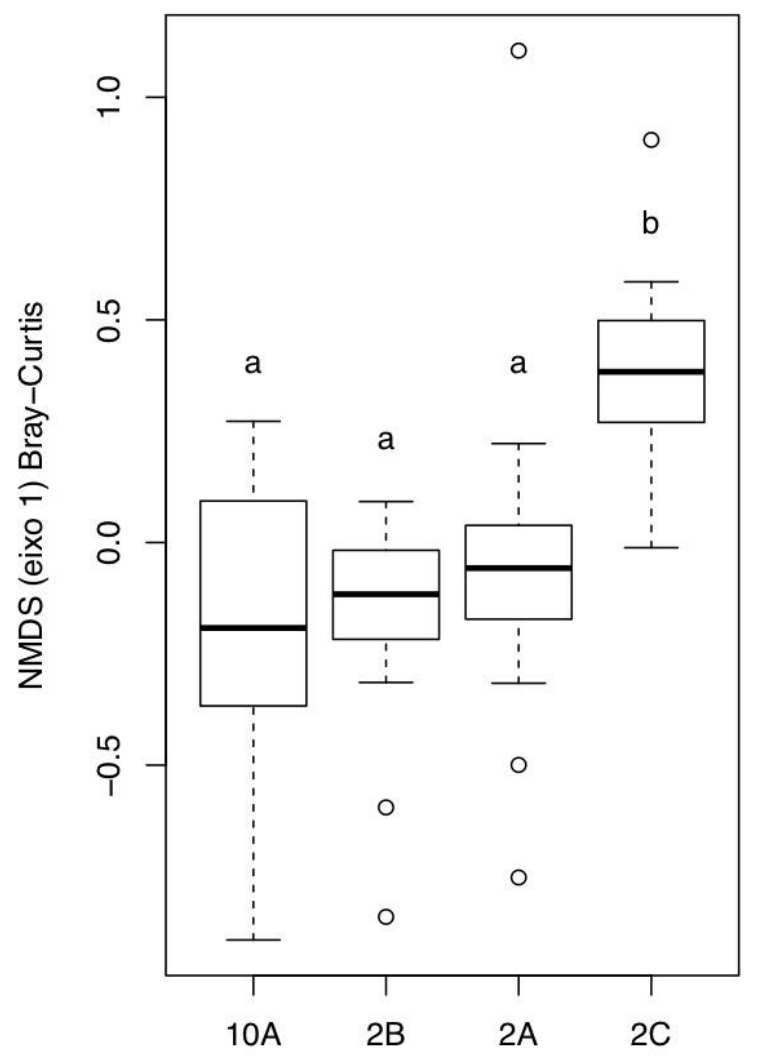

Áreas com diferentes regimes de fogo

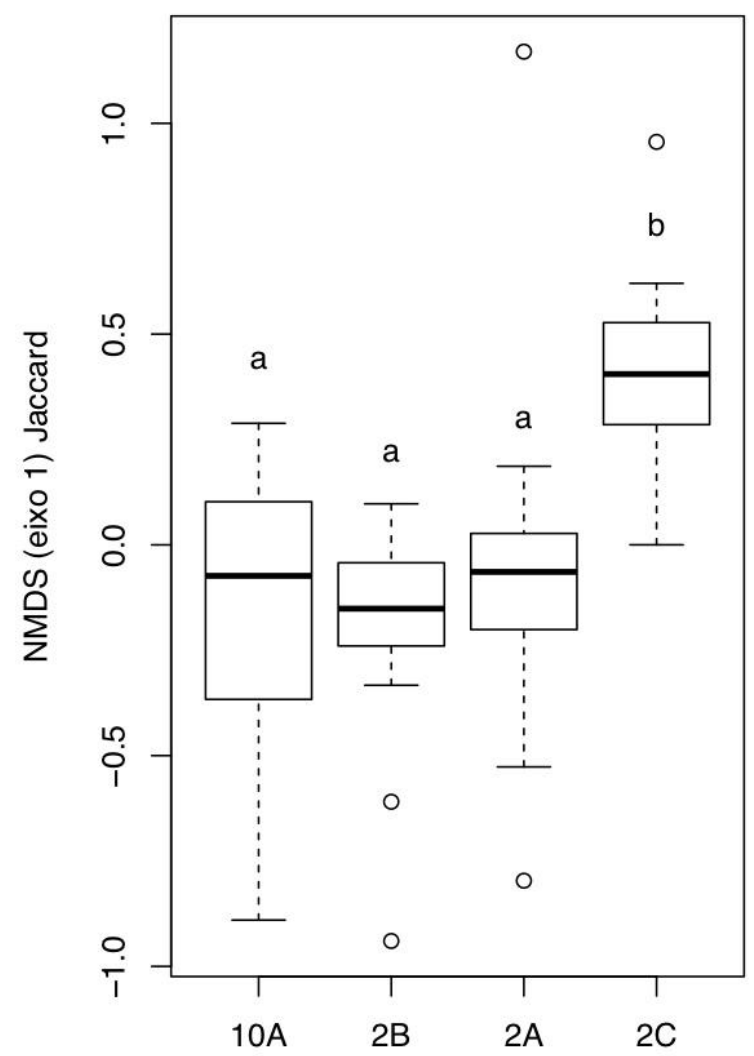

Áreas com diferentes regimes de fogo

Figura 5- Análise comparativa da composição de espécies nas áreas com diferentes regimes de fogo na região do Jalapão, TO., considerando NMDS com um eixo. À esquerda, índice de BrayCurtis e, à direita, índice de Jaccard. 10A é a área há 10 anos protegida do fogo, e 2A, $2 \mathrm{~B}$ e $2 \mathrm{C}$ são as áreas com regime de queima bienal. 

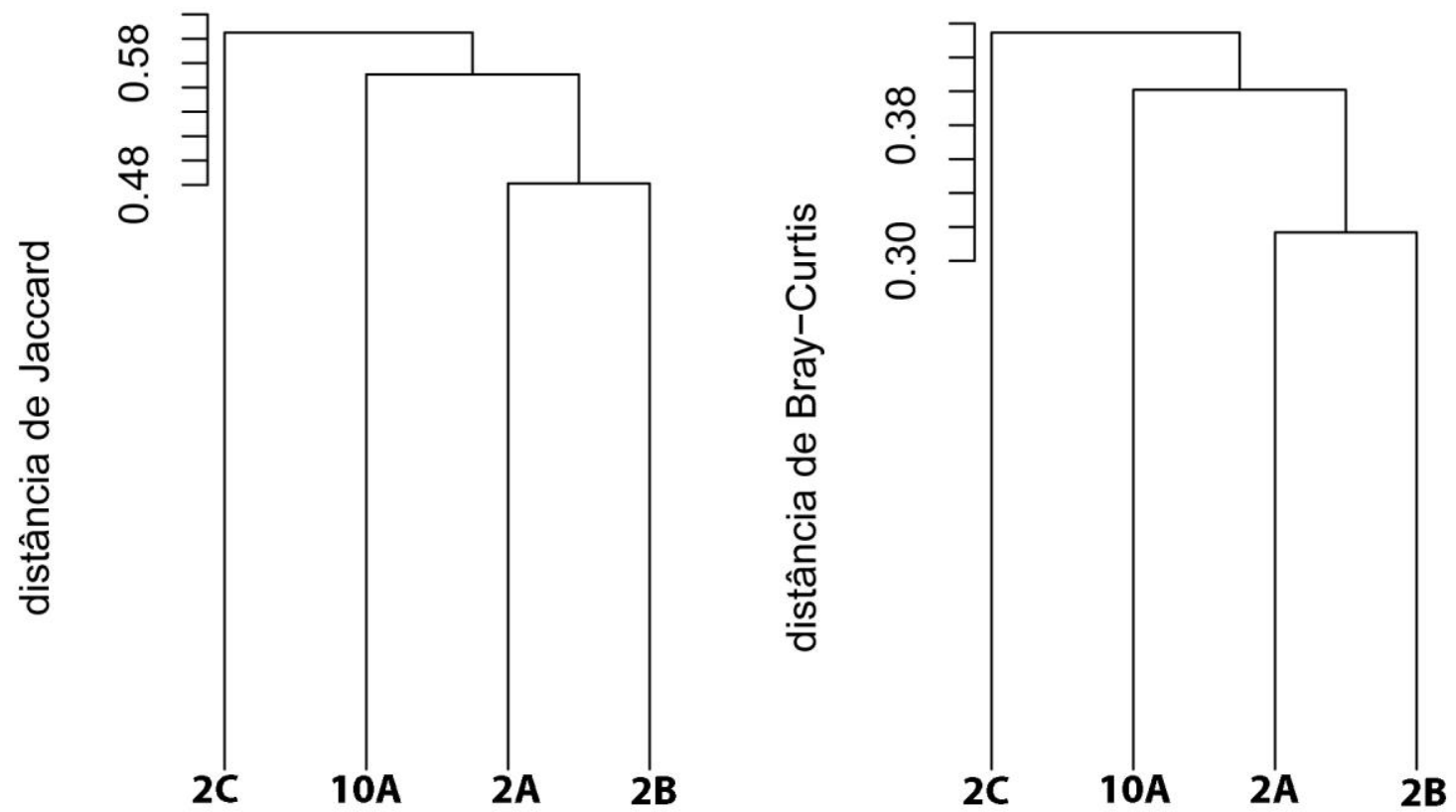

Áreas com diferentes regimes de fogo Áreas com diferentes regimes de fogo

Figura 6 - Análise de UPGMA comparando composição de espécies entre as áreas de campo sujo com diferentes regimes de fogo, na região do Jalapão, TO. À esquerda, índice de Bray-Curtis e, à direita, índice de Jaccard. 10A é a área há 10 anos protegida do fogo, e 2A, 2B e 2C são as áreas com regime de queima bienal.

Os índices de diversidade de Shannon e equabilidade de Pielou são apresentados na tabela 2.

Tabela 2- Índice de Shannon e equabilidade de Pielou para as diferentes áreas de campo sujo com diferentes regimes de fogo na região do Jalapão, TO. Base logarítmica natural.10A é a área há 10 anos protegida do fogo, e 2A, 2B e 2C são as áreas com regime de queima bienal.

$\begin{array}{lllll}\text { Índice } & 10 \mathrm{~A} & 2 \mathrm{~A} & 2 \mathrm{~B} & 2 \mathrm{C} \\ \text { Shannon } & 2,640761 & 3,009145 & 2,945348 & 3,078041 \\ \text { Pielou } & 0,748863 & 0,8000492 & 0,7830872 & 0,7868157\end{array}$

\section{Discussão}

Como o solo se mostrou muito semelhante entre as áreas, podemos considerar que tem 
pequeno significado na estruturação das comunidades, tornando o fogo, possivelmente, um dos principais fatores moduladores dessa estruturação.

Consideramos que a caracterização florística da comunidade herbáceo-subarbustiva nas quatro áreas amostradas é suficiente e representativa, uma vez que as curvas do coletor mostraram-se próximas da estabilização.

As famílias com maior número de espécies e maior número de indivíduos também são majoritariamente as famílias mais representativas com esse tipo de hábito em outros levantamentos florísticos em campo sujo (Munhoz, 2003; Ribeiro e Walter, 2008), sendo também muito representativas no domínio do Cerrado (Gottsberger e Silberbauer-Gottsberger, 2006).

O número de espécies foi considerado pequeno, se comparado com outros estudos que também enfocavam o mesmo estrato vegetacional (César, 1980; Loiolla et al., 2010; Amaral et al., 2013); entretanto, nesse estudo foram consideradas apenas plantas de hábito herbáceo e subarbustivo, enquanto que os outros trabalhos citados incluem outros hábitos, como arbustivo de pequeno porte. Na literatura, são empregados os termos estrato herbáceo e lenhoso para distinguir os dois estratos de formações savânicas do domínio do Cerrado (por exemplo: Coutinho, 1990; Moreira, 2000; Gottsberger e Silberbauer-Gottsberger, 2006; Munhoz et al., 2010). Entretanto, do ponto de vista morfológico, essa distinção é equivocada, já que muitos arbustos pequenos (lenhosos) são incluídos nesse estrato herbáceo. Sugere-se, então, o uso dos termos estrato rasteiro e estrato superior, seguindo Ratter et al. (2003), para diferenciar os dois estratos do cerrado, sem incorrer em erro morfológico caracterizado pela definição do grau de lenhosidade, o que, devido aos órgãos subterrâneos lenhosos comuns no Cerrado, torna-se uma tarefa ainda mais difícil (Warming, 1908; Coutinho, 1990). Caracteriza-se assim o estrato rasteiro composto por plantas herbáceas, subarbustivas e pequenos arbustos e o estrato superior composto por árvores e arbustos com maiores alturas. Uma mesma espécie, reprodutivamente madura, pode ser classificada em dois estratos distintos, por exemplo, Simaba sp. e Vellozia squamata Pohl que apresentam flores com pequena altura, sendo enquadradas no estrato rasteiro, mas podem chegar até alturas maiores (Figura 7), sendo enquadradas no estrato superior. 


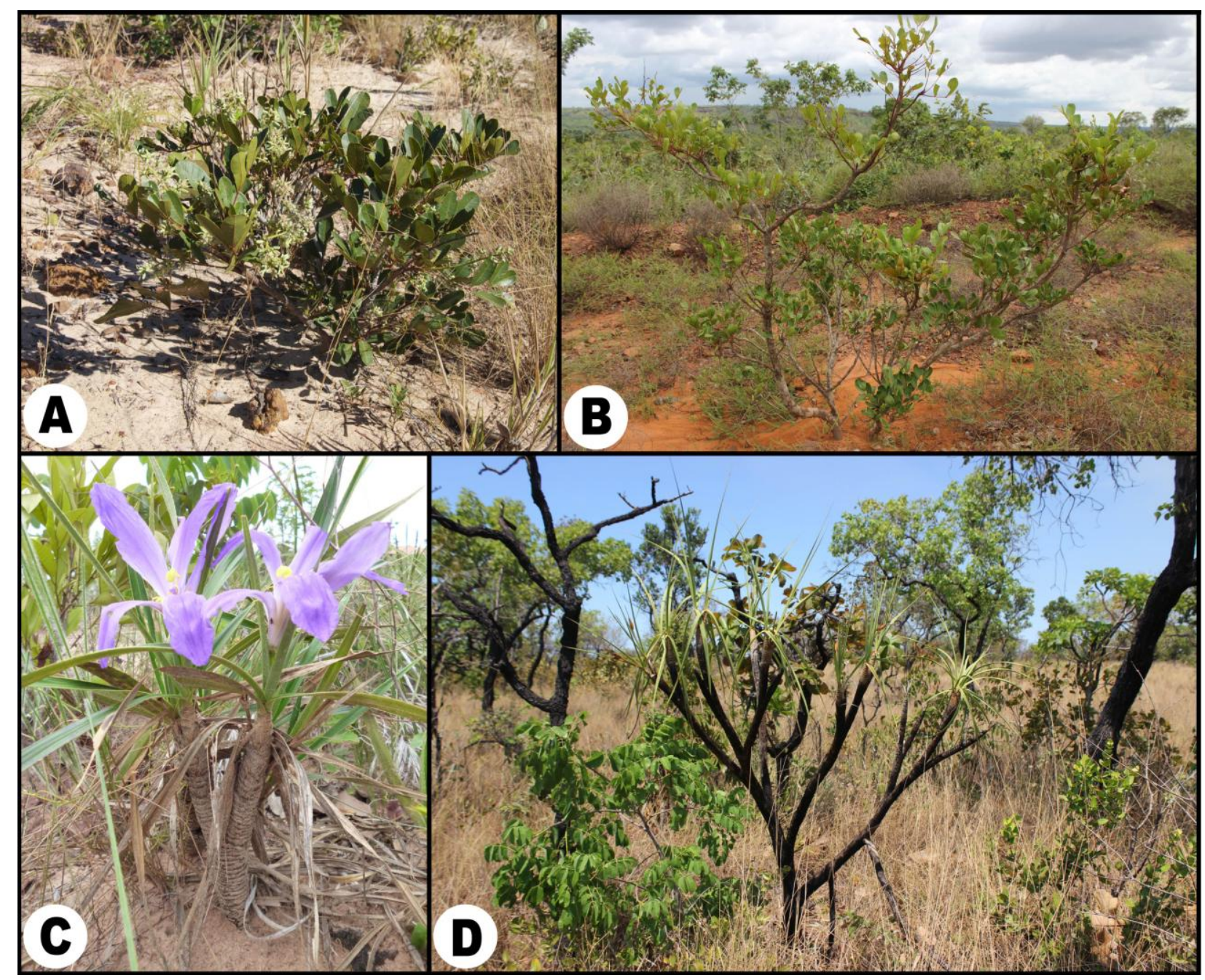

Figura 7 - Plantas em estágio reprodutivo exibindo diferentes alturas e sendo enquadradas em diferentes estratos. A-B: Simaba sp. C-D: Vellozia squamata Pohl. Foto A: Marcelo Devecchi. Fotos B-D: Guilherme Antar.

Ainda assim, tal classificação não reflete funcionalmente a resposta ao fogo pela comunidade do Cerrado. O fogo, nesse Domínio, é caracterizado como queima de superfície, de alta velocidade, utilizando como combustível o estrato rasteiro, principalmente plantas de hábito graminoide (Miranda et al., 2010). Para a resistência a um evento de fogo isolado, características como maior espessura do caule e maior altura são significativos (Hoffmann, 1999; Sato et al., 2010). Entretanto, a relação entre a altura e a espessura do caule não é linear, existindo número significativo de arbustos pequenos com grande espessura do caule, como, por exemplo, Erythroxylum tortuosum Mart. (Erythroxylaceae) (Gottsberger e Silberbauer-Gottsberger, 2006). Dessa maneira, uma possível classificação funcional para o fogo dividiria o cerrado em quatro estratos: i) o constituído por gramíneas, subarbustos e arbustos com pequena espessura do caule, que são totalmente queimados e rebrotam no nível do solo ou suas sementes germinam após a 
passagem do fogo; ii) os arbustos pequenos que possuem casca espessa, que são atingidos pelo fogo, têm suas folhas queimadas, mas podem resistir à queima e produzir novas folhas a partir do caule vivo; iii) as árvores e arbustos de maior porte, que possuem casca espessa e maior altura, resistem à queima e não têm suas folhas diretamente atingidas pelo fogo; e iv) as árvores sensíveis à passagem do fogo, que, apesar da altura, não possuem casca espessa para resistir às queimas e morrem.

Devido a esse viés de classificação dos estratos do Cerrado, não foi encontrado nenhum outro estudo que analisasse exclusivamente plantas herbáceas e subarbustivas, componentes do estrato rasteiro, o que desfavoreceu possíveis comparações entre riqueza e densidade média, independentemente de tratamento.

A densidade de indivíduos e a riqueza por parcela são maiores nas áreas com passagem de fogo que na área com o fogo suprimido. Considerando a riqueza do estrato rasteiro em trabalhos com fisionomias semelhantes, César (1980) encontrou resultados similares; entretanto, Miranda (2002) encontrou menor riqueza para Poaceae em áreas frequentemente queimadas e Amaral et al. (2013) constataram aumento da riqueza após a proteção da área por sete anos.

Vários estudos anteriores suportam os resultados obtidos nesse trabalho, referentes aos benefícios de queimas para plantas de hábito herbáceo-subarbustivo. Tais trabalhos demonstram que o fogo possui papel importante para reprodução de certas espécies do componente rasteiro (Coutinho, 1990); mostram a existência de espécies dependentes do fogo para ocorrerem (Sarmiento, 1984; Canales et al., 1994); demonstram que, após a passagem do fogo, existe um aumento na quantidade de nutrientes disponíveis para plantas com raízes próximas à superfície (Coutinho, 1990); e reportam o aumento na incidência luminosa, diminuindo a competição pelo acesso a esse fator (César, 1980).

Apesar de haver densidade menor de plantas herbáceo-subarbustivas na área 10A, o espaço não ocupado da parcela não estava preenchido por solo nu e, sim, majoritariamente, por plantas arbustivas. Dessa forma, é possível que a área 10A esteja em processo de transição para uma área mais lenhosa, como reportado em outros estudos (Coutinho, 1990; Moreira, 2000; Miranda et al., 2010; Amaral et al., 2013). Apesar de os solos no Jalapão serem muito arenosos, e pobres em nutrientes, acredita-se que o regime de queima possui forte influência na estrutura fisionômica dos cerrados da região, e por sua alta frequência (Schimidt et al., 2007), esteja relacionado com a predominância de formações abertas. 
Diferentemente do observado por Loiola et al. (2013), a composição específica entre áreas com diferentes regimes de fogo não mostrou diferenças. Apesar de haver uma riqueza maior nas áreas com regime de queimas bienal, as principais espécies encontradas na área 10A são também as principais espécies das áreas com queimas bienais. A área 2C mostrou-se diferente das outras áreas com queimas bienais e da área protegida, apresentando maior riqueza. Algumas espécies mostraram-se muito importantes para a composição da área $2 \mathrm{C}$, sendo ausentes ou com pequena abundância nas áreas 2A, 2B e 10A

O índice de Shannon apresentou alta diversidade para as áreas, sendo mais elevadas para as áreas queimadas, que também são as mais heterogêneas.

Em dois anos, a vegetação herbáceo-subarbustiva mostrou-se totalmente recuperada e ainda mais rica e mais densa que a vegetação em uma área sem queima, concordando com Batmanian e Haridasan (1985), que sugerem 18 meses para a recuperação total dessa vegetação.

Contrariamente aos ambientes florestais, onde o fogo é majoritariamente prejudicial, em savanas, como o Cerrado, o fogo pode ser benéfico (Bond e Keeley, 2005), o que ainda é pouco entendido pela sociedade e pelos órgãos ambientais no Brasil, de uma forma geral, muito embora, em alguns casos, as populações locais reconheçam tais benefícios e façam uso dele em suas práticas tradicionais. A política de supressão total de queimadas, adotada no país, vem sendo timidamente modificada com alterações na legislação do código florestal, possibilitando queimas controladas em unidades de conservação (Brasil. Lei no 12.651, de 25 de maio de 2012), visando evitar incêndios de grandes proporções e alta intensidade.

Acredita-se que o melhor manejo do regime de fogo para as áreas de Cerrado seja aquele que mais se aproxima do regime de fogo natural, com queimadas durante a estação chuvosa, que formam mosaicos de áreas queimadas e áreas livres do fogo e que permitem a reincorporação dos nutrientes perdidos na queima (Pivello e Coutinho, 1992; Ramos-Neto e Pivello, 2000). Dessa maneira, queimadas prescritas durante a estação chuvosa, principalmente nos meses que antecedem a estação seca, em diferentes áreas ao longo dos anos, seriam ideais para a manutenção da alta biodiversidade no Cerrado.

\section{Agradecimentos}

Agradecemos à equipe do Parque Estadual do Jalapão pela ajuda logística, principalmente à Rejane, Aline, Lauana, ao Claudemir, Jucinei, Alessandro, Edson e Reinaldo. À Naturatins, pela 
licença de coleta concedida. Ao Manoel, pela ajuda no campo e auxílio na escolha das áreas. Ao Anselmo Nogueira, Luiz H. Fonseca, Matheus Januário, Sérgio Tadeu e Caian Gereolano pela ajuda com as análises. A todos os especialistas que confirmaram ou identificaram o material. Ao Marcelo Devecchi por ter cedido fotos. À CAPES, à FAPESP (processo 2014/01851-7) e à IdeaWild pelo apoio financeiro ao primeiro autor e ao CNPQ (proc.308300/2012-2) pela bolsa de produtividas do terceiro autor.

\section{Referências Bibliográficas}

ALVARES, CA., STAPE, JL., SENTELHAS, PC., GONÇALVES, JLM. e SPAROVEK, G., 2014. Köppen's climate classification map for Brazil. Meterologische Zeitschrift, vol. 22, no. 6, p. 711728.

AMARAL, AG., MUNHOZ, CBR., EUGÊNIO, CUO. e FELFILI, JM., 2013. Vascular flora in dryshrub and wet grassland Cerrado seven years after a fire, Federal District, Brazil. Check List vol. 9, no. 3, p. 387-503.

APG III, 2009. An update of the Angiosperm Phylogeny Group classification for the orders and families of flowering plants: APG III. Botanical Journal of Linnean Society, vol. 161, p. 105-121.

BATMANIAN, GJ. e HARIDASAN, M., 1985. Primary production and accumulation of nutrients by the ground layer community of cerrado vegetation of central Brazil. Plant and Soil vol. 88, p. 437-440.

BEENTJE, H., 2012. The Kew Plant Glossary: An Illustrated Dictionary of Plant Terms. Royal Botanical Garden, Kew 164 pp.

BEUCHLE, R., GRECCHI, RC., SHIMABUKURO, YE., SELIGER, R., EVA, HD., SANO, E. and ACHARD, F., 2015. Land cover changes in the Brazilian Cerrado and Caatinga biomes from 1990 to 2010 based on a systematic remote sensing sampling approach. Applied Geography, vol. 58, p. 116-127.

BOND, WJ. and KEELEY, JE., 2005. Fire as a global "herbivore": The ecology and evolution of flammable ecosystems. Trends in Ecology \& Evolution, vol. 20, p. 387-394.

BROOKS, TM., MITTERMEIER, RA., MITTERMEIER, CG., FONSECA, GA., RYLANDS, AB., KONSTANT, WR., FLICK, P., PILGRIM, J., OLDFIELD, S., MAGIN, G. e HILTONTAYLOR, C., 2002. Habitat loss and extinction in the hotspots of biodiversity. Conservation Biology, vol. 16, p. 909-923

CAMARGO, OA., MONIZ, AC., JORGE, JA. e VALADARES, JMAS., 1986. Métodos de análise química e física de solos do Instituto Agronômico do Estado de São Paulo. Boletim Tecnico. vol., 106. 94 p.

CANAlES, J., TREVISAN, MC., SILVA, JF. e CASWELL, H., 1994. A demographic study of an annual grass (Andropogon brevifolius Schwrz) in burnt and unburnt savanna. Acta Oecologica, vol. 15 , no. 3 , p. $261-273$. 
CÉSAR, HL. 1980. Efeitos da queima e corte sobre a vegetação de campo sujo na Fazenda Água Limpa, Brasília-DF. Brasília: Universidade de Brasília. 59 p. Dissertação de Mestrado em Ecologia.

CHIARELlO, AG., AGUIAR, LMS., CERQUEIRA, R., MELO, FR., RODRIGUES, FHG. and Silva, VMF., 2008. Mamíferos Ameaçados de Extinção no Brasil. In: MACHADO, ABM., DRUMMOND, GM. and PAGLIA, AP. Livro Vermelho da Fauna Brasileira Ameaçada de Extinção. 1st ed. Rio de Janeiro: Fundação Biodiversitas.

COUTINHO LM., 1982. Ecological effects of fire in Brazilian Cerrado. In: Huntley, B. J. e Walker, B. H. (Eds). Ecology of tropical savannas. Springer Verlag, p. 273-291.

COUTINHO, LM., 1990. Fire in the ecology of Brazilian Cerrado. Ecological Studies: analysis and synthesis, vol. 84, p. 82-105

DIAS, BFS. e MIRANDA, HS., 2010. O projeto fogo. In Miranda, H.S. (Eds.). Efeitos do regime do fogo sobre a comunidade de cerrado: Resultados do Projeto Fogo. Brasília: Ibama-MMA. p. 1522.

EITEN, G., 1972. The cerrado vegetation of Brazil. Botanical Review, vol. 38, no. 2, p. 201-341.

FERRAZ-VICENTINI, K.R.C. 1993. Análise palinológica de uma vereda em Cromínia, GO. Brasília: Universidade de Brasília. 99 p. Dissertação de Mestrado em Ecologia.

FORZZA, RC., BAUMGRATZ, JFA., BICUDO, CEM., CANHOS, DAL., CARVALHO, A., COELHO, MAN., COSTA, AF., COSTA, DP., HOPKINS, MG., LEITMAN, PM., LOHMANN, LG., LUGHADHA, EN., MAIA, LC., MARTINELLI, G., MENEZES, M., MORIM, MP., PEIXOTO, AL., PIRANI, JR., PRADO, J., QUEIROZ, LP., SOUZA, S., V.C. SOUZA, VC., STEHMANN, JR., SYLVESTRE, LS., WALTER, BMT. and ZAPPI, DC., 2012. New Brazilian floristic list highlights conservation challenges, Bioscience, vol. 62, p 39-45.

GOTTSBERGER, G., SILBERBAUER-GOTTSBERGER, I., 2006. Life in the Cerrado, a South American Tropical Seasonal Ecosystem. Volume 1. Origin, Structure, Dynamics and Plant Use. Germany: Reta Verlag, 277 p.

HENRIQUES, RPB., 2005. Influência da história, solo e fogo na distribuição e dinâmica das fitofisionomias no bioma do Cerrado. In SOUZA SILVA, JC. e FELFILI, JM. (Eds.) Cerrado: Ecologia, Biodiversidade e Conservação. Ministério do Meio Ambiente, Brasília, p.73-92.

HOFFMANN, WA., 1999. Fire and population dynamics of woody plants in a neotropical savanna: Matrix model projections. Ecology, vol. 80, p. 1354-1369.

KEELEY, JE., PAUSAS, JG., RUNDEL, PW, BOND, WJ., e BRADSTOCK, RA., 2011. Fire as an evolutionary pressure shaping plant traits. Trends in plant Science, vol. 16, n 8, p. 406-411.

KLINK, CA. e MACHADO, RB., 2005. Conservation of Brazilian Cerrado. Conservation Biology vol. 19, no. 3, p. 707-713.

Lista de Espécies da Flora do Brasil. Jardim Botânico do Rio de Janeiro. Electronic database accessible at http://floradobrasil.jbrj.gov.br/. Accessed at 20 May 2015.

LOIOLA, PP., CIANCIARUSO, MV., SILVA, IA. e BATALHA, MA., 2010. Functional diversity of herbaceous species under different fire frequencies in Brazilian savannas. Flora vol. 205, p. 674681.

MEDEIROS, M. B.; FIEDLER, N. C. Incêndios florestais no Parque Nacional da Serra da Canastra: desafios para a conservação da biodiversidade. Ciência Florestal, Santa Maria, v. 14, n. 2, p. 157168, 2004. 
MENDONÇA, RC., FELFILI, JM., WALTER, BMT., SILVA JÚNIOR, MC., REZENDE, AV., FILGUEIRAS, TE. e NOGUEIRA, PE., 1998. Flora vascular do Cerrado. In: Sano, S.M. e Almeida, S.P. (eds.) Cerrado: Ambiente e Flora. CPAC-EMBRAPA. Planaltina, Brasil. pp. 289556.

MIRANDA, M.I. 2002. Efeito de diferentes regimes de queima sobre a comunidade de gramíneas de Cerrado. Dissertação de Mestrado. Universidade Nacional de Brasília.

MIRANDA, HS., NETO, WN. e NEVES, BMC., 2010. Caracterização das queimadas de Cerrado. In MIRANDA, HS., 2010. Efeitos do regime do fogo sobre a comunidade de cerrado: Resultados do Projeto Fogo. Brasília: Ibama-MMA. p. 23-33.

MITTERMEIER RA, GIL PR, HOFFMAN M, PILGRIM J, BROOKS T, MITTERMEIER CG, LAMOUREUX, J. e FONSECA GBA. 2004. Hotspots revisited: Earth's biologically richest and most endangered terrestrial ecoregions. Cemex, Mexico City.

MOREIRA, AG., 2000. Effects off fire protection on savanna structure in Central Brazil. Journal of Biogeography vol. 27, p. 1021-1029.

MUNHOZ, C.B.R. 2003. Padrões de destribuição sazonal e espacial das espécies do estrato herbáceosubarbustivo em comunidades de campo limpo úmido e de campo sujo. Brasília: Universidade de Brasília. 274 p. Tese de Doutorado.em Ecologia.

OKSANEN, JF., BLANCHET, G., KINDT, R., LEGENDRE, P., MINCHIN, PR., O'HARA, RB., SIMPSON, GL., SOLYMOS, P., HENRY, M., STEVENS, H. e WAGNER, H., 2015. Vegam: Community Ecology Package. $\mathrm{R}$ package version - 2.2.-1.http:/CRAN.Rproject.org/package $=$ vegan

PIVELLO, VR. e COUTINHO, LM., 1992. Transfer of macro-nutrients to the atmosphere during experimental burnings in an open cerrado (Brazilian savanna). Journal of Tropical Ecology, vol. 8, no. 4, p.487-497.

PIVELLO, VR., 2011. The use off ire in the Cerrado and Amazonian rainforests of Brazil: past and present. Fire ecology, vol. 7, no. 1, p. 24-39.

PROENÇA, CEB., FARIAS-SINGER, R. e GOMES, BM., 2007. Pleonotoma orientalis (BignoniaceaeBignonieae): Expanded description, distribution and a new variety of a poorly known species. Edinburgh Journal of Botany, vol. 64, no 1, p. 17-23.

R CORE TEAM (2014). R: A language and environment for statistical computing. R Foundation for Statistical Computing, Vienna, Austria - URL http://www.R-project.org/.

RAIJ, BV., QUAGGIO, JA., CANTARELLA, H., FERREIRA, ME., LOPES, AS. e BATAGLIA, OC., 1987. Análise química de solos para fins de fertilidade. Fundação Cargill, Campinas, 170p.

RAMOS-NETO, MB., e PIVELLO, VR., 2000. Lightning fires in a Brazilian savanna national park: rethinking management strategies. Environmental Management vol. 26, p. 675-684.

RATTER, JA., RIBEIRO, JF. e BRIDGEWATER, S., 1997. The brazilian cerrado vegetation and threats to its biodiversity. Annals of biology, vol. 80, p. 223-230.

RATTER, JA., BRIDGEWATER, S. e RIBEIRO, JF., 2003. Analysis of the floristic composition of the Brazilian cerrado vegetation III: Comparison of the Woody vegetation of 376 areas. Edinburgh Journal of Botany vol. 60, no 1, p 57-109. 
RIBEIRO, JF. e WALTER, BMT., 2008. As pricipais fitofisionomias do bioma Cerrado. In SANO, SM., ALMEIDA, SP. e RIBEIRO, JF., 2008. Cerrado: Ecologia e flora. EMBRAPA. Vol 1. Capítulo 6. p. 153-212.

SARMIENTO, G., 1984. The ecology of neotropical savannas. Harvard University, Cambridge, 235 p.

SATO, MN., MIRANDA, HS. e MAIA, JMF., 2010. O fogo e o estrato arbóreo do Cerrado: efeitos imediatos e de longo prazo. In Miranda, H.S. (Eds.). Efeitos do regime do fogo sobre a comunidade de cerrado: Resultados do Projeto Fogo. Brasília: Ibama-MMA. p. 77-91.

SCHMIDT. IB., FIGUEIREDO, IB. e SCARIOT, A., 2007. Ethnobotany and Effects of Harvesting on the Population of Syngonanthus nitens (Bong.) Ruhland (Eriocaulaceae), a NTFP from Jalapão Region, Central Brazil. Economic Botany, vol. 61 no. 1, p. 73-85.

SEPLAN - Secretaria do Planejamento e Meio Ambiente do Estado de Tocantins. 2003a. Plano de Manejo do Parque Estadual do Jalapão. Palmas; Seplan, 132p.

SEPLAN - Secretaria do Planejamento e Meio Ambiente do Estado de Tocantins. 2003b. Plano de Manejo da Área de Proteção Ambiental do Jalapão. Palmas; Seplan. 205p.

SILVA, JMC., .e BATES, JM., 2002. Biogeographyc patterns and conservation in the South America Cerrado: A Tropical Savana Hotspot. BioScience vol. 52, no. 3, p. 225-233..

SILVA, IA. e BATALHA, MA.,, 2010. Phylogenetic structure of Brazilian savannas under different fire regimes. Journal of Vegetation Science vol. 21, p. 1003-1013..

SIMON, MF., GRETHER, R., QUEIROZ, LP., SKEMA, C., PENNINGTON, RT. and HUGHES, CE., 2009. Recent assembly of the cerrado, a neotropical plant diversity hotspot, by in situ evolution of ad aptations to fire. Proceedings of the National Academy of Science, vol. 10, p. 20.35920.364 .

UYS, RG.,, BOND, WJ. e,EVERSON, TM., 2004. The effect of different fire regimes on plant fiversity in southern African grasslands. Biological Conservation, vol. 118, p. 489-499.

WARMING, E., 1908. Lagoa Santa, contribuição para a geographia phytobiológica. Belo Horizonte, Imprensa Oficial do Estado de Minas Gerais, II+282p.

ZAR, JH., 2010. Biostatistical analysis.Fifth edition. Pearson editora. New Jersey . United States 


\section{Considerações finais}

O levantamento florístico realizado nas formações savânicas de solo seco, não pedregoso, na região do Jalapão, registrou uma grande riqueza de espécies, dentre elas, 13 espécies ainda não descritas pela ciência. Tais resultados destacam a importância de levantamentos florísticos regionais no Domínio do Cerrado, a despeito da menor relevância atualmente atribuída a esse tipo de estudo. O conhecimento da flora local é essencial para se elaborar planos de conservação efetivos, e, por conseguinte, estudos com esse foco deveriam ser mais valorizados.

Esse estudo contribuiu para o conhecimento sobre a flora do Jalapão, duplicando o número de espécies para as fisionomias estudadas na região. Entretanto, a região ainda é floristicamente pouco conhecida, com outras fisionomias e áreas de municípios adjacentes com raras coletas.

O regime de fogo bienal, muito comum na região do Jalapão, mostrou-se benéfico para a comunidade herbáceo-subarbustiva, aumentando sua densidade e riqueza em relação à área protegida da ação do fogo, sem alterar a composição das comunidades.

O manejo do fogo na região do Jalapão deve ser considerado, visando uma aproximação do regime natural, com queimas na estação chuvosa. O fogo não pode ser entendido como vilão na região do Jalapão e no Cerrado, posto que, no componente herbáceo-subarbustivo, apresenta efeitos benéficos, entretanto, para o estrato superior, é claramente prejudicial. Dessa maneira, manejos que possibilitem um mosaico de áreas com diferentes frequências de fogo devem ser propostos. 